Prepared for the

U.S. Nuclear Regulatory Commission under a Related Services Agreement

with the U.S. Department of Energy

under Contract DE-AC05-76RL01830

\title{
NDE to Manage Atmospheric SCC in Canisters for Dry Storage of Spent Fuel: An Assessment
}
RM Meyer
A Qiao
AF Pardini
JM Cuta
$M$ Larche
HE Adkins
AA Diaz
AM Casella
SR Doctor

September 2013

\section{Pacific Northwest}

NATIONAL LABORATORY

Proudly Operated by Battelle Since 1965 


\title{
DISCLAIMER
}

This report was prepared as an account of work sponsored by an agency of the United States Government. Neither the United States Government nor any agency thereof, nor Battelle Memorial Institute, nor any of their employees, makes any warranty, express or implied, or assumes any legal liability or responsibility for the accuracy, completeness, or usefulness of any information, apparatus, product, or process disclosed, or represents that its use would not infringe privately owned rights. Reference herein to any specific commercial product, process, or service by trade name, trademark, manufacturer, or otherwise does not necessarily constitute or imply its endorsement, recommendation, or favoring by the United States Government or any agency thereof, or Battelle Memorial Institute. The views and opinions of authors expressed herein do not necessarily state or reflect those of the United States Government or any agency thereof.

\author{
PACIFIC NORTHWEST NATIONAL LABORATORY \\ operated by \\ BATTELLE \\ for the \\ UNITED STATES DEPARTMENT OF ENERGY \\ under Contract DE-AC05-76RL01830
}

Printed in the United States of America
Available to DOE and DOE contractors from the Office of Scientific and Technical Information,
P.O. Box 62, Oak Ridge, TN 37831-0062;
ph: (865) 576-8401
fax: (865) 576-5728
email: reports@adonis.osti.gov

\author{
Available to the public from the National Technical Information Service, \\ U.S. Department of Commerce, 5285 Port Royal Rd., Springfield, VA 22161 \\ ph: (800) 553-6847 \\ fax: $(703) 605-6900$ \\ email: orders@ntis.fedworld.gov \\ online ordering: http://www.ntis.gov/ordering.htm
}

This document was printed on recycled paper.

(9/2003) 


\title{
NDE to Manage Atmospheric SCC in Canisters for Dry Storage of Spent Fuel: An Assessment
}

\author{
RM Meyer \\ A Qiao \\ AF Pardini \\ M Larche \\ JM Cuta \\ AA Diaz \\ HE Adkins \\ SR Doctor \\ AM Casella
}

September 2013

Prepared for the

U.S. Nuclear Regulatory Commission under a Related Services Agreement with the U.S. Department of Energy under Contract DE-AC05-76RL01830

Pacific Northwest National Laboratory

Richland, Washington 99352 



\begin{abstract}
In this effort, an assessment of bulk ultrasonic (UT) and eddy current (ECT) methods and techniques is performed for inspecting the surfaces of dry cask storage systems (DCSSs) canisters. Some DCSS canisters (especially those located in coastal environments) will be exposed to environmental conditions, which can cause atmospheric stress corrosion cracking (SCC). Information collected from the field and from laboratory studies has not been able to rule out the possibility of atmospheric SCC in DCSS canisters, although no occurrences of atmospheric SCC in DCSS canisters have been detected. UT and ECT methods and techniques are already used to inspect nuclear power plant components and this experience, along with their relative maturity, makes these methods and techniques likely frontrunners for near-term application to examination of dry storage canister surfaces. In this report, the results of several performance reliability studies for UT and ECT are reviewed. The detection, depth-sizing, and lengthsizing results are documented and summarized to quantitatively estimate the adequacy of UT and ECT for inspecting dry storage canister surfaces. In addition, this effort focuses on the implementation of NDE methods and techniques in the Holtec HI-STORM 100 system and the Transnuclear NUHOMS horizontal storage modules and considers environmental compatibility, accessibility constraints, and NDE sensor deployment options for these systems.
\end{abstract}





\section{Summary}

Dry cask storage systems (DCSSs) for used nuclear fuel (UNF) are intended for temporary storage periods that are currently undefined. The initial license term for an Independent Spent Fuel Storage Installation (ISFSI) is 40 years from the date of issuance per Title 10 of the Code of Federal Regulations (CFR) 72.42 limits and may be renewed by the U.S. Nuclear Regulatory Commission (NRC) for a period of up to 40 years upon submission and approval of an application by the licensee (Chopra et al. 2012). The current uncertainty regarding the opening of a permanent repository in the United States implies the potential for reliance on DCSSs for extended storage periods that are much longer than originally envisioned. This report assesses the performance of nondestructive examination (NDE) methods or techniques for inspecting the surface of canisters with a focus on the Holtec HI-STORM 100 and Transnuclear NUHOMS DCSS systems to represent vertical and horizontal systems, respectively. This assessment is performed by considering access and deployment (Section 4.0), environmental compatibility (Section 5.0), the performance of bulk ultrasonic testing (UT) (Section 6.0), and the performance of eddy current testing (ECT) (Section 7.0). This report focuses on UT and ECT methods and techniques because their use in the nuclear power industry and relative maturity makes them good candidates for near-term application to examination of dry storage canister surfaces.

A potential aging degradation associated with the confinement boundary of DCSSs is the occurrence of atmospheric stress corrosion cracking (SCC) in stainless steel canisters that form the confinement boundary. This is expressed in a recent NRC information notice (NRC 2012b) titled, "Potential Chloride-Induced Stress Corrosion Cracking of Austenitic Stainless Steel and Maintenance of Dry Cask Storage System Canisters.” Although there have been no reported occurrences of atmospheric SCC in DCSS canisters in the field, many canisters are located in coastal environments where this form of degradation is considered possible. Like other types of SCC, atmospheric SCC can occur in susceptible materials in a corrosive environment under tensile stress. Chloride deposits on canister surfaces provide the corrosive environment necessary for atmospheric SCC while residual stresses in weld regions or caused by cold work may provide the necessary driving force for crack growth. The heat-affected zones (HAZs) near welds are potentially susceptible to atmospheric SCC due to sensitization of the material caused by chromium depletion during the welding process. In addition, crevice conditions may contribute to canister degradation by trapping chloride deposits on the surface of the canister. Generally, it is accepted that SCC susceptibility increases with temperature; however, for atmospheric SCC, the effect of deliquescence of chloride deposits creates a threshold temperature below which atmospheric SCC is considered possible. As the absolute humidity increases, the temperature below which deliquescence may occur also increases (Caseres and Mintz 2010). One of several important distinctions between atmospheric SCC of DCSS canisters and SCC occurrences in nuclear reactor components due to high temperature water conditions is that atmospheric SCC initiates on the outside surface of canisters whereas most SCC occurrences in nuclear reactor components initiates on the inside surface of components.

The HI-STORM 100 refers to an evolution of systems referred to as the HI-STORM 100, HI-STORM 100S, and HI-STORM 100 version B systems, in this report. The differences between the system variants are mostly associated with the dimensions and location of ventilation ports through the concrete overpack and the height of the pedestal supporting the multi-purpose canister (MPC). The Transnuclear NUHOMS system also refers to several variants of the basic horizontal storage module (HSM) concept. The differences between the NUHOMS systems are mostly associated with the design of ventilation ports through the concrete shield module and the design of the shielded door assembly. 
“Rolled-out” depictions of the HI-STORM 100, HI-STORM 100S, and HI-STORM 100 version B systems are shown in Figure S.1 through Figure S.3, respectively. These figures illustrate how the difference in inlet and outlet ventilation port alignment in the overpack can potentially impact accessibility. The HI-STORM 100 system has ventilation ports that are in vertical alignment whereas the ventilation ports for the HI-STORM 100S, and HI-STORM 100 version B systems are staggered potentially enabling access to a greater portion of the MPC surface. Further, these figures show how the pedestal height affects access to the bottom plate-to-shell weld. The much shorter pedestal in the HI-STORM 100 version B systems results in the bottom plate-to-shell weld being free from obstruction by channels on the inner cavity wall of the overpack. Multiple options may be available for deployment of NDE sensors to the surface of the MPC. Some of the options include mounting of sensors on the end of long flexible wands (Figure S.4) or deployment with autonomous crawlers (Figure S.5). Hybridization of these deployment methods is also an option.

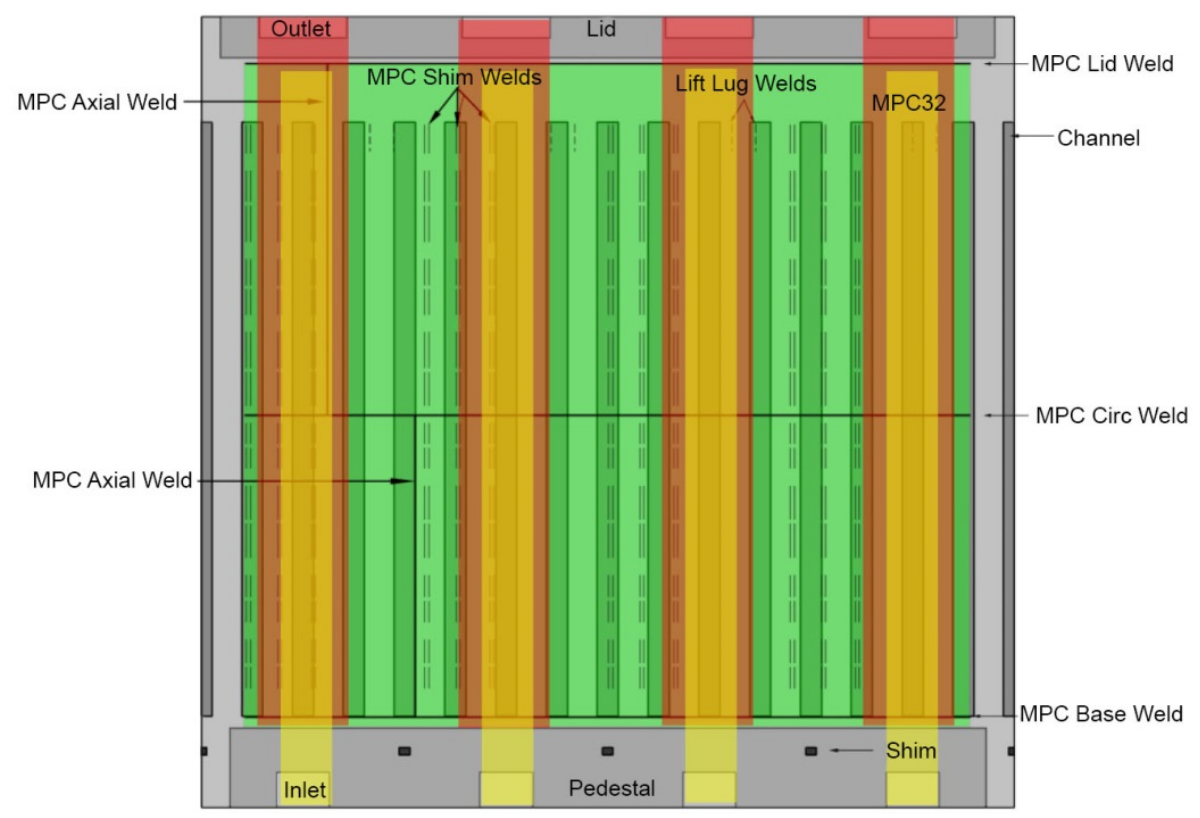

Figure S.1. Illustration of Accessible Zones of the MPC Surface from Inlet and Outlet Ventilation Ports of the HI-STORM 100 System 


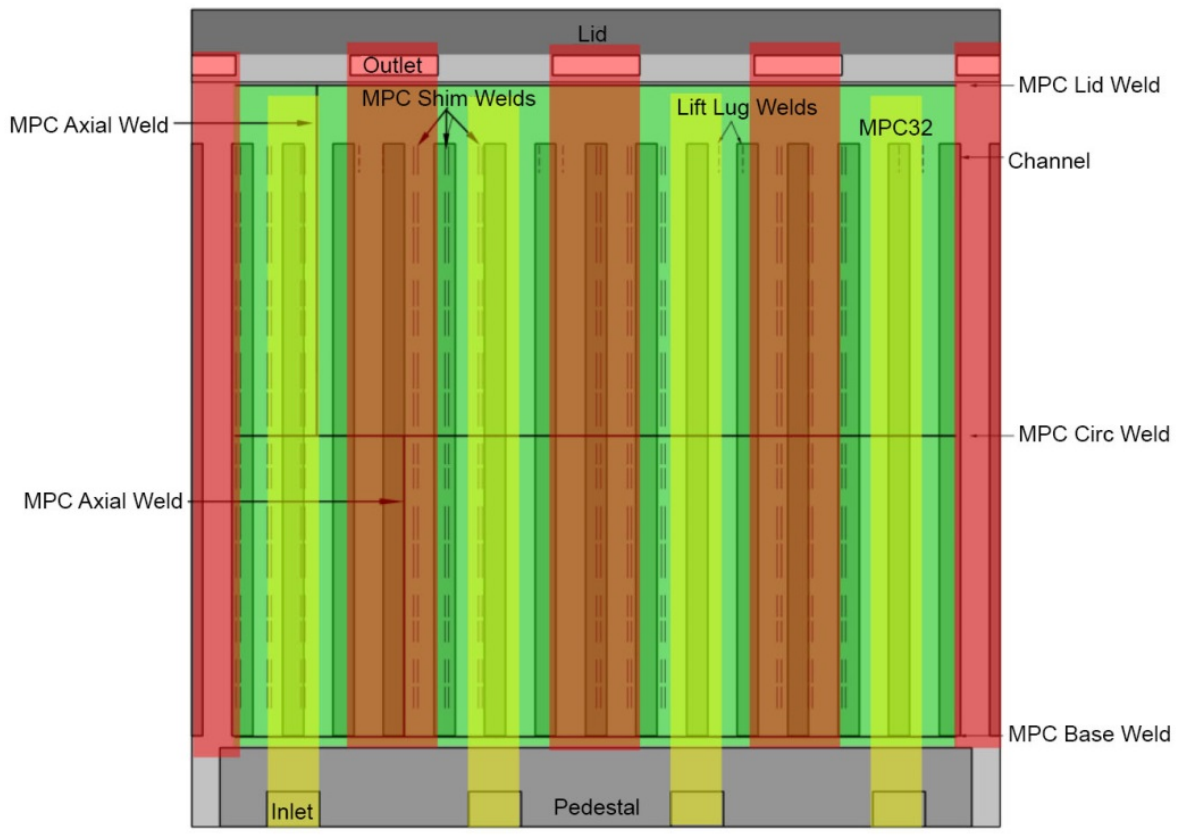

Figure S.2. Illustration of Accessible Zones of the MPC Surface from Inlet and Outlet Ventilation Ports of the HI-STORM 100S System

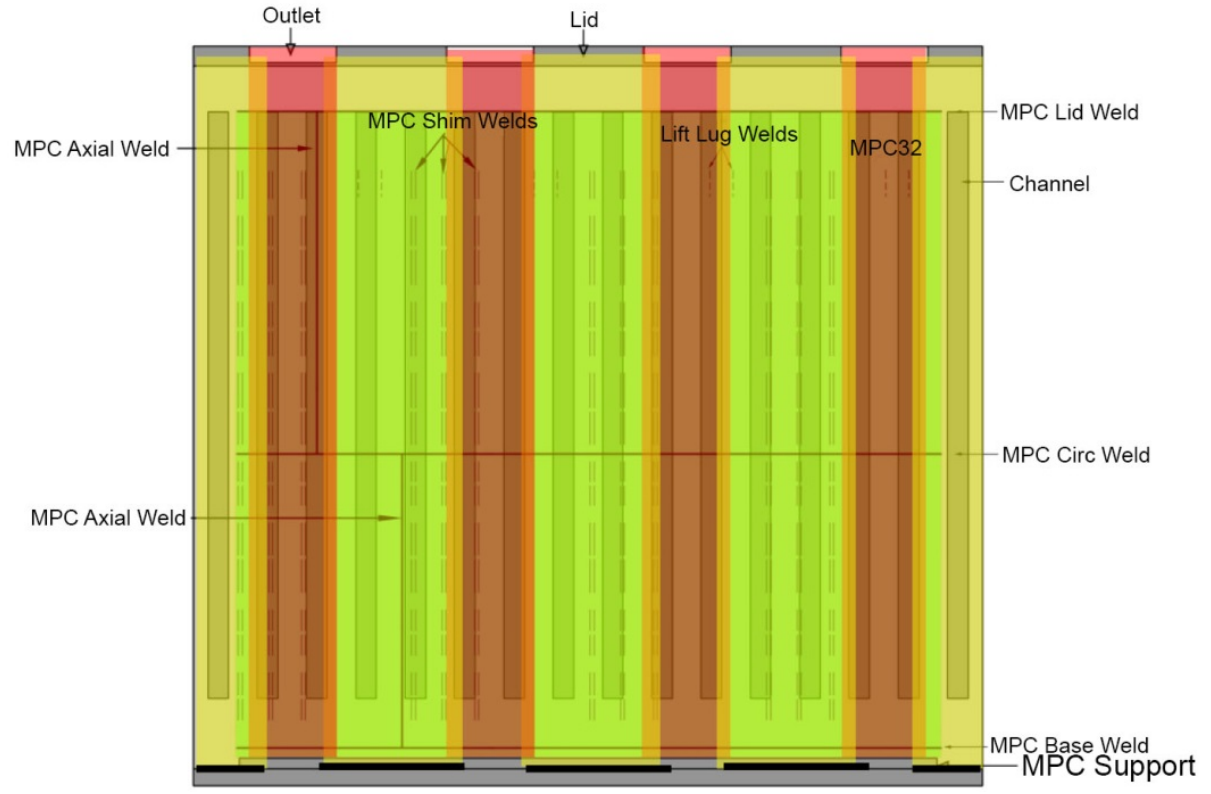

Figure S.3. Illustration of Accessible Zones of the MPC Surface from Inlet and Outlet Ventilation Ports of the HI-STORM 100S Version B System 


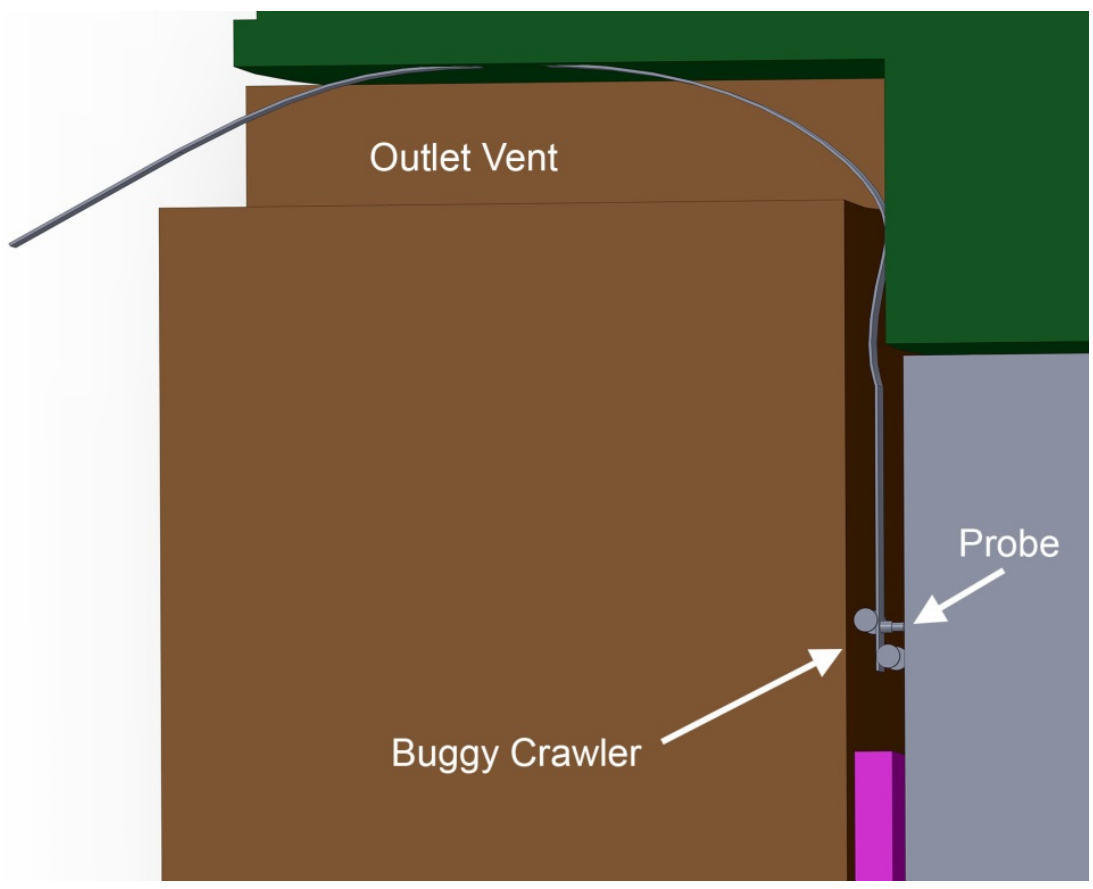

Figure S.4. NDE Sensor Deployment Concept Utilizing a Spring-Loaded Wheeled Buggy on End of Flexible Wand

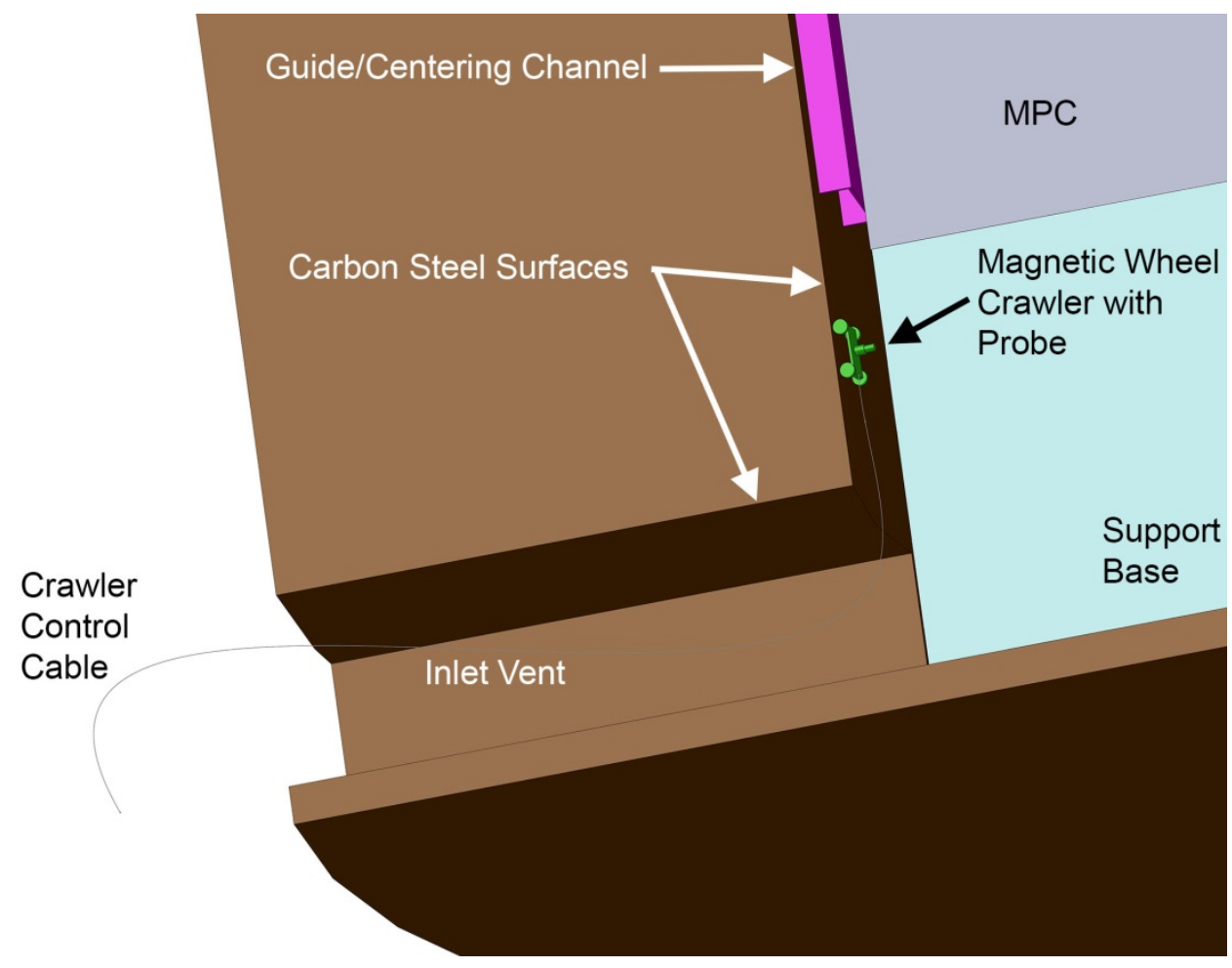

Figure S.5. NDE Sensor Deployment Concept Utilizing a Magnetic Crawler System 
In the NUHOMS design, access to the dry shielded canister (DSC) may be possible through paths provided by the inlet and outlet ventilation ports and the front entry port to the HSM. Access to the DSC through the top ventilation port is illustrated in Figure S.6 using a sensor mounted to a flexible spring steel wand. In this case, access to a strip of the top of the canister is all that is feasible. An environmental compatibility assessment was performed and revealed significant variation of the temperature over the surface of DCSS canisters as indicated in Figure S.7 and Figure S.8. In the case of the NUHOMS system (see Figure S.7), regions located at both ends on the bottom side of the canister will be the first to drop below the deliquescence threshold. For the HI-STORM 100 system, the bottom of the canister will be first to drop below this threshold (Figure S.8). Approximately the bottom $25 \%$ of the canister may be expected to drop below this threshold first, followed by the lid assembly. Figure S.9 illustrates a scenario where portions of the bottom plate-to-shell weld for the HI-STORM 100 MPC are sampled near the inlet ventilation ports. Figure S.10 illustrates sampling of the bottom side end of the NUHOMS DSC nearest to the shielded door entry.

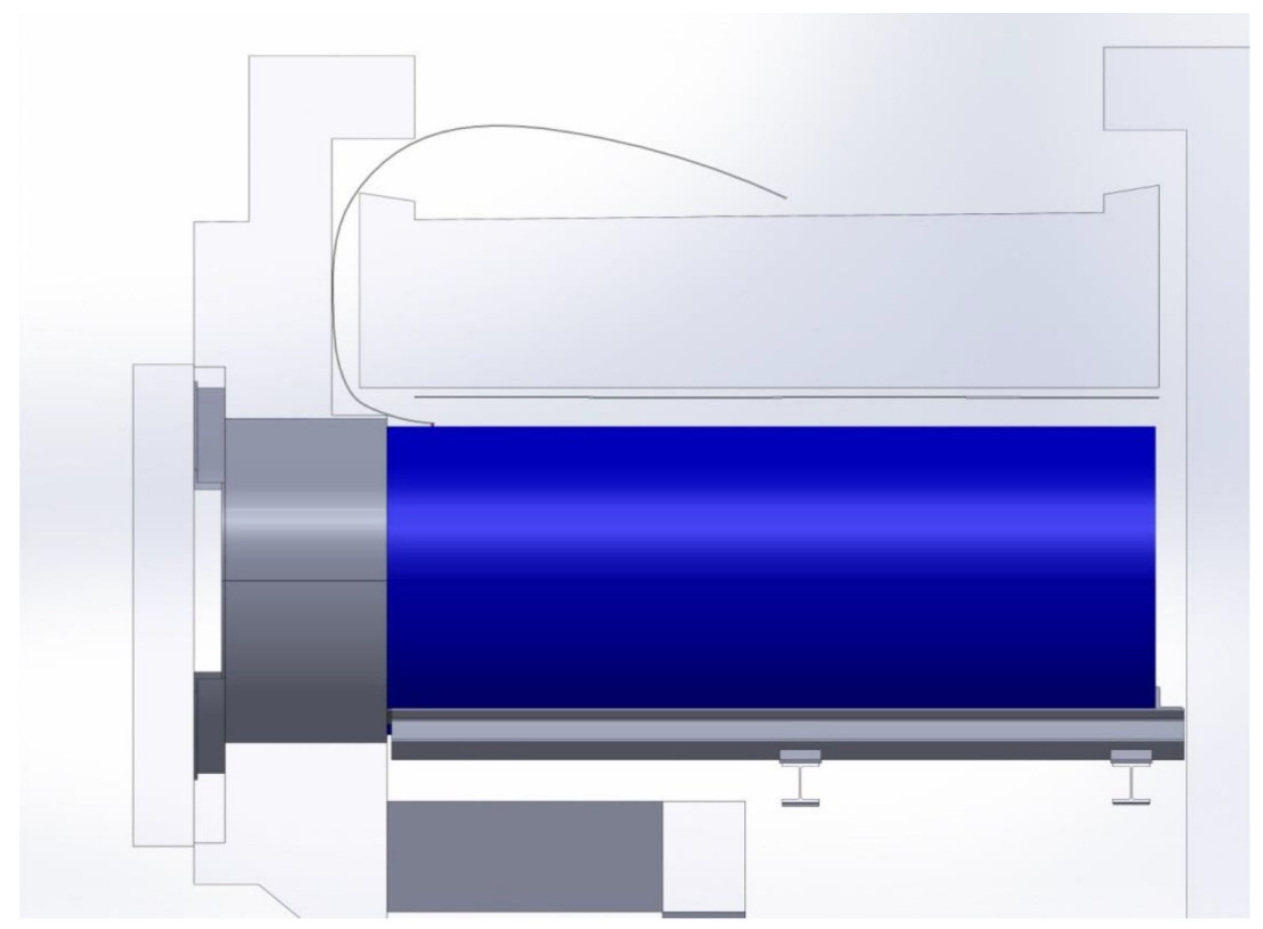

Figure S.6. Illustration of Insertion of NDE Probe Mounted to Spring Steel Probe through HSM Outlet Vent 


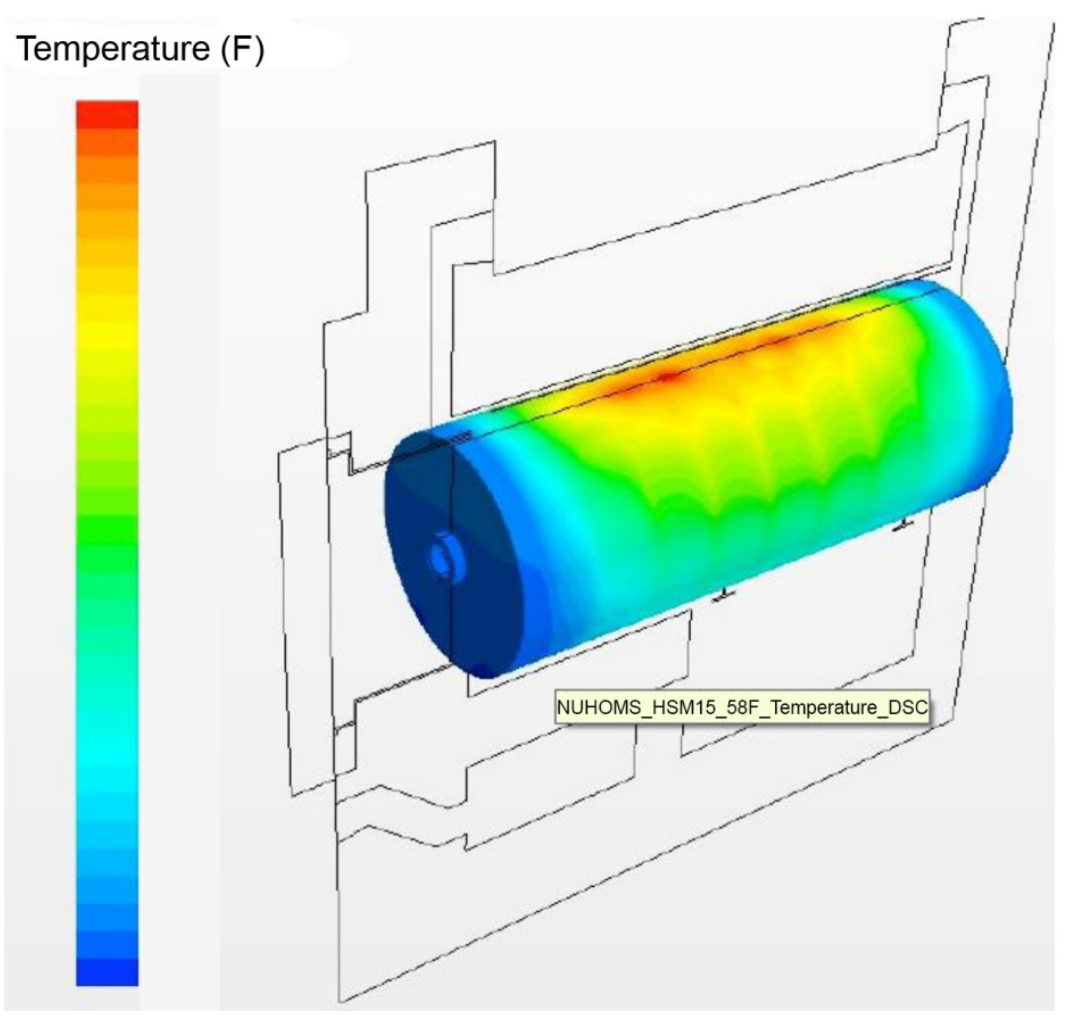

Figure S.7. Simulated DSC Shell Surface Temperatures for Calvert Cliffs HSM-15 (Suffield et al. 2012)

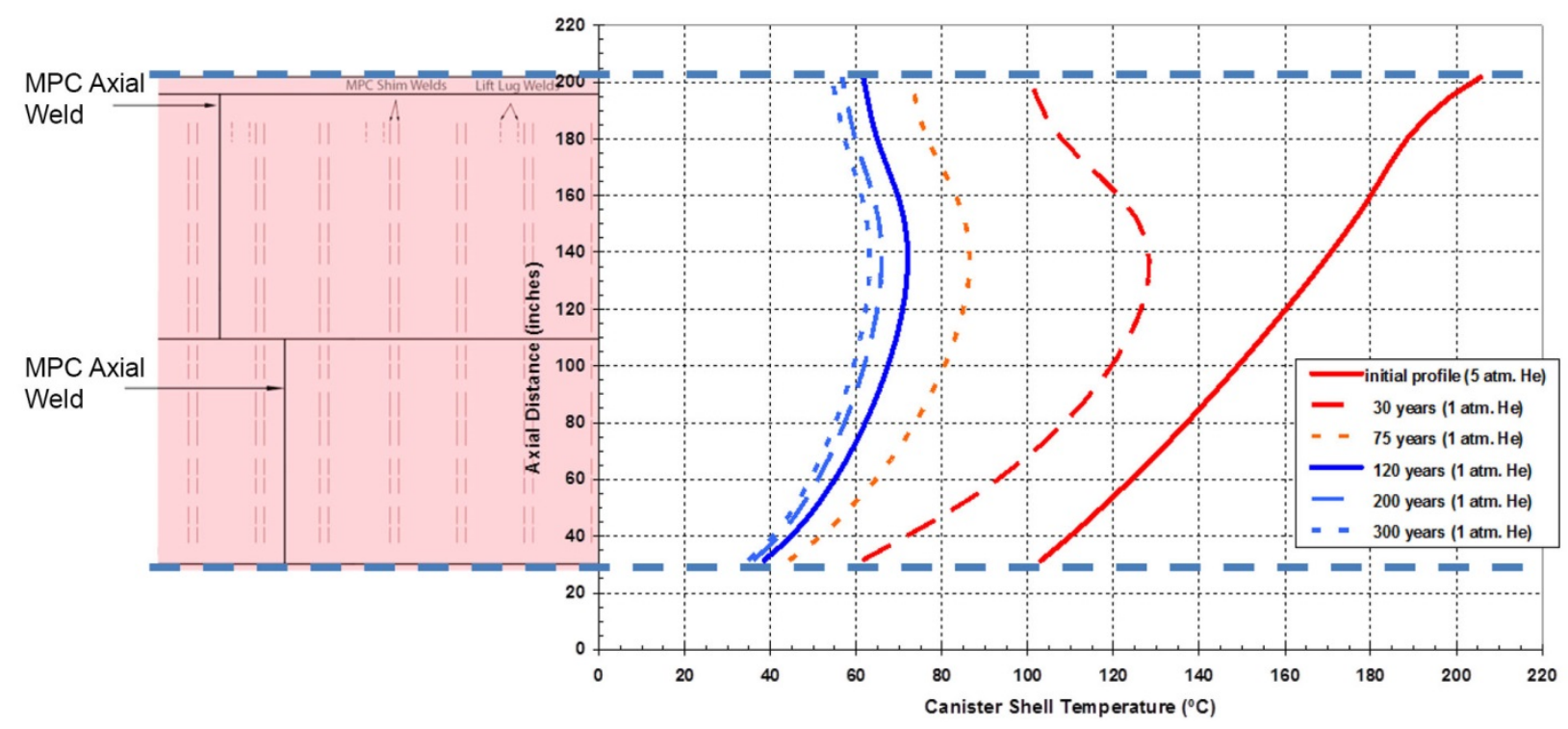

Figure S.8. Axial Temperature Distribution at the Canister Shell Surface for Projected Decay Heat Decrease over Time in Vertical Storage 


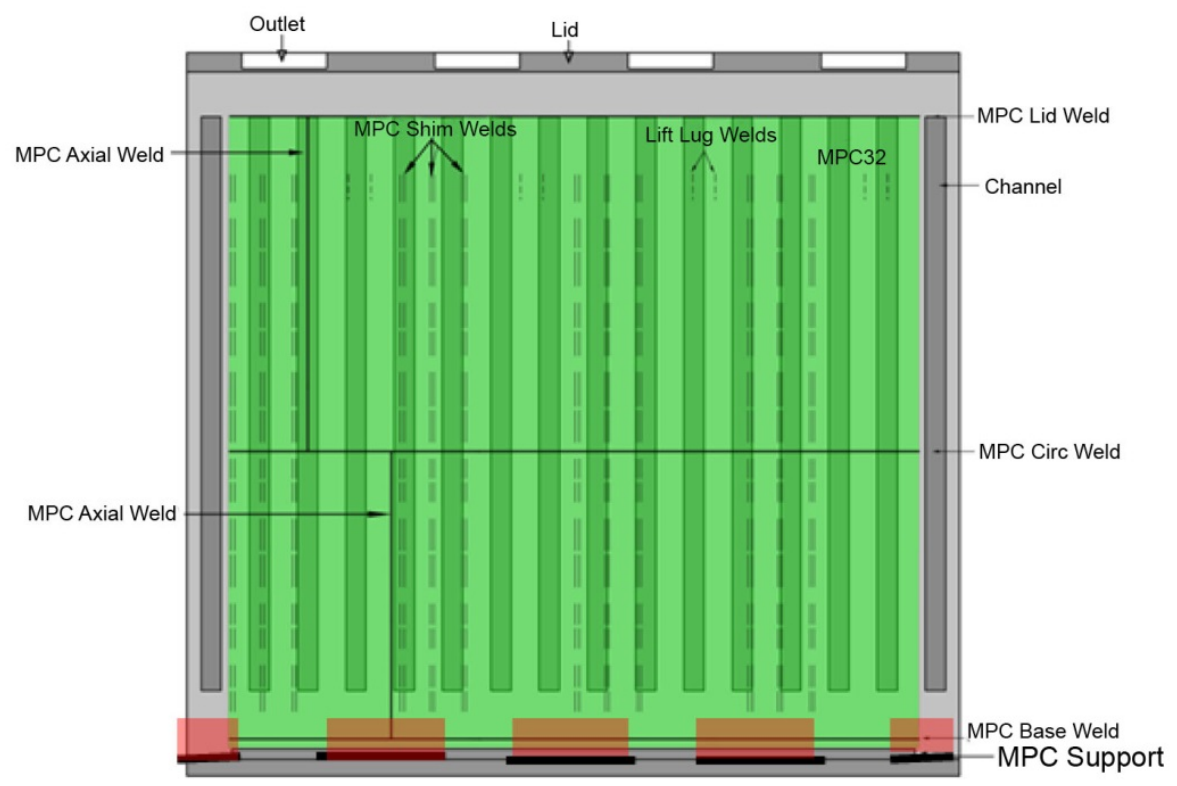

Figure S.9. Depiction of Inspection Scenario for UT and ECT on HI-STORM 100S Version B with MPC-32 Illustrating Sampling of the Bottom Plate-to-Shell Weldment over Regions in Alignment with Inlet Ventilation Ports

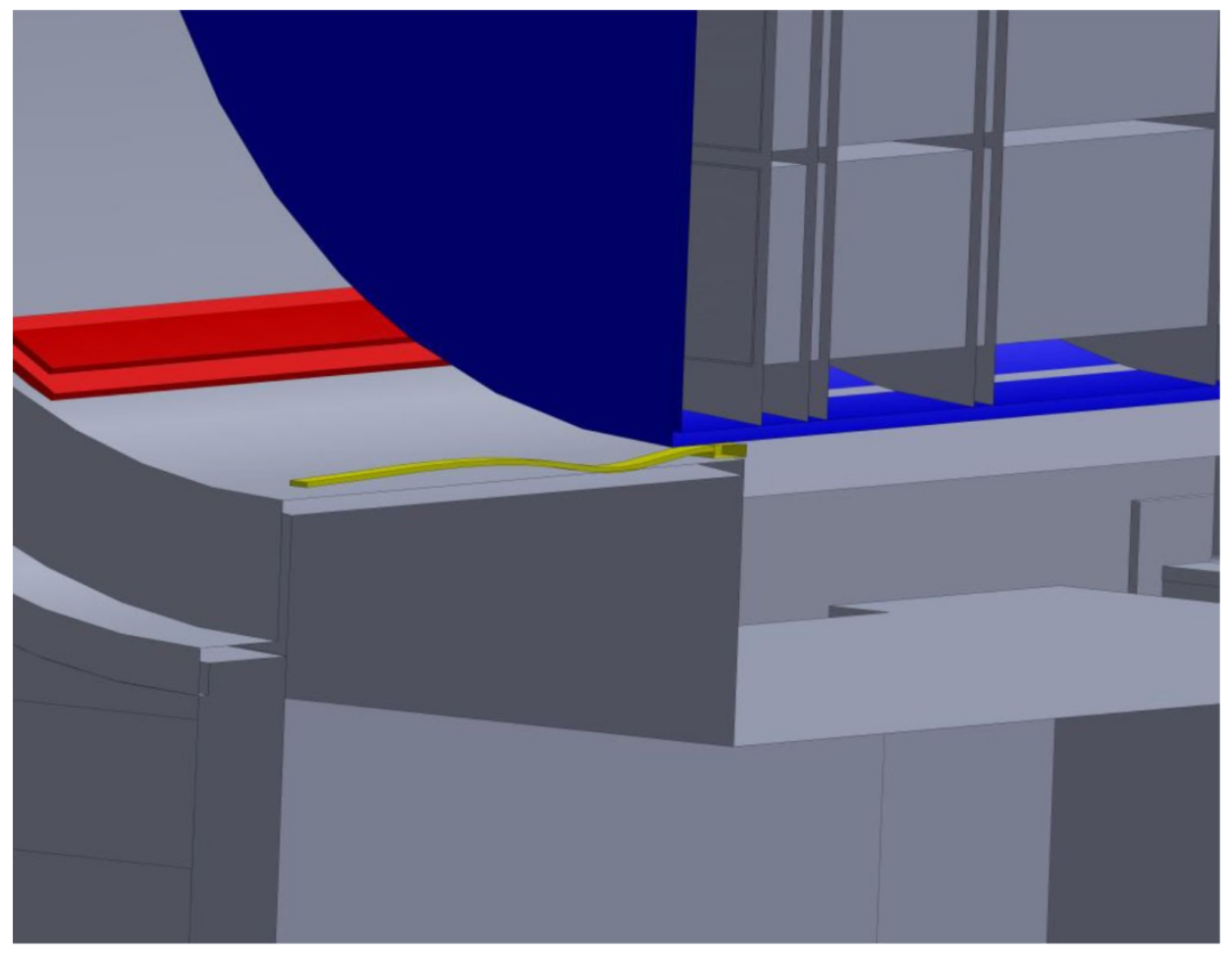

Figure S.10. Illustration of NDE Probe Mounted to Spring Steel Wand for Examination of the DSC Surface 
The best performance data documented in this report for UT and ECT are summarized in Table S.1. The performance data indicates that both UT and ECT should be capable of detecting flaws that do not fully penetrate DCSS canisters with good reliability. Eddy current is likely to exhibit better detection performance than UT for shallow flaws and good detection performance has been exhibited for submillimeter deep flaws (> 85\%) in steam generator tubing (Kupperman et al. 2007). In the case of flaw length-sizing, improved performance is gained by encoding the signals with transducer position. In this case, length-sizing accuracy for ECT performed on heterogeneous cast austenitic stainless steel (CASS) material is similar to length-sizing performance observed for UT performed for far-side weld examinations and is approximately 6-mm root mean squared error (RMSE). It may be possible to determine flaw depth based on measurements of flaw length, but only if a relationship between flaw depth and flaw length can be determined. Depth-sizing performance for ECT cannot be quantified from the performance studies documented in this report. In fact, many studies highlight the difficulties of depthsizing stress corrosion cracks in thick components (Yusa and Hashizume 2009; Huang et al. 2011). For UT techniques, data from the Electric Power Research Institute's (EPRI's) Performance Demonstration Initiative (PDI) indicates that the ASME Code, Section XI, Appendix VIII criteria for depth-sizing performance can be met (RMSE $<=3.2 \mathrm{~mm}$ ) (Latiolais 2013). This level of depth-sizing accuracy indicates that flaws in $12.7 \mathrm{~mm}$ thick canister shells may be classified into approximately two size categories.

Table S.1. Summary of Best Documented Performance Data for UT and ECT

\begin{tabular}{|c|c|c|}
\hline & UT & ECT \\
\hline $\begin{array}{l}\text { Probability of } \\
\text { Detection }\end{array}$ & $\begin{array}{l}90 \% \text { for flaws } 10 \mathrm{~mm} \text { deep and } 70 \% \text { for flaws } \\
5 \mathrm{~mm} \text { deep (Heasler and Doctor 2003) }\end{array}$ & $\begin{array}{l}\text { Can be inferred that good performance is } \\
\text { observed for detecting sub-millimeter deep } \\
\text { flaws in steam generator tubes (probability } \\
\text { of detection > 85\%) (Kupperman et al. 2007) }\end{array}$ \\
\hline Depth-sizing & $\begin{array}{l}\text { Can meet the ASME Code Section XI, } \\
\text { Appendix VIII criteria for depth-sizing } \\
\text { accuracy, which specifies that the RMSE of } \\
\text { the depth measurement is less than } 3.2 \mathrm{~mm} \\
\text { (Latiolais 2013) }\end{array}$ & $\begin{array}{l}\text { The development of techniques and theory } \\
\text { for depth-sizing of SCC flaws is a current } \\
\text { area of research (Huang et al. 2011) }\end{array}$ \\
\hline Length-sizing & $\begin{array}{l}\text { RMSE from } 2.2 \mathrm{~mm} \text { to } 9.2 \mathrm{~mm} \text { for encoded } \\
\text { techniques (Anderson et al. 2011) }\end{array}$ & $\begin{array}{l}\text { 39.4-mm to } 69.9-\mathrm{mm} \text { long flaws were } \\
\text { undersized with a RMSE of } 7.7 \mathrm{~mm} \text { in CASS } \\
\text { material (Diaz et al. 2007) }\end{array}$ \\
\hline
\end{tabular}

Several caveats should be considered with respect extrapolating performance data from previous reliability studies to the inspection of dry storage canisters. First, the previous performance studies targeted flaws that initiated on the far surface of components with respect to transducer placement, in which case the sound field propagates along a half V-path for crack detection (see Figure S.11). In the application considered here, flaws will initiate on the near surface, requiring the sound field to travel along a full V-path (see Figure S.12), at a large angle, or on the surface of the canister. The second caveat relates to the component geometry. Reliability studies are often performed on representative samples of piping that have a much smaller diameter than dry storage canister shells. Third, surface conditions of the canisters can have an impact on inspection performance. The build-up of dust or other deposits can adversely impact ECT if a consistent lift-off (distance between probe and test surface) cannot be 
maintained. In the case of UT, dust or deposits may need to be removed to ensure/enable adequate coupling. Fourth, for both UT and ECT, additional challenges to performance are associated with deployment. The choice of deployment method (e.g., flexible wand or robotic crawler) can significantly influence the effectiveness of an examination. As noted, encoding the data with the position of the transducer can significantly improve performance. Finally, the frequency at which inspections are performed and the growth rate of atmospheric flaws will impact the effectiveness of inspections. For instance, even though UT may exhibit good performance reliability for the detection of 10-mm deep flaws (90\%), such flaws may be unlikely to exist at the time of an inspection if flaw growth is too rapid. On the other hand, if residual stress distributions, or other effects, result in slow crack growth rates when they reach approximately $10 \mathrm{~mm}$ in depth, then it is more likely that flaws will be detected during UT inspections. In light of all of these factors, techniques and deployment methods should be carefully selected to ensure best performance.

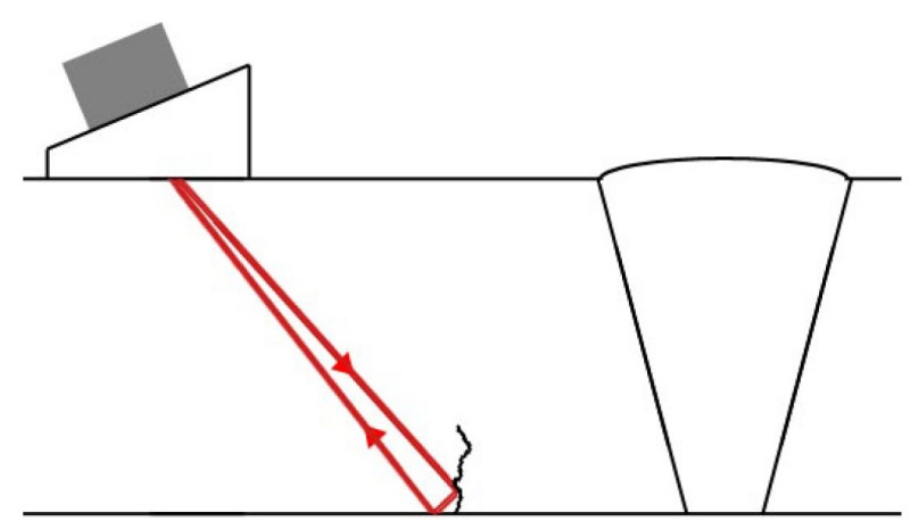

Figure S.11. Depiction of a Hall V-path Inspection for Far Surface Flaw Detection

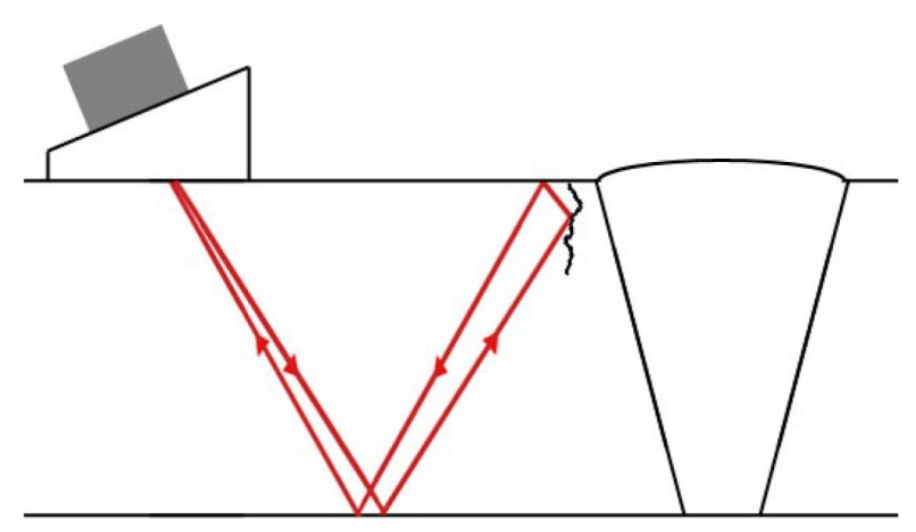

Figure S.12. Depiction of a Full V-path Inspection for Near-Surface Flaw Detection 



\section{Acknowledgments}

The work described in this report was sponsored by the U.S. Nuclear Regulatory Commission under NRC Job Code Number V6354. Gratitude is extended to Bruce Lin, NRC Project Manager and to NRC staff members Sara DePaula, James Rubenstone, Tae Ahn, Darrell Dunn, David Tarantino, and Robert

Einziger for the guidance, input, and information they provided over the duration of this project. Special thanks to Kay Hass, Lisa Staudinger, and Earlene Prickett who helped edit and format this report. 



\section{Acronyms and Abbreviations}

\begin{tabular}{|c|c|}
\hline AET & acoustic emission testing \\
\hline $\mathrm{BC}$ & bobbin coil \\
\hline BMI & bottom-mounted instrumentation \\
\hline BWR & boiling water reactor \\
\hline CASS & cast austenitic stainless steel \\
\hline CCD & charge coupled device \\
\hline CFR & Code of Federal Regulations \\
\hline CID & charge injection device \\
\hline CMOS & complementary metal-oxide-semiconductor \\
\hline COD & crack opening displacement \\
\hline CRIEPI & Japanese Central Research Institute of the Electric Power Industry \\
\hline DCSS & dry cask storage system \\
\hline DMW & dissimilar metal weld \\
\hline DOE & U.S. Department of Energy \\
\hline DSC & dry shield canister \\
\hline ECIRE & Eddy Current Inspection Reliability Experiment \\
\hline ECT & eddy current testing \\
\hline EDM & electro-discharge machined \\
\hline EMAT & electromagnetic acoustic transducers \\
\hline EPRI & Electric Power Research Institute \\
\hline FAA & Federal Aviation Administration \\
\hline FFTF & Fast Flux Test Facility \\
\hline FSAR & Final Safety Analysis Reports \\
\hline GUT & guided ultrasonic wave testing \\
\hline HAZ & heat-affected zone \\
\hline HEDL & Hanford Engineering Development Laboratory \\
\hline HSM & horizontal storage module \\
\hline IGSCC & intergranular SCC \\
\hline INL & Idaho National Laboratory \\
\hline ISFSI & Independent Spent Fuel Storage Installation \\
\hline ISI & in-service inspection \\
\hline LIDSCC & longitudinal inner diameter stress corrosion cracking \\
\hline LODSCC & longitudinal outer diameter stress corrosion cracking \\
\hline MPC & multi-purpose canisters \\
\hline MRPC & magnetic rotating pancake coil \\
\hline MRR & Mini Round Robin \\
\hline
\end{tabular}


NASA

NDE

NPP

NRC

ODSCC

PDI

PINC

PIRR

PISC III AST

POD

PWR

PZT

RMSE

SAFT

SCC

SKI

SONGS

TGSCC

UNF

UT

UV
National Aeronautic and Space Agency

nondestructive examination

nuclear power plant

U.S. Nuclear Regulatory Commission

outer diameter stress corrosion cracking

Performance Demonstration Initiative

U.S. NRC’s Program for the Inspection of Nickel Alloy Components

Piping Inspection Round Robin

Programme for Inspection of Steel Components III Austenitic Stainless Steel Testing Study

probability of detection

pressurized water reactor

lead zirconate titanate

root mean square error

synthetic aperture focusing technique

stress corrosion cracking

Swedish Nuclear Power Inspectorate

San Onofre Nuclear Generating Station

transgranular SCC

used nuclear fuel

ultrasonic testing

ultraviolet 


\section{Contents}

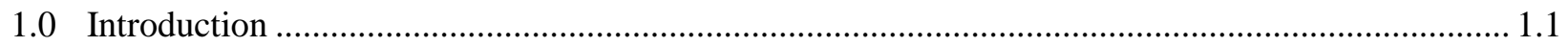

1.1 Inspection and Monitoring of Degradation in DCSS Canisters ............................................ 1.1

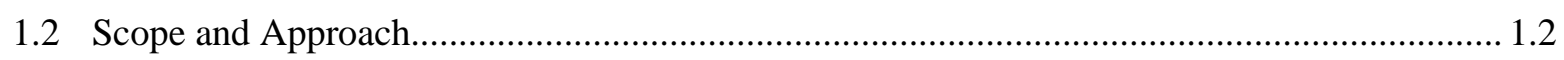

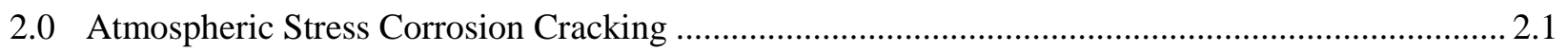

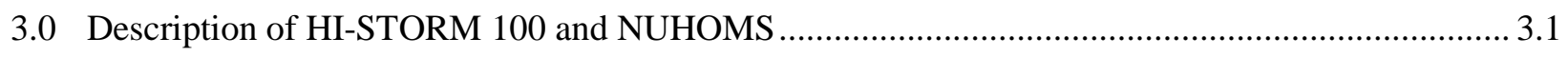

3.1 HI-STORM 100 (Holtec International) ............................................................................... 3.1

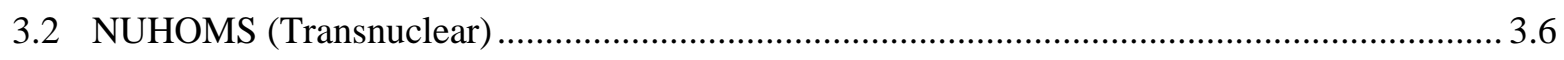

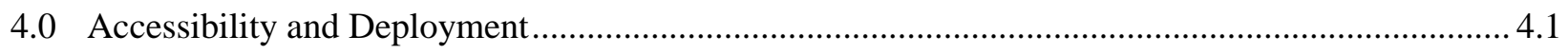

4.1 HI STORM 100 System Accessibility ................................................................................. 4.1

4.2 Deployment of NDE Sensors in the HI-STORM 100 System ............................................... 4.8

4.3 NUHOMS System Accessibility and Deployment .......................................................... 4.10

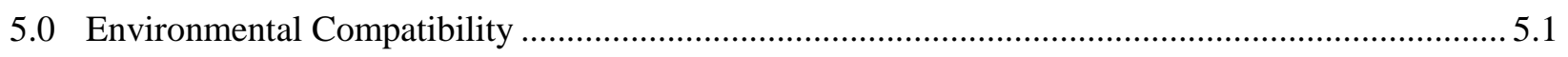

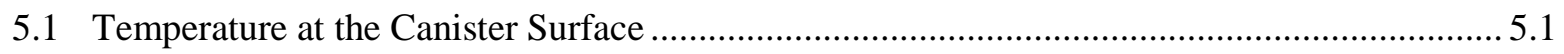

5.2 Gamma Radiation Dose at the Canister Surface .................................................................... 5.5

5.3 Environmental Tolerance of NDE Sensors ............................................................................ 5.6

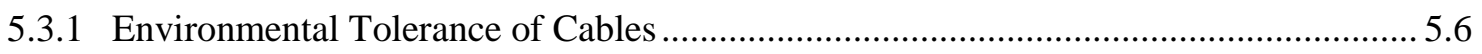

5.3.2 Environmental Tolerance of Eddy Current Probes ...................................................... 5.8

5.3.3 Environmental Tolerance of Piezoelectric Transducers............................................... 5.9

5.3.4 Environmental Tolerance of Video Cameras ............................................................ 5.10

5.3.5 Environmental Tolerance of Fiber Optic Cables ....................................................... 5.11

5.4 Assessment of Environmental Compatibility ................................................................... 5.12

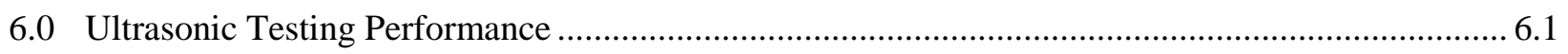

6.1 Probability of Detection (POD) Performance ...................................................................... 6.1

6.2 DCSS Canister Inspection versus NPP Component Inspection .............................................. 6.3

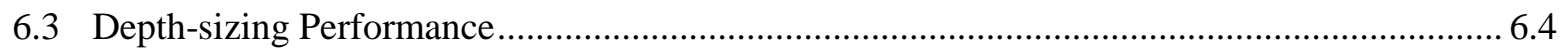

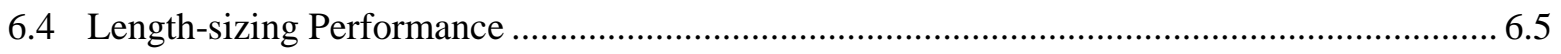

6.5 Relationship Between Crack Depth and Crack Surface Profile ............................................. 6.6

6.6 Discussion of Ultrasonic Examination Performance.............................................................. 6.6

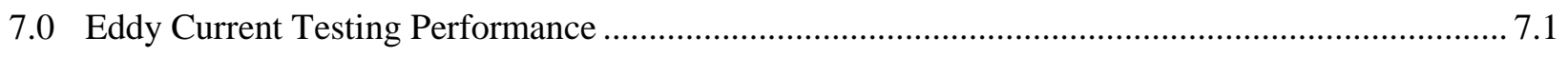

7.1 Probability of Detection Performance ............................................................................... 7.1

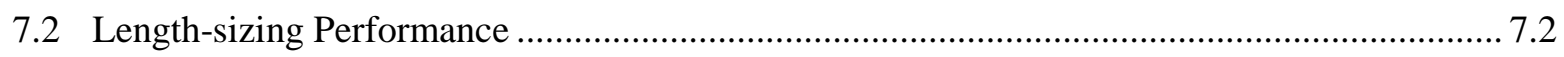

7.3 Detection and Characterization of Stress Corrosion Cracks (SCC) ....................................... 7.3

7.4 Relationship Between Crack Depth and Crack Surface Profile .............................................. 7.3

7.5 Discussion of Eddy Current Performance ..................................................................... 7.3

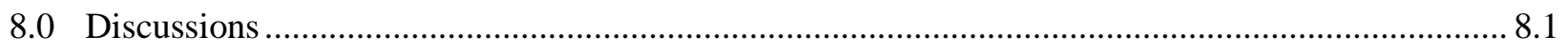

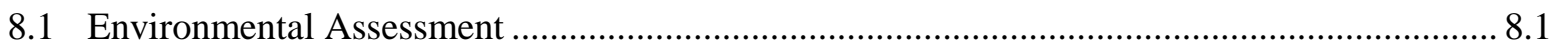




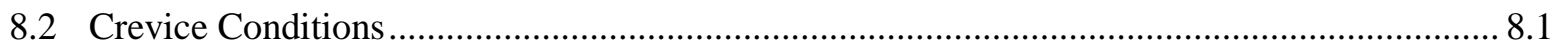

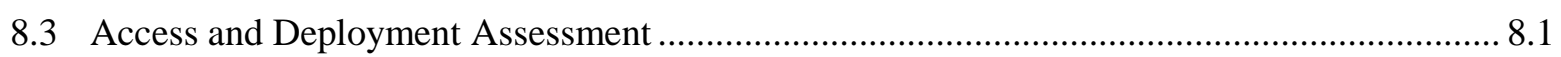

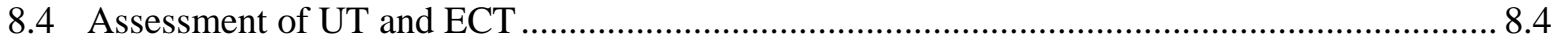

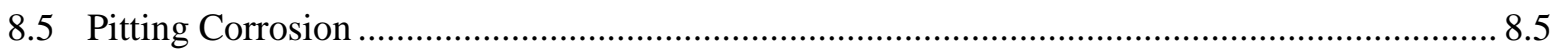

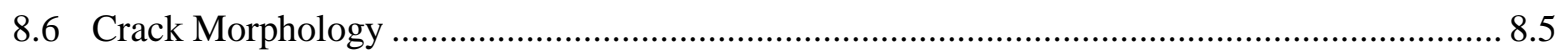

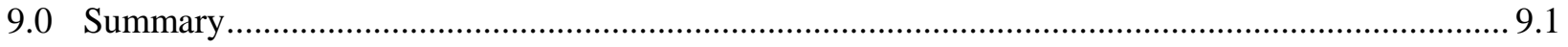

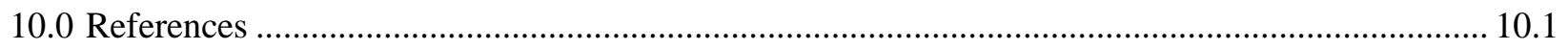




\section{Figures}

Figure 3.1. Cut-away Illustration of the Holtec HI-STORM 100 System with MPC and Overpack (Holtec International 2010) (Used with permission of HOLTEC International)............. 3.2

Figure 3.2. Cut-away Illustration of the Holtec HI-STORM 100S System with MPC and Overpack (Holtec International 2010) (Used with permission of Holtec International).................. 3.3

Figure 3.3. Cut-away Illustration of the Holtec HI-STORM 100S Version B System with MPC and Overpack (Holtec International 2010) (Used with permission of Holtec International)....

Figure 3.4. C C C C Hoss-sectional View of Holtec MPC (Holtec International 2010) (Used with permission of Holtec International).

Figure 3.5. Drawing of an Array of Standardized NUHOMS HSM Modules (Transnuclear 2004a) $\quad 3.6$

Figure 3.6. Photograph of a NUHOMS Storage Facility at INL (photograph courtesy of INL) 3.7

Figure 3.7. Drawing of the HSM for the Standardized NUHOMS System (Transnuclear 2004a)........... 3.8

Figure 3.8. Drawing of the HSM-H for the NUHOMS HD (Transnuclear 2004b) .................................. 3.8

Figure 3.9. SolidWorks Cross Section of the HSM Deployed at Calvert Cliffs ....................................... 3.9

Figure 3.10. Drawing of a NUHOMS DSC (Transnuclear 2004a) .................................................... 3.10

Figure 4.1. Dimensioned Drawing of Inner Cavity Wall of the HI-STORM 100 System with

Overlay of Lid and Pedestal Also Depicted (dimensions are in inches) ....................................... 4.2

Figure 4.2. Dimensioned Drawing of the Inner Cavity Wall and Lid of the HI-STORM 100S System with Overlay of the Pedestal Depicted (dimensions are in inches).

Figure 4.3. Dimensioned Drawing of the Inner Cavity Wall and Lid of the HI-STORM 100S Version B System with Overlay of the Pedestal Depicted (dimensions are in inches).

Figure 4.4. Drawing of the HI-STORM 100S Version B Overpack Baseplate Depicted from

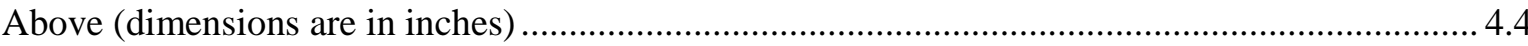

Figure 4.5. Drawing of the Gamma Shield for the HI-STORM 100S Version B Inlet Opening in the Overpack Baseplate (dimensions are in inches)

Figure 4.6. D D Depawing of the MPC-24 Canister Depicting Shell and Lid Welds, Shell-toBaseplate Welds, and Canister Internal Welds for the Lift Lugs and Fuel Basket Shims

Figure 4.7. Drawing of the MPC-32 Canister Depicting Shell and Lid Welds, Shell-toBaseplate Welds, and Canister Internal Welds for the Lift Lugs and Fuel Basket Shims

Figure 4.8. D D Deawing of the MPC-68 Canister Depicting Shell and Lid Welds, Shell-toBaseplate Welds, and Canister Internal Welds for the Lift Lugs and Fuel Basket Shims

Figure 4.9. Overlay of MPC-32 on the HI-STORM 100 Overpack with Clearance Dimensions Specified Between the Overpack Inner Cavity Wall and the Canister, Between the Channels and the Canister, and Between the Overpack Lid and MPC Lid.

Figure 4.10. Overlay of MPC-32 on the HI-STORM 100S Overpack with Clearance Dimensions Specified Between the Overpack Inner Cavity Wall and the Canister, Between the Channels and the Canister, and Between the Overpack Lid and MPC Lid....

Figure 4.11. Overlay of MPC-32 on the HI-STORM 100S Version B Overpack with Clearance Dimensions Specified Between the Overpack Inner Cavity Wall and the 
Canister, Between the Channels and the Canister, and Between the Overpack Lid and MPC Lid $\quad 4.7$

Figure 4.12. NDE Sensor Deployment Concept Utilizing a Long Spring Steel Handle to Maintain the Integrity of Sensor Contact with the Canister

Figure 4.13. NDE Sensor Deployment Concept Utilizing a Spring-Loaded Wheeled Buggy ................. 4.9

Figure 4.14. NDE Sensor Deployment Concept Utilizing a Magnetic Crawler System........................ 4.10

Figure 4.15. Cross-sectional View of the Calvert Cliffs HSM Module with Dimensional Indications for Possible Access Paths for NDE Probes (dimensions are in inches)

Figure 4.16. Illustration of Insertion of NDE Probe Mounted to Spring Steel Probe through HSM Outlet Vent

Figure 4.17. Illustration of Front View of HSM Module and Depiction of Clearance between HSM Entry Sleeve and Canister.

Figure 4.18. Illustration of NDE Probe Mounted to Spring Steel Wand for Examination of the DSC Surface.

Figure 4.19. Illustration of NDE Probed Deployed on Robotic Crawler for Examination of End Plate to Shell Weld for DSC

Figure 5.1. Axial Temperature Distribution at the Canister Shell Surface at the Peak Temperature Location for Projected Decay Heat Decrease over Time in Horizontal Storage ........ 5.2

Figure 5.2. Simulated DSC Shell Surface Temperatures for Calvert Cliffs HSM-15 (Suffield

et al. 2012)........................................................................................................................... 5.3

Figure 5.3. Peak Canister Shell Temperature Predictions for Projected Decay Heat Decrease Over Time in Horizontal Storage

Figure 5.4. Axial Temperature Distribution at the Canister Shell Surface for Projected Decay Heat Decrease Over Time in Vertical Storage.

Figure 5.5. Axial Temperature Profile Measurements for Canisters in Vertical Concrete Storage Module (Takeda et al. 2008). Copyright 2008, with permission from Elsevier.

Figure 5.6. Calculated Temperature Estimations for Canisters with an Initial Heat Loading of 24 kW Under Different Ambient Conditions (Gordon et al. 2006). Copyright 2006, Electric Power Research Institute; used with permission. .............................................................. 5.5

Figure 5.7. Illustration of a Typical Coaxial Cable Structure .................................................................. 5.7

Figure 5.8. Schematic of Eddy Current Probe ................................................................................ 5.8

Figure 5.9. Photograph of an Eddy Current Surface Probe and View Showing the Coil Winding .......... 5.8

Figure 5.10. Illustration of the Typical Components of a Standard Piezoelectric Transducer ................. 5.9

Figure 5.11. Illustration Depicting Typical Fiber Optic Cable Structure.............................................. 5.11

Figure 5.12. Illustration of the Relative Thermal Tolerance of Various NDE Sensor Component Materials to Anticipated Canister Temperature Values.

Figure 5.13. Illustration of the Relative Tolerance of Many NDE Sensor Component Materials to Gamma Radiation Compared to Anticipated Gamma Radiation Dose Values Near the Canister Surface.

Figure 6.1. Depiction of Far Surface UT Probe Placement for a Near-Side Weldment

Examination

Figure 6.2. POD Results for IGSCC in 304 Stainless Steel Piping with 1.51-cm and

1.27-cm Wall Thickness (Heasler and Doctor 1996a). 
Figure 6.3. POD Results for Thermal Fatigue Cracks in 304 Stainless Steel Piping with

1.51-cm and $1.27 \mathrm{~cm}$ Wall Thickness (Heasler and Doctor 1996a)............................................... 6.2

Figure 6.4. Depiction of a Half V-path Inspection for Far-Surface Flaw Detection................................. 6.3

Figure 6.5. Depiction of a Full V-path Inspection for Near-Surface Flaw Detection............................... 6.4

Figure 6.6. Depiction of a High Angle Path Inspection for Near-Surface Flaw Detection...................... 6.4

Figure 6.7. Depth-sizing of Flaws Based on Detection of Corner Reflection Signal and Tip-

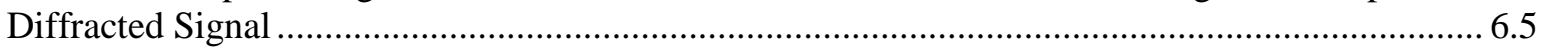

Figure 6.8. Depiction of Multiple Tip-Diffracted Signals from a Multi-Branched Flaw Such as

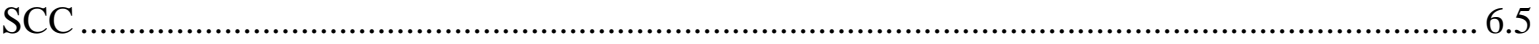

Figure 8.1. Illustration of Accessible Zones of the MPC Surface from Inlet and Outlet

Ventilation Ports of the HI-STORM 100 System ..................................................................... 8.2

Figure 8.2. Illustration of Accessible Zones of the MPC Surface from Inlet and Outlet

Ventilation Ports of the HI-STORM 100S System ..................................................................... 8.3

Figure 8.3. Illustration of Accessible Zones of the MPC Surface from Inlet and Outlet

Ventilation Ports of the HI-STORM 100S Version B System..................................................... 8.3

\section{Tables}

Table 5.1. Summary of Results of Peak Dose Rate Calculations ......................................................... 5.6

Table 5.2. Summary of Temperature and Gamma Radiation Tolerance of Several Types of

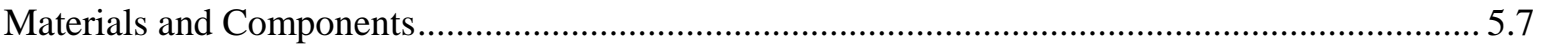

Table 5.3. Summary of Curie Temperatures and Radiation Dosage Exposures for Selected

Piezoelectric Materials (Rempe et al. 2011) ............................................................................... 5.9

Table 5.4. Summary of Temperature and Radiation Specifications for Video Cameras from

Multiple Vendors (Meyer et al. 2013)..................................................................................... 5.11

Table 8.1. Summary of Best Documented Performance Data for UT and ECT ...................................... 8.4 



\subsection{Introduction}

Dry cask storage systems (DCSSs) for used nuclear fuel (UNF) are intended for temporary storage periods. The initial license term for an Independent Spent Fuel Storage Installation (ISFSI) is 40 years from the date of issuance per Title 10 of the Code of Federal Regulations (CFR) 72.42 limits and may be renewed by the U.S. Nuclear Regulatory Commission (NRC) for a period of up to 40 years upon submission and approval of an application by the licensee (Chopra et al. 2012). The current uncertainty regarding the opening of a permanent repository in the United States implies the potential for reliance on DCSSs for extended storage periods that are much longer than originally envisioned. This raises the possibility that DCSSs could be vulnerable to long term aging degradation mechanisms outside of the original design envelopes.

Defense-in-depth is a core safety philosophy in the nuclear power industry to protect the general public from releases of radioactive materials into the environment. In a nuclear reactor, defense-in-depth is provided by multiple barriers, including the fuel and fuel cladding, reactor vessel, and containment structure. Nondestructive examination (NDE) is often applied to verify the integrity of barriers employed to prevent the release of radioactive materials. In DCSSs, the confinement barrier is the final barrier preventing the potential release of radioactive materials into the surrounding environment. Ensuring the integrity of this barrier is essential to preventing the release of radioactive materials into the surrounding environment due to potential damage to fuel cladding from long term aging mechanisms or handling. In some cases, damaged fuel may be loaded into DCSSs at the outset.

\subsection{Inspection and Monitoring of Degradation in DCSS Canisters}

Recently, the NRC issued a draft technical report identifying and prioritizing the technical information needs for extended dry storage of UNF and transportation of UNF following long-term storage. One of the potential degradation issues to be assigned the highest priority in this evaluation includes stress corrosion cracking (SCC) of stainless steel canister body and weld materials (NRC 2012a). In addition, the concern regarding SCC degradation in canisters is more specifically addressed in a recent NRC information notice (NRC 2012b) titled, "Potential Chloride-Induced Stress Corrosion Cracking of Austenitic Stainless Steel and Maintenance of Dry Cask Storage System Canisters,” summarized in Section 2.0. SCC is prevalent in the nuclear power industry, and has been observed in numerous internal components and piping weldments of boiling water reactors (BWRs) and in several pressurized water reactor (PWR) components, including steam generator tubing and reactor pressure vessel penetrations. Inspections of nuclear power plant (NPP) components are performed on a periodic basis during outages. The main NDE methods used for the in-service inspection (ISI) of NPP components include bulk ultrasonic techniques, eddy current techniques, and visual techniques (including dye penetrant and magnetic particle). However, the conditions under which SCC is induced in light-water reactors are different than the conditions anticipated to induce SCC in DCSS canisters. This difference in the SCC mechanism could impact detectability with NDE through differences in geometry, dimensions, morphology, and growth rate. Another difference is that atmospheric SCC begins on the outer surface of DCSS canisters, whereas SCC that occurs under BWR or PWR conditions initiates on the inside surface of components.

In-situ examinations of DCSS canisters create challenges for deployment of NDE sensors near the canister. Accessibility issues arise due to the design requirements for shielding and to minimize radiation 
streaming effects through vents. Therefore, there generally is no line-of-sight access to the canister surface through ventilation ports, and at least one or more right angle turns are required to access the surface of a DCSS canister through a ventilation port. The radiation fields and temperature values near the canister may prevent the deployment of certain types of sensors and, together with accessibility, will constrain how and which sensors may be deployed. In contrast to outage-based maintenance performed for NPPs, manual scanning of sensors in close proximity to the canister is not a likely option for most conditions.

A recent report reviewed several NDE methods for application to DCSS canisters (Meyer et al. 2013). The report considered methods based on their use in the nuclear power industry and perceived potential for inspecting and monitoring DCSS canisters. The methods reviewed included bulk ultrasonics, eddy current, acoustic emission, visual, and guided wave techniques. Other reports also discuss the potential of visual, eddy current, and phased array ultrasonic methods (Kunerth et al. 2012) and non-linear elastic wave techniques (TenCate et al. 2012). Visual techniques and coupons for salt deposit measurements are discussed as potential methods for monitoring canister corrosion, and miniature electromagnetic acoustic transducer (EMAT) sensors are mentioned as having potential to monitor degradation in DCSS canister shells (Lambert et al. 2012). Other groups engaged in research efforts to better understand the potential for atmospheric SCC in DCSS canisters and methods for detection include the Japanese Central Research Institute of the Electric Power Industry (CRIEPI) and the Electric Power Research Institute (EPRI) in the United States.

Meyer et al. (2013) noted that visual techniques may not reliably detect atmospheric SCC flaws because many flaws may feature a crack opening displacement (COD) that is below the reliable detection thresholds of standard cameras used to perform inspections in the nuclear power industry. This work is documented in NUREG/CR-6943 (Cumblidge et al. 2007). Techniques such as acoustic emission testing (AET) and guided ultrasonic wave testing (GUT) are attractive because they may provide the capability for continuous monitoring of DCSS canisters or for more complete monitoring coverage. However, the efficacy of each of these techniques is unclear and requires further research and development efforts. The need for continuous monitoring or full canister coverage is not yet clear and will depend on several factors, including the growth rate of atmospheric SCC and deficiencies in other inspection methods. A more immediate need is associated with the capability to detect atmospheric SCC flaws in DSCC canisters during an inspection and depth-sizing of detected flaws to estimate potential through wall penetration. In this regard, eddy current (ECT) and bulk ultrasonic (UT) techniques have demonstrated appropriate capabilities applicable to the inspection needs of several nuclear power plant components.

\subsection{Scope and Approach}

This report assesses the performance of ECT and UT methods or techniques for inspecting the surface of canisters with a focus on the Holtec HI-STORM 100 and Transnuclear NUHOMS DCSS systems to represent vertical and horizontal systems, respectively. This assessment is performed by considering access and deployment, environmental compatibility, the performance of UT methods and techniques, and the performance of ECT methods and techniques. This report focuses on UT and ECT methods and techniques because their use in the nuclear power industry and relative maturity makes them good candidates for near-term application to examination of dry storage canister surfaces. With respect to the performance assessments for UT and ECT methods and techniques, the emphasis of this effort is to highlight and summarize quantified information regarding the performance of UT and ECT methods and 
techniques for detection, length-sizing, and depth-sizing of flaws to assess if these techniques can reliably detect flaws before they penetrate a canister, and to determine if and to what extent the depth of flaws can be measured.

Section 2.0 includes a brief discussion of atmospheric SCC, while Section 3.0 provides an overview of the HI-STORM 100 and NUHOMS storage systems. Deployment options and accessibility constraints are documented in Section 4.0 for both systems. Section 5.0 treats environmental compatibility by documenting the environmental conditions (temperature and gamma radiation field) near the canister surface and the environmental tolerance of several materials that make up components of NDE

transducers. Section 6.0 summarizes performance information for UT methods and techniques while Section 7.0 summarizes performance information for ECT methods and techniques. Discussions are provided in Section 8.0 and a summary is provided in Section 9.0. 



\subsection{Atmospheric Stress Corrosion Cracking}

Engineering analysis of SCC susceptibility involves an assessment of materials, environment, and mechanical loading conditions. For SCC to occur, three factors must be present: a susceptible material, corrosive environment, and tensile loading conditions. Atmospheric SCC in DCSSs is induced by chloride contamination on the outer surface of components in marine or coastal environments. Atmospheric SCC is also dependent on the deliquescence of salt deposits on the surface of the component which is a function of both temperature and humidity. Generally, it is accepted that SCC susceptibility increases with temperature, however, deliquescence zones exist above threshold relative humidity values that are nearly independent of temperature. As the absolute humidity increases, the temperature below which deliquescence may occur also increases (Caseres and Mintz 2010). Caseres and Mintz (2010) document the results of salt fog studies conducted on U-bend specimens as several discrete temperature values. It is noted that specimens held at $85^{\circ} \mathrm{C}$ and above did not exhibit susceptibility to SCC due to lack of deliquescence. Therefore, in this report, the temperature of $85^{\circ} \mathrm{C}$ is referred to as a deliquescence threshold. However, the exact value of the threshold for deliquescence is not as important for the purpose of this report as is the concept of a deliquescence threshold and that its value appears to be significantly less than the peak canister temperature at the time of fuel loading under typical conditions.

Sensitization (chromium depletion) is the most important metallurgical factor impacting SCC susceptibility, regardless of stainless steel grade. Sensitization can occur due to sufficient heating of materials during the welding process to cause chromium to diffuse toward the grain boundaries and form chromium carbides, resulting in chromium-depleted regions adjacent to the weld. Thus, if sensitization is a contributing factor to SCC, it is likely to occur in the heat-affected zones (HAZs) adjacent to welds. Sensitization is in turn impacted by carbon concentration and/or the presence of stabilizing elements in the material. Sensitization can be minimized by using stabilized stainless steels or stainless steels with reduced carbon content (<0.03\%) (Andresen 2010).

The presence of tensile stress is also an important condition for SCC initiation and growth; however, there does not appear to be a minimum stress level for SCC incidence and the stress level largely influences time-to-failure. Contributions to the stress state may include weld residual stresses, stress resulting from cold work or corrosion, bending moments, pressurization, and/or thermal expansion and contraction. Crevice conditions can promote localized corrosion and thus SCC by trapping moisture and contaminants on the material surface. SCC is often distinguished by its mode of fracture. SCC that propagates by following grain boundaries in materials is referred to as intergranular stress corrosion cracking (IGSCC) while SCC that propagates through grains is referred to as transgranular stress corrosion cracking (TGSCC). Propagation can occur through a combination of both modes or may involve switching between modes as the crack progresses.

Thus far, no instances of atmospheric SCC have been reported in DCSS canisters currently in use for the storage of used nuclear fuel (UNF), but there is acknowledgement that conditions may exist for atmospheric SCC to occur, especially for canisters located in coastal areas. A recent information notice (IN 2012-20) by the NRC titled, "Potential Chloride-Induced Stress Corrosion Cracking of Austenitic Stainless Steel and Maintenance of Dry Cask Storage System Canisters,” advises ISFSI license holders and license applicants of the potential regarding chloride-induced SCC in the austenitic stainless steels from which canisters are generally fabricated (304, 304L, 316 and 316L) and recommends that the degradation mode be considered as appropriate in aging management plans (NRC 2012b). The 
information notice cites several instances of chloride-induced outer-diameter stress corrosion cracking (ODSCC) in austenitic stainless steel components located near salt water bodies and exposed to atmospheric conditions. These instances occurred in 304 stainless steel piping located at the San Onofre Nuclear Generating Station (SONGS), St. Lucie Nuclear Power Plant, Turkey Point Nuclear Generating Station, and in 304L stainless steel tanks at the Koeberg Nuclear Power Station in South Africa. Through-wall cracks were generally observed after 16-25 years of exposure and located near welds. Surface pitting was also reported at SONGS and it is noted that the crack observed at Turkey Point initiated "at the base of a pit” (NRC 2012b). At St. Lucie, it is noted that more severe indications were discovered in field welds than at fabrication welds, which were solution annealed.

Another NRC information notice (IN 2011-04) titled, "Contaminants and Stagnant Conditions Affecting Stress Corrosion Cracking in Stainless Steel Piping in Pressurized Water Reactors” also cites several instances of chloride-induced ODSCC (NRC 2011). The intent of the information notice was to inform addressees of the effects that contaminants and stagnant water conditions can have on the potential for SCC in PWR components fabricated from stainless steels. The ODSCC occurrences at SONGS are referenced in IN 2011-04 as well as instances of ODSCC at Callaway and Wolf Creek. At Callaway and Wolf Creek, axially oriented flaws were discovered beneath pipe support clamps on 304 stainless steel pressurizer auxiliary spray piping. Further examination noted chloride contamination on the fracture surfaces of flaws and that the crack propagation mode was transgranular in nature.

A PWR Owner's Group whitepaper (Hosler and Hall 2010) describes several instances of ODSCC that are also discussed in IN 2012-20 and IN 2011-04. Additional instances of ODSCC within the industry are also tabulated, including instances at Seabrook, Ikata, Sequoyah Units 1\&2, Salem Unit 1, River Bend, North Anna Unit 1, and Fukushima Daiichi Unit 3. Most of the instances were detected after 23 years of operation and were discovered in components ranging from less than 1 inch in diameter to 24 inches in diameter. Besides marine environments, it is evident that other potential sources of chloride contamination include insulation, use of vinyl chloride tapes, and historical spills or contamination.

The Swedish Nuclear Power Inspectorate (SKI) (now part of the Swedish Radiation Authority [SSN]) has performed a systematic evaluation of service-induced crack characteristics (Ekstrom and Wåle 1995; Wåle 2006). Cracks are assessed according to crack type and material, with several different crack types considered in the analysis. Several flaw parameters were catalogued, including the flaw orientation, flaw size, fracture surface roughness, flaw tortuosity, flaw branching characteristics, COD, and crack tip radius. The mean COD for SCC cracks analyzed ranged from 16-30 $\mu \mathrm{m}$. In many instances, the crack tip radius could not be measured; however, given the data available; the mean crack tip radius appears to be approximately $1 \mu \mathrm{m}$ or less for SCC cracks. In general, SCC flaws exhibit more branching and complexity in shape in comparison to fatigue cracks. 


\subsection{Description of HI-STORM 100 and NUHOMS}

This section provides an overview description of the Holtec HI-STORM 100 and Transnuclear NUHOMS systems. The information in this section comes primarily from public safety evaluation reports for the HI-STORM 100 and NUHOMS systems.

\subsection{HI-STORM 100 (Holtec International)}

The HI-STORM 100 dry storage module belongs to Holtec International's HI-STORM line of storage systems for UNF. A good description of the system is contained in the Final Safety Analysis Report (FSAR) for the HI-STORM 100 systems (Holtec International 2010). The HI-STORM storage systems utilize multi-purpose canisters (MPCs), which represent the actual confinement boundary for the stored UNF. The MPCs are stored in a vertical orientation and cooled by natural circulation. The HI-STORM 100 series of storage modules consists of a combination metal-concrete overpack and MPC. Natural circulation is enabled by the presence of at least four ventilation ducts in both the lower and top portions of the storage module. The overpack consists of concrete (for shielding) encased inside of cylindrical metal shells, a metal baseplate, and a metal top plate. The encasing metal components are fabricated from carbon steel. The inside diameter of the overpack cavity consists of channels to guide MPC insertion and removal and to absorb tip-over loads.

The HI-STORM 100 series storage modules include two additional variations associated with the design of the overpack. These variations are designated as HI-STORM 100S and HI-STORM 100S version $\mathrm{B}$. The "S" designation is used to indicate an enhanced overpack design, while the "version B" designation indicates an enhancement to the $100 \mathrm{~S}$ overpack. In the "100" systems, the ventilation ducts penetrate the overpack body and the top and bottom ducts are in vertical alignment. In the 100S and 100S version B systems, outlet ventilation ducts are integrated into the overpack lid assembly and are not vertically aligned with inlet ventilation ducts at the bottom of the module. In addition to differences in ventilation duct locations, these three models also differ in cask height and the height of the pedestal located on the floor of the overpack cavity to support the MPC. In the case of the 100S version B system, the 17-in. thick concrete pedestal is replaced with a 3-in. thick steel plate. Additionally, the bottom (inlet) ventilation ducts of the $100 \mathrm{~S}$ version $\mathrm{B}$ system are of shorter height and greater width to reduce radiation shine. Cut-away illustrations of the 100, 100S, and 100S version B systems are provided in Figure 3.1 through Figure 3.3, respectively.

The MPCs are welded stainless steel containers that act as a confinement boundary for the UNF stored inside. The outer diameter of the MPC is 68-3/8 inches and the maximum overall height of the MPC is approximately 190-1/2 inches. The MPC consists of several components, including a lid, closure ring, bottom plate, fuel basket, and a cylindrical shell. The cylindrical shell is fabricated from $1 / 2$-in. thick stainless steel alloy material (304, 304LN, 316, or 316LN) and contains longitudinal and circumferential seam full penetration shop welds. Lifting lugs are welded to the inner surface of the canister shell for transfer of the empty canister to the HI-TRAC cask for fuel loading. The lift lugs are not used for canister handling after loading with fuel. Figure 3.4 provides a cross-sectional drawing of a Holtec MPC. 


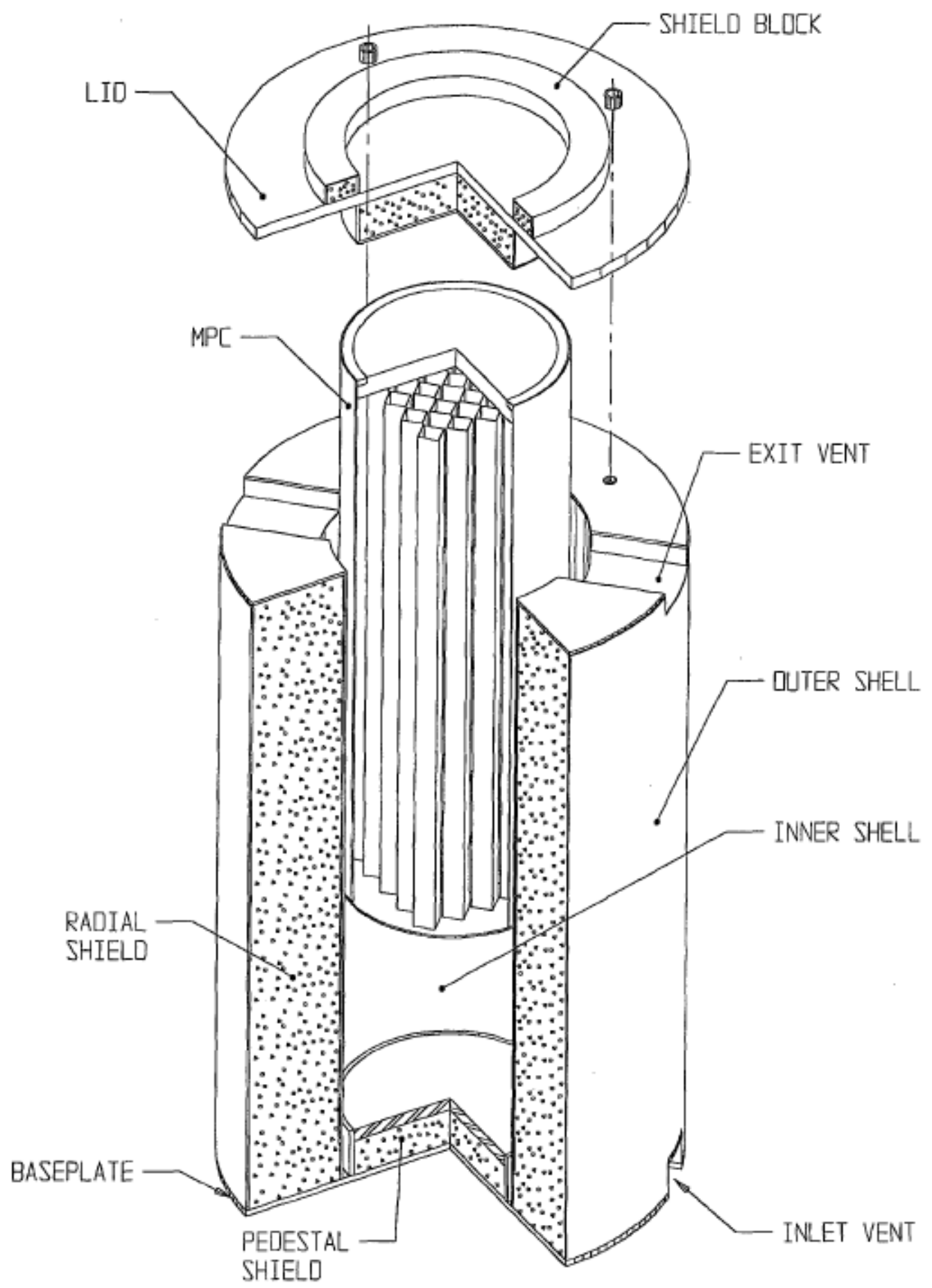

Figure 3.1. Cut-away Illustration of the Holtec HI-STORM 100 System with MPC and Overpack (Holtec International 2010) (Used with permission of HOLTEC International) 


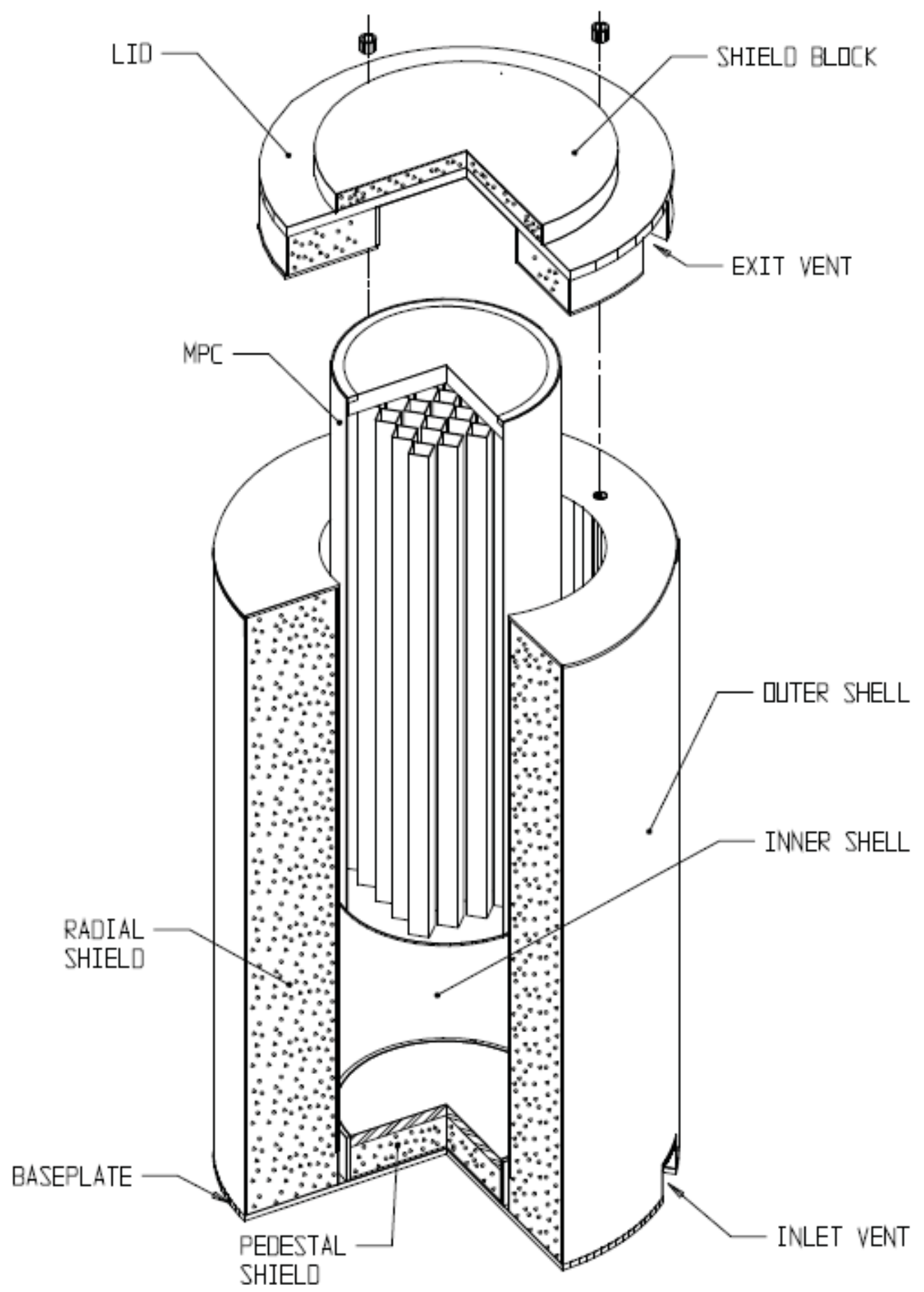

Figure 3.2. Cut-away Illustration of the Holtec HI-STORM 100S System with MPC and Overpack (Holtec International 2010) (Used with permission of Holtec International) 


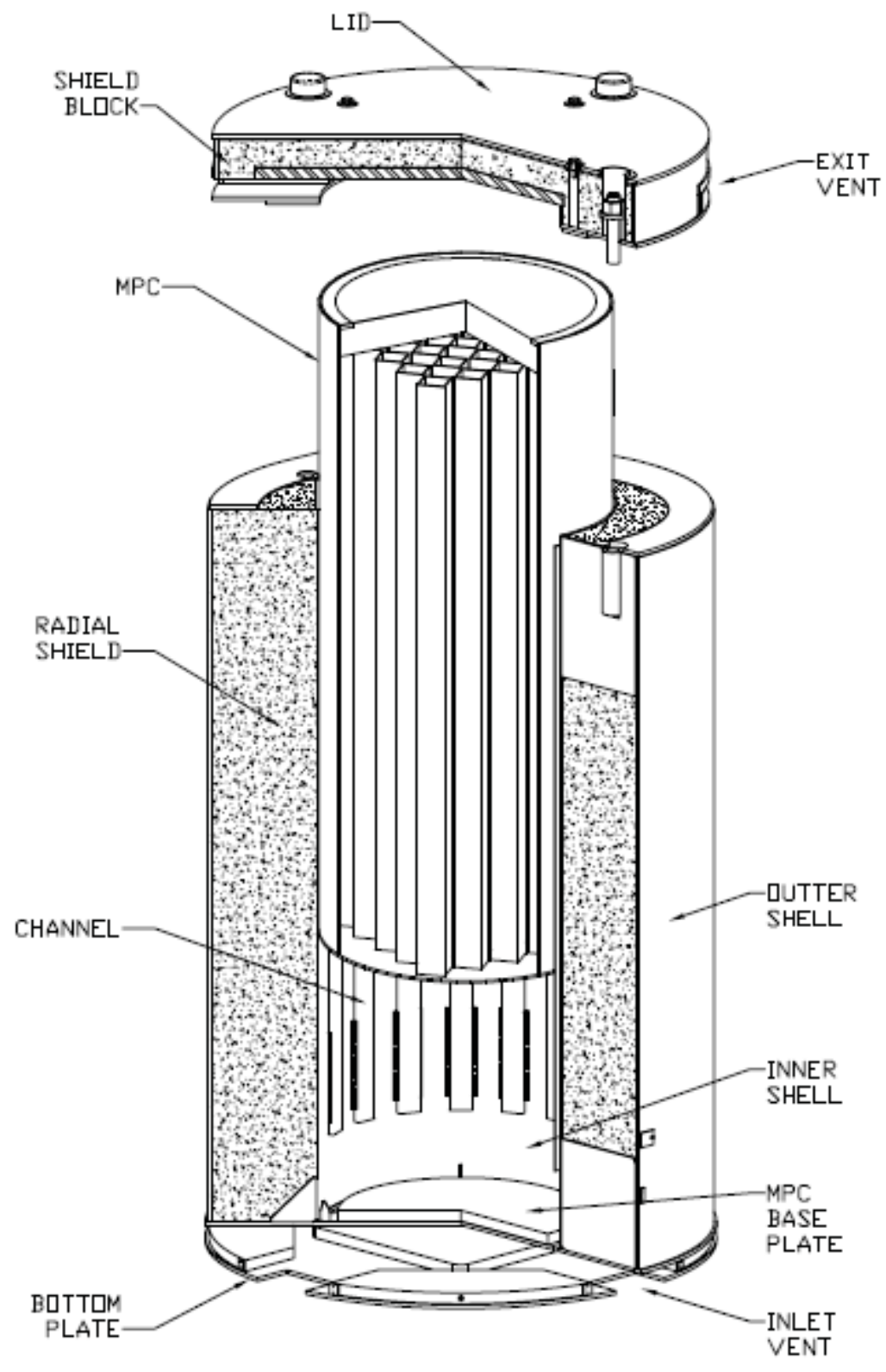

Figure 3.3. Cut-away Illustration of the Holtec HI-STORM 100S Version B System with MPC and Overpack (Holtec International 2010) (Used with permission of Holtec International) 


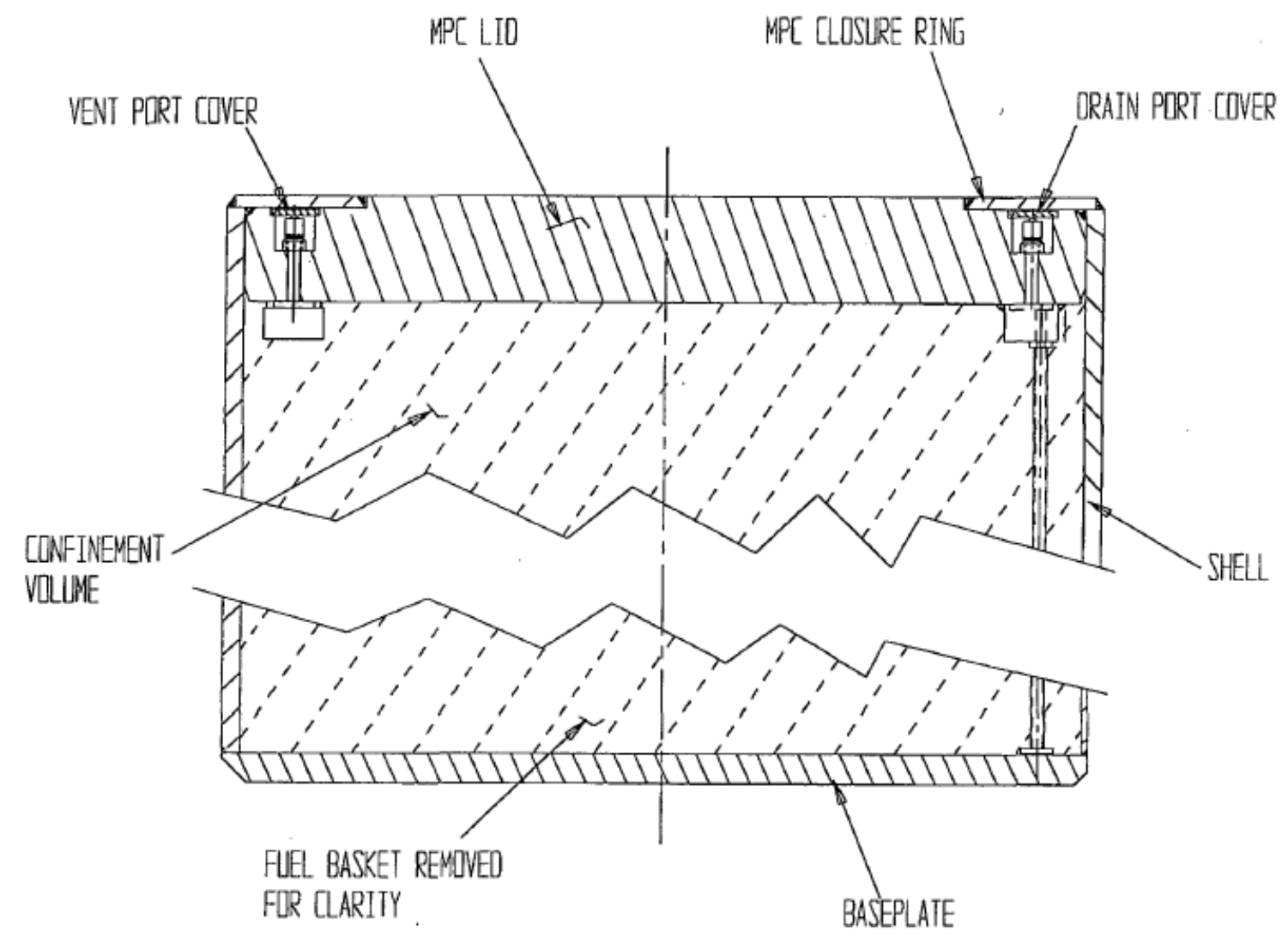

Figure 3.4. Cross-sectional View of Holtec MPC (Holtec International 2010) (Used with permission of Holtec International)

There are several variations of MPCs, although the outer diameters of all models are identical so that they may be used interchangeably with the same overpack. Differences exist with the internal hardware configuration to accommodate different types of fuel (PWR vs. BWR) and different quantities of fuel assemblies (24, 32, and 68). Additional variations exist to accommodate damaged fuel assemblies or fuel debris, often within specified fuel basket locations. The internal hardware configurations are detailed in the FSAR for the HI-STORM 100 systems. For the most part, internal hardware configurations are not expected to have a significant influence on examinations performed on the outer canister surface.

However, brackets are welded to the inner surface of the canister to constrain the fuel basket, and HAZs near these welds may be susceptible to SCC.

The MPC lid is described as a redundant closure system and consists of either a one- or a two-piece circular stainless steel plate and a closure ring. The lid plate is several inches thick to provide radiation shielding and is edge welded to the circumferential shell. The lid is penetrated by vent and drain ports that are used to remove water and air from the MPC and to backfill with inert gas. Cover plates are seal welded over the ports and then a closure ring is installed and edge-welded to the shell and lid. The MPC lid also includes bolt holes near the center of the top surface of the plate for attachment of lift cleats. The lift cleats are the primary lift points for the MPC after it has been loaded with fuel and the lid has been attached to the shell. 


\subsection{NUHOMS (Transnuclear)}

The NUHOMS systems provide for horizontal storage of UNF in a dry shielded canister (DSC) placed inside of a concrete horizontal storage module (HSM). Similar to the line HI-STORM storage systems, multiple variations of the NUHOMS system exist. The standardized NUHOMS is described in revisions of the FSAR for the "Standardized NUHOMS ${ }^{\circledR}$ Horizontal Modular Storage System for Irradiated Nuclear Fuel” (Transnuclear 2004a). Another variation referred to as the NUHOMS HD system is described in the safety analysis report titled "NUHOMS ${ }^{\circledR}$ HD Horizontal Modular Storage System for Irradiated Nuclear Fuel” (Transnuclear 2004b). Additional variations feature key differences associated with the design of the HSM. NUHOMS systems are generally designed for installation of a single or an array of other HSMs. Figure 3.5 is a depiction of an array of standardized NUHOMS HSMs and Figure 3.6 is a photograph of an array of standardized NUHOMS HSMs located at Idaho National Laboratory (INL).

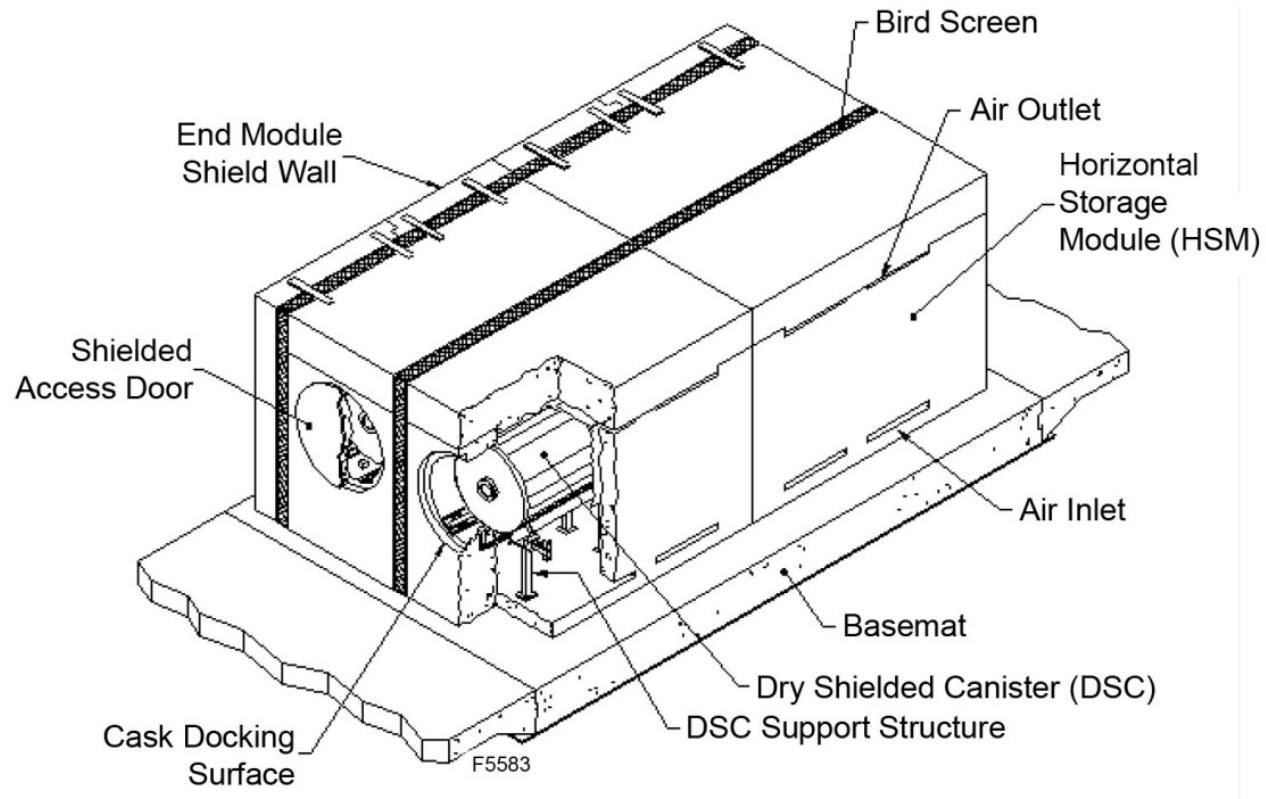

Figure 3.5. Drawing of an Array of Standardized NUHOMS HSM Modules (Transnuclear 2004a) 


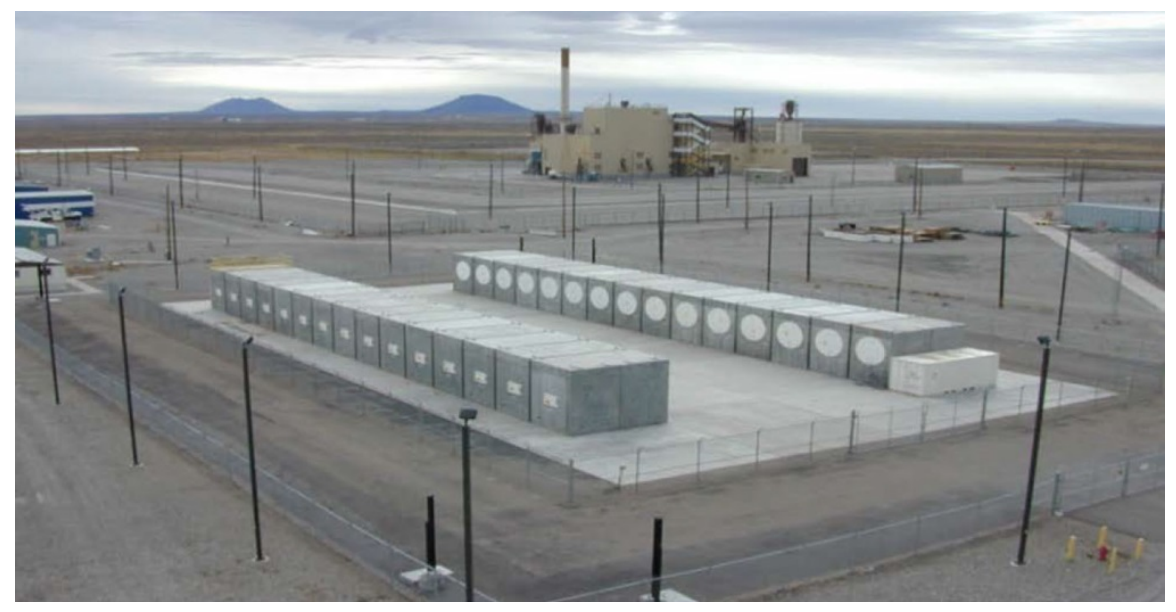

Figure 3.6. Photograph of a NUHOMS Storage Facility at INL (photograph courtesy of INL)

The HSM is fabricated from reinforced concrete and structural steel and designed to withstand normal condition loadings as well as abnormal condition loading caused by earthquakes, tornadoes, etc. Each HSM provides a self-contained module for the storage of a single DSC. The roof and walls of an HSM are several feet thick to provide substantial shielding of neutron and gamma radiation. Decay heat is removed from the stored fuel through radiation, convection, and conduction. Ventilation ports enable the circulation of ambient air around the DSC for heat removal by convection. Heat is also radiated from the DSC surface to a heat shield and the HSM walls, which also reject heat to the ambient air through convection and by conduction through the walls. The cavity of the HSM includes a DSC support structure and a shielded door assembly is attached to the front of the HSM. As noted, there are multiple variations of the HSM, some of which are depicted in Figure 3.7 through Figure 3.9. One of the key distinctions between the systems is the location and design of the ventilation ports. In the HSM for standardized NUHOMS, inlet and outlet vents are located in the sidewalls of the HSM and a 6-in. gap is maintained between other modules in the HSM array to enable circulation (see Figure 3.5 and Figure 3.7). In the HSM-H system, the vents are reconfigured so that the inlet vents direct air from the rear and front of the module and into the sidewall of the cavity. The outlet vent redirects air from the sidewall of the cavity through a U-shaped path before exiting above the HSM (see Figure 3.8). Finally, in the system deployed at Calvert Cliffs, the inlet vent directs air flow through the front of the HSM and two outlet vents are located at the top of the HSM above each end of the DSC (see Figure 3.9). The outlet vents direct the air flow so that it exits above the HSM roof. 


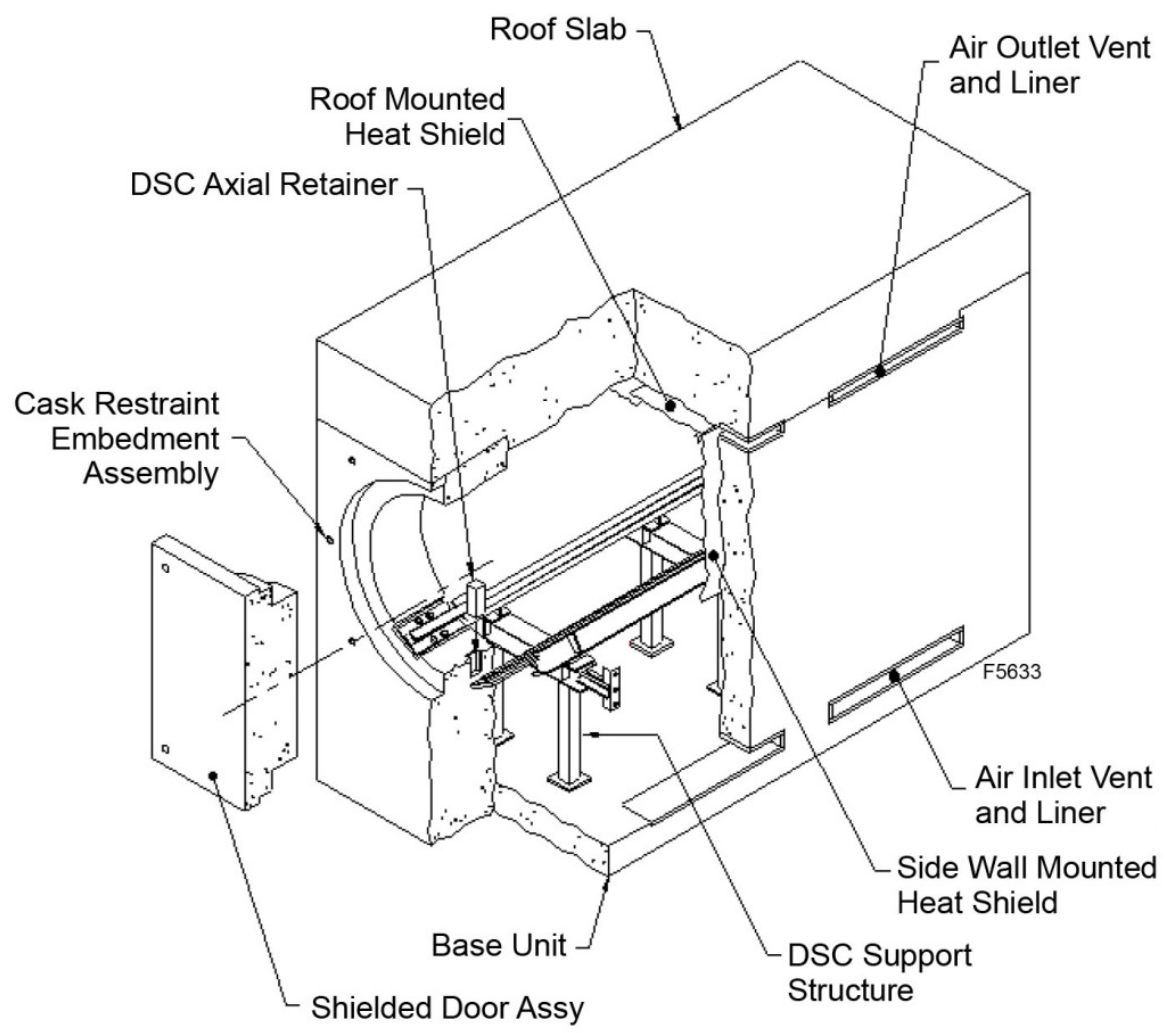

Figure 3.7. Drawing of the HSM for the Standardized NUHOMS System (Transnuclear 2004a)

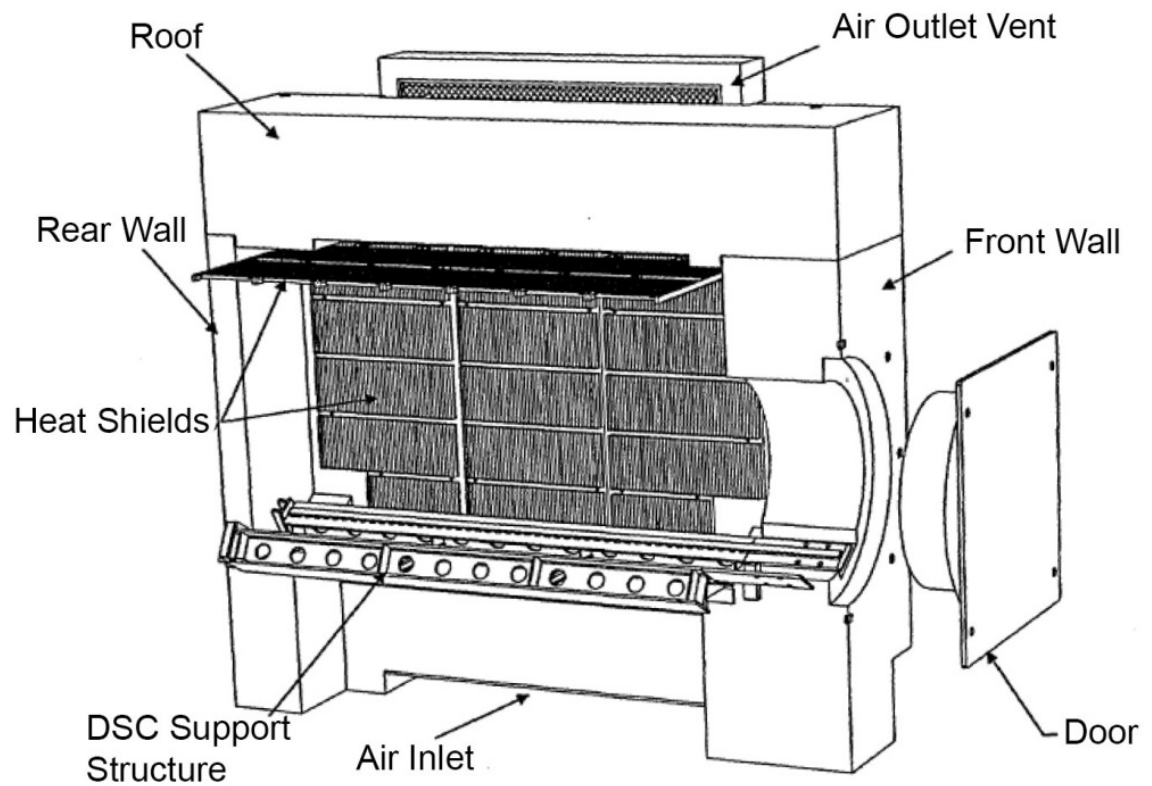

Figure 3.8. Drawing of the HSM-H for the NUHOMS HD (Transnuclear 2004b) 


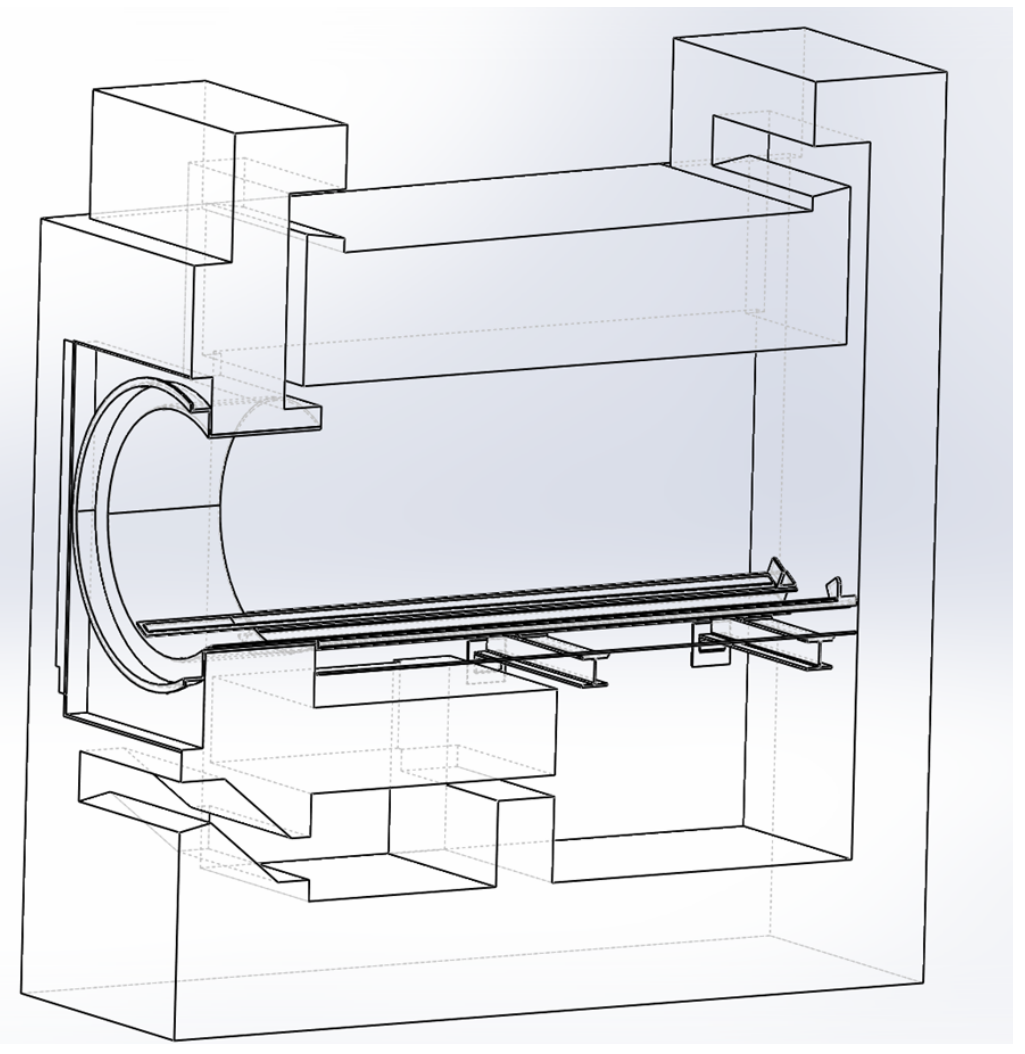

Figure 3.9. SolidWorks Cross Section of the HSM Deployed at Calvert Cliffs

Typical DSC components include a cylindrical shell, top and bottom cover plates, top and bottom shield plugs, and a fuel basket assembly (see Figure 3.10). Fuel basket assemblies are designed to hold 7, 24, and 32 PWR fuel assemblies and 52 and 61 BWR fuel assemblies. Different types of DSCs are approved for storage only under 10CFR72, or for both storage and transportation under 10CFR71. Further distinctions are made for canisters intended to store high burn-up fuel. The numbering of NUHOMS system models reflects the variations with respect to reactor type, number of assemblies, fuel burn-up, and use for storage only or storage and transportation. The numbering method follows the designation of NUHOMS-XXY where (XX) refers to the number of fuel assemblies and (Y) refers to either PWR (P) or BWR (B) fuel. Additional characters may be added to indicate use for transportation (T) or storage of high burn-up fuel (HB). The outside diameters for all NUHOMS canisters are standardized for compatibility, with the exception of the NUHOMS-07P canister. Canisters are fabricated from stainless steel with shell thicknesses of 0.5 in. or 0.625 in. Typical canister lengths are 186 in. to 196 in. $(4.7 \mathrm{~m}-5.0 \mathrm{~m})$. 


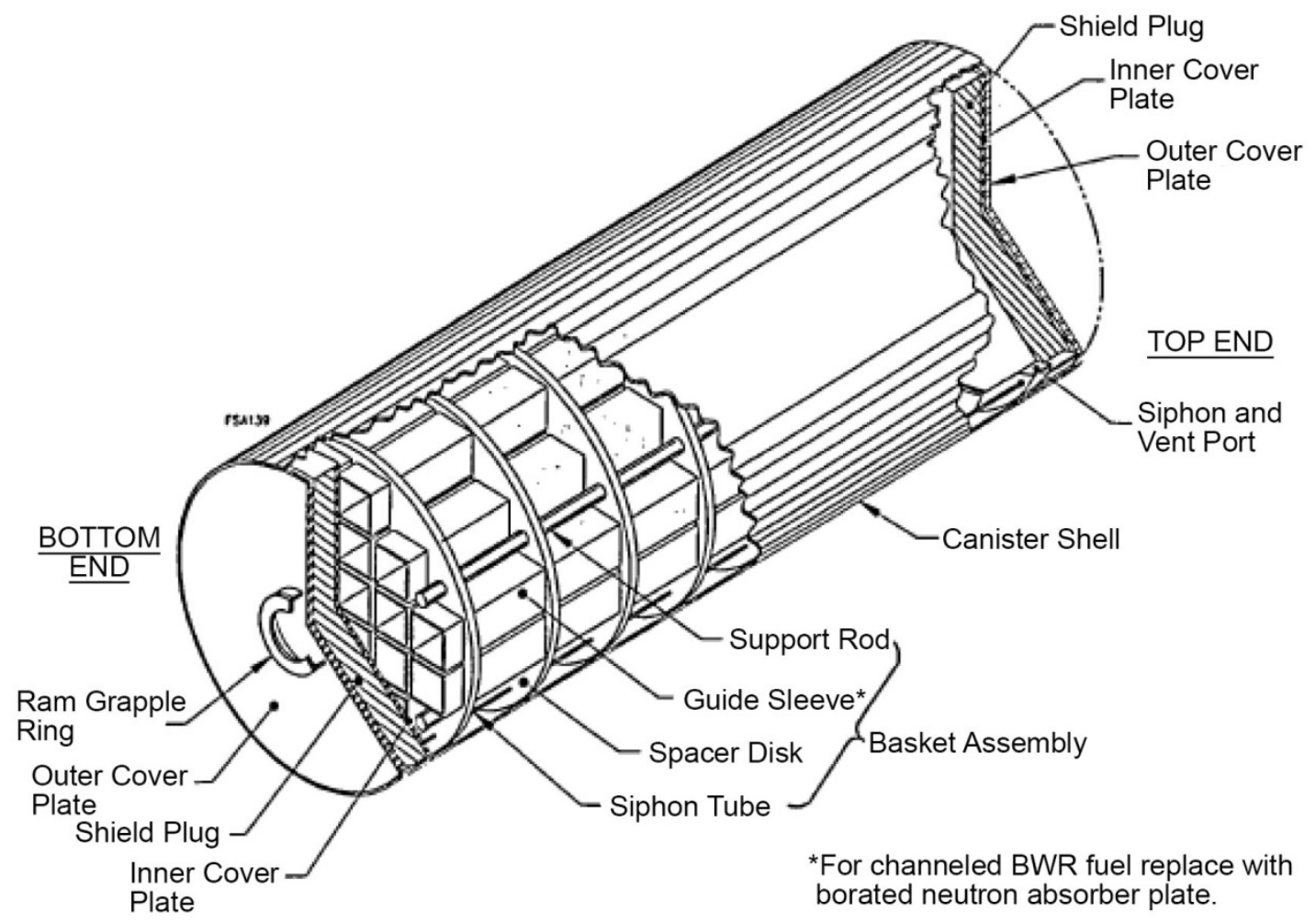

Figure 3.10. Drawing of a NUHOMS DSC (Transnuclear 2004a) 


\subsection{Accessibility and Deployment}

This section discusses accessibility constraints and some deployment options for NDE sensors in the HI-STORM 100 and NUHOMS systems. Accessibility for the HI-STORM systems is documented through "rolled-out" view drawings of the overpack, inner cavity wall, pedestal, lid, and canisters and deployment options are documented with the aid of three-dimensional models. Accessibility constraints for the NUHOMS system is documented with the aid of a Solidworks model for the HSM systems at Calvert Cliffs.

\subsection{HI STORM 100 System Accessibility}

Accessibility constraints are documented in this section for the HI-STORM 100, HI-STORM 100S, and HI-STORM 100S version B systems, as well as for the MPC-24, MPC-32, and MPC-68 canisters. Dimensioned drawings of the inner cavity wall, lids, and pedestals of the HI-STORM 100, HI-STORM 100S, and HI-STORM 100 version B systems are included in Figure 4.1 through Figure 4.3, respectively. The drawings depict to scale the position and size of system features such as the channels on the inner cavity wall, the pedestals, and lids. As noted in Section 3.0, the outlet vents for the HI-STORM 100 system are integrated into the wall of the overpack body, while the outlet vents for the HI-STORM 100S and HI-STORM 100 version B system are integrated into the overpack lid assemblies. The inlet vents for the HI-STORM 100 version B system are much shorter and wider compared to the HI-STORM 100 and HI-STORM 100S systems and are integrated into an overpack baseplate. The 3-in. thick steel pedestal sits on top of this baseplate and four 2-in. wide curved slots around the baseplate provide a path for air from inlet vents to flow up around the canister. A top view drawing of the HI-STORM 100S version B overpack baseplate is provided in Figure 4.4. Cross-plate gamma shields are also inserted into the ventilation ports of the overpacks. This can result in additional accessibility restrictions because the openings of the gamma shields are much smaller than the entire ventilation port opening. Numerous gamma shields are provided to fit the inlet and outlet ports of the different HI-STORM 100 systems. The gamma shield for the HI-STORM 100S version B inlet vents have the smallest openings as depicted in Figure 4.5 .

Drawings of the MPCs are shown to scale in Figure 4.6 through Figure 4.8 for MPC-24, MPC-32, and MPC-68, respectively, in relation to the overpack drawings in Figure 4.1 through Figure 4.3. The dark lines depict structural welds in the shell, and welds connecting the lid and MPC baseplate to the shell. Dashed lines depict interior welds for the attachment of lifting lugs and fuel basket shims.

Figure 4.9 to Figure 4.11 depict the MPC-32 overlaid on the HI-STORM 100, 100S, and 100S version B overpack modules, respectively. These figures illustrate the MPC in relation to overpack features and provide information about the clearances between the MPC and overpack inner cavity wall, between the MPC and channels, and between the MPC and overpack lids.

A significant observation from these figures is that there is more space above the MPC lid for the HI-STORM 100S and HI-STORM 100S version B systems compared to the HI-STORM 100 system. Another important observation is that channels appear to partially limit access to the MPC bottom plateto-shell weld for the HI-STORM 100 and HI-STORM 100S systems, while the weld easily clears the bottom of the channels in the HI-STORM 100S version B system. However, in the HI-STORM 100S version B system, access to the MPC lid-to-shell weld will be partially obstructed from the shell side. The base assembly of the $100 \mathrm{~S}$ version B overpack results in a more complex path for wand-mounted 
probes to access the canister surface. After entering the inlet ventilation port, a probe must be directed upward at $90^{\circ}$ through a 2 -in. wide slide in the top plate of the base assembly without the aid of a canister pedestal to provide a counteracting force to direct the probe upward. Access will be significantly more restricted if gamma shields are not removed for inspection.

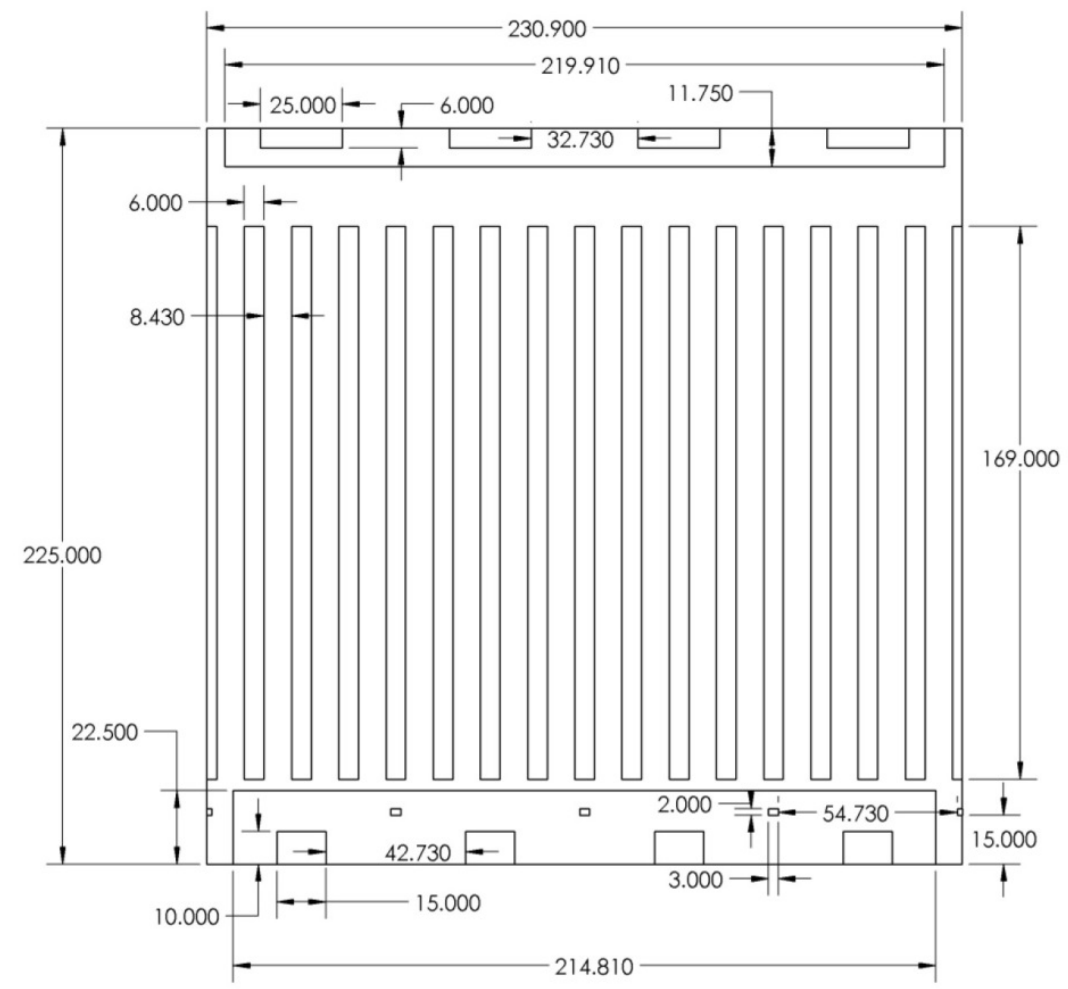

Figure 4.1. Dimensioned Drawing of Inner Cavity Wall of the HI-STORM 100 System with Overlay of Lid and Pedestal Also Depicted (dimensions are in inches) 


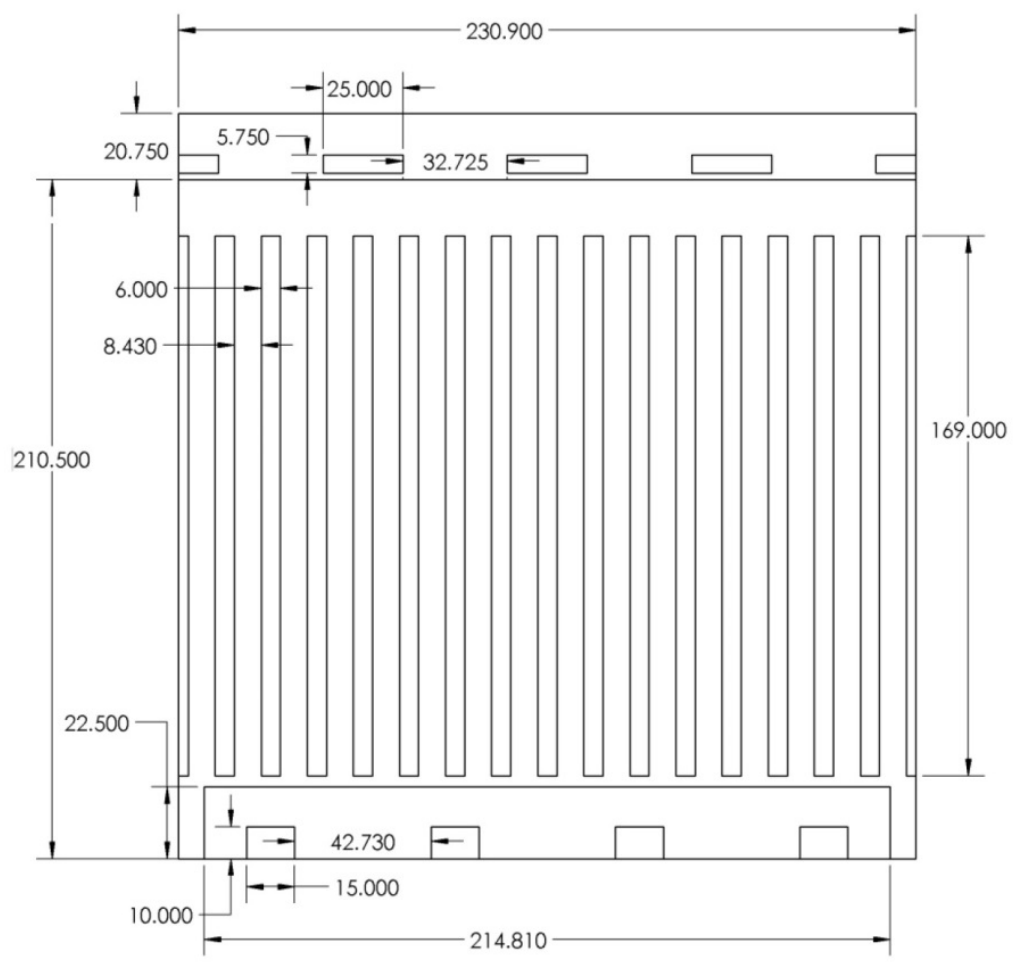

Figure 4.2. Dimensioned Drawing of the Inner Cavity Wall and Lid of the HI-STORM 100S System with Overlay of the Pedestal Depicted (dimensions are in inches)

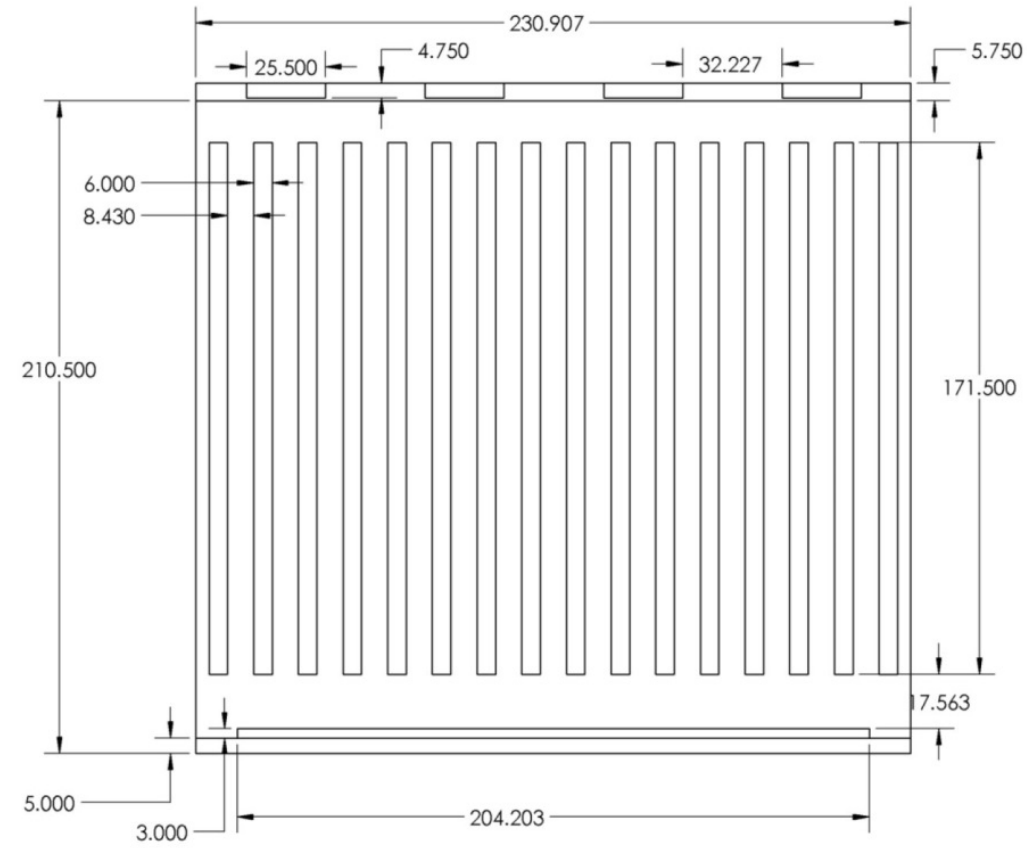

Figure 4.3. Dimensioned Drawing of the Inner Cavity Wall and Lid of the HI-STORM 100S Version B System with Overlay of the Pedestal Depicted (dimensions are in inches) 


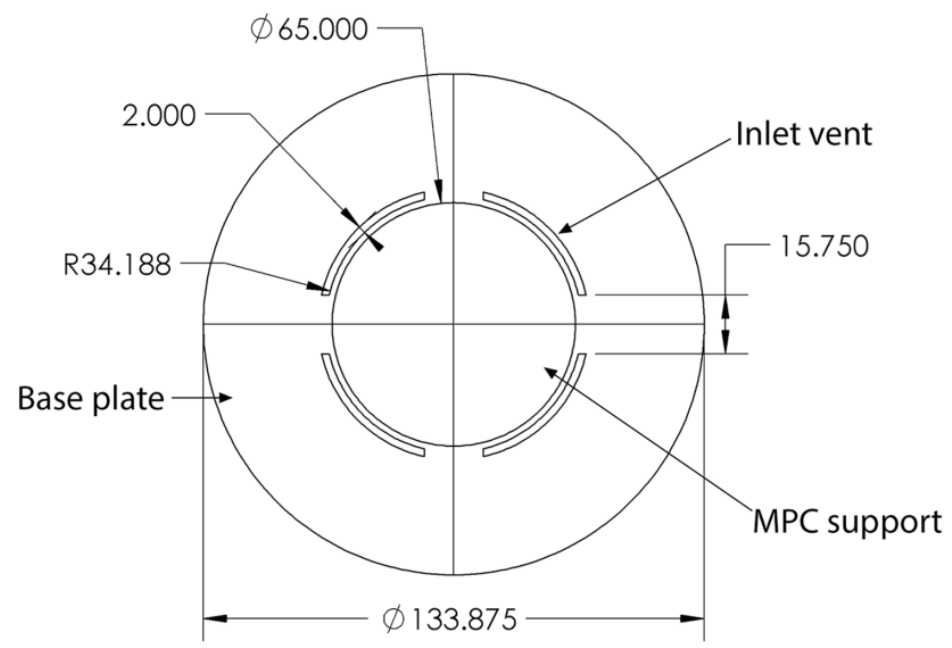

Figure 4.4. Drawing of the HI-STORM 100S Version B Overpack Baseplate Depicted from Above (dimensions are in inches)

\section{S Version B Inlet Gamma Shield}

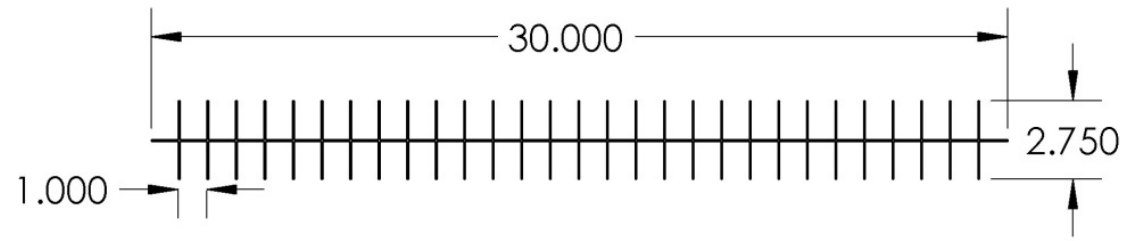

Figure 4.5. Drawing of the Gamma Shield for the HI-STORM 100S Version B Inlet Opening in the Overpack Baseplate (dimensions are in inches) 


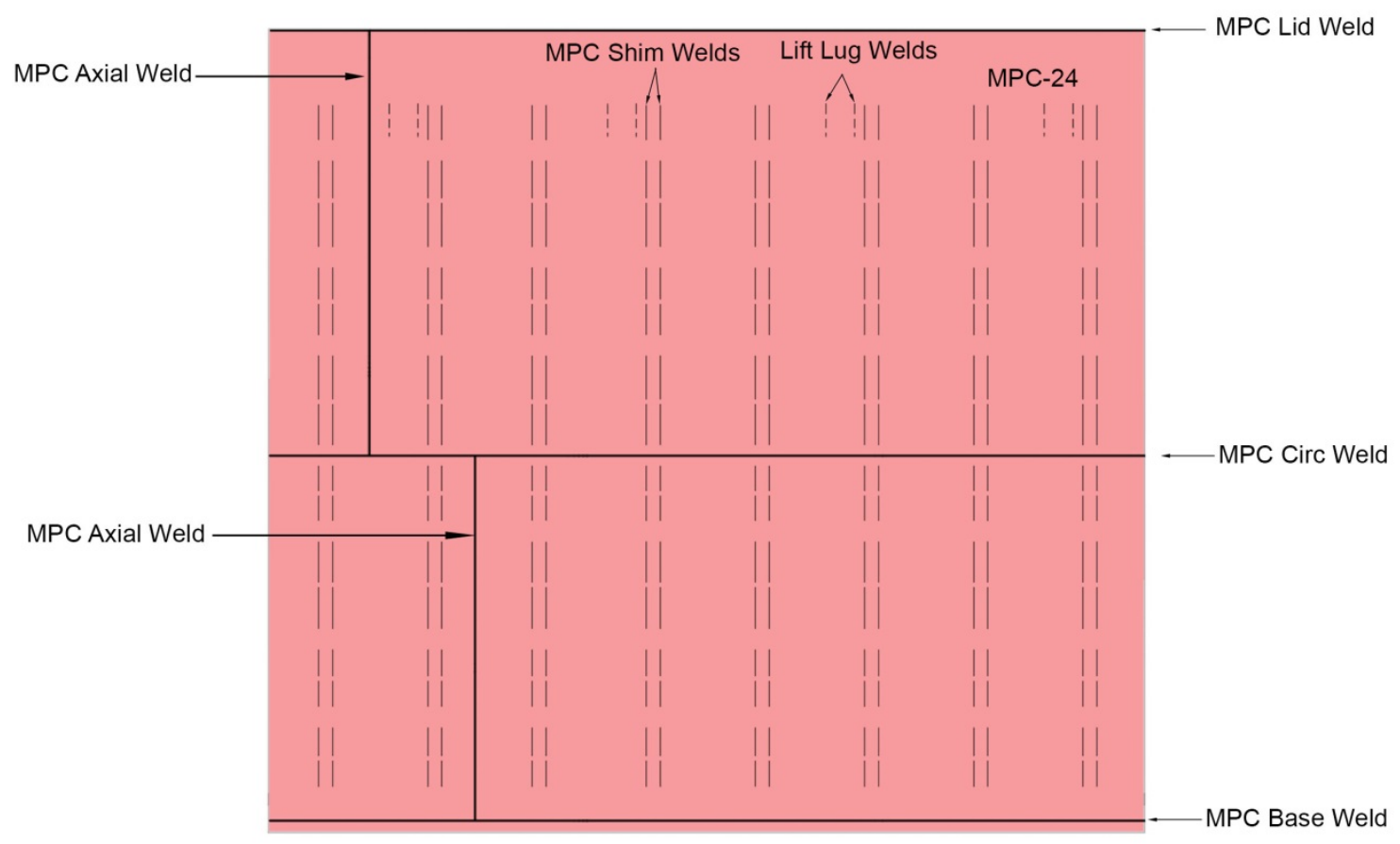

Figure 4.6. Drawing of the MPC-24 Canister Depicting Shell and Lid Welds, Shell-to-Baseplate Welds, and Canister Internal Welds for the Lift Lugs and Fuel Basket Shims

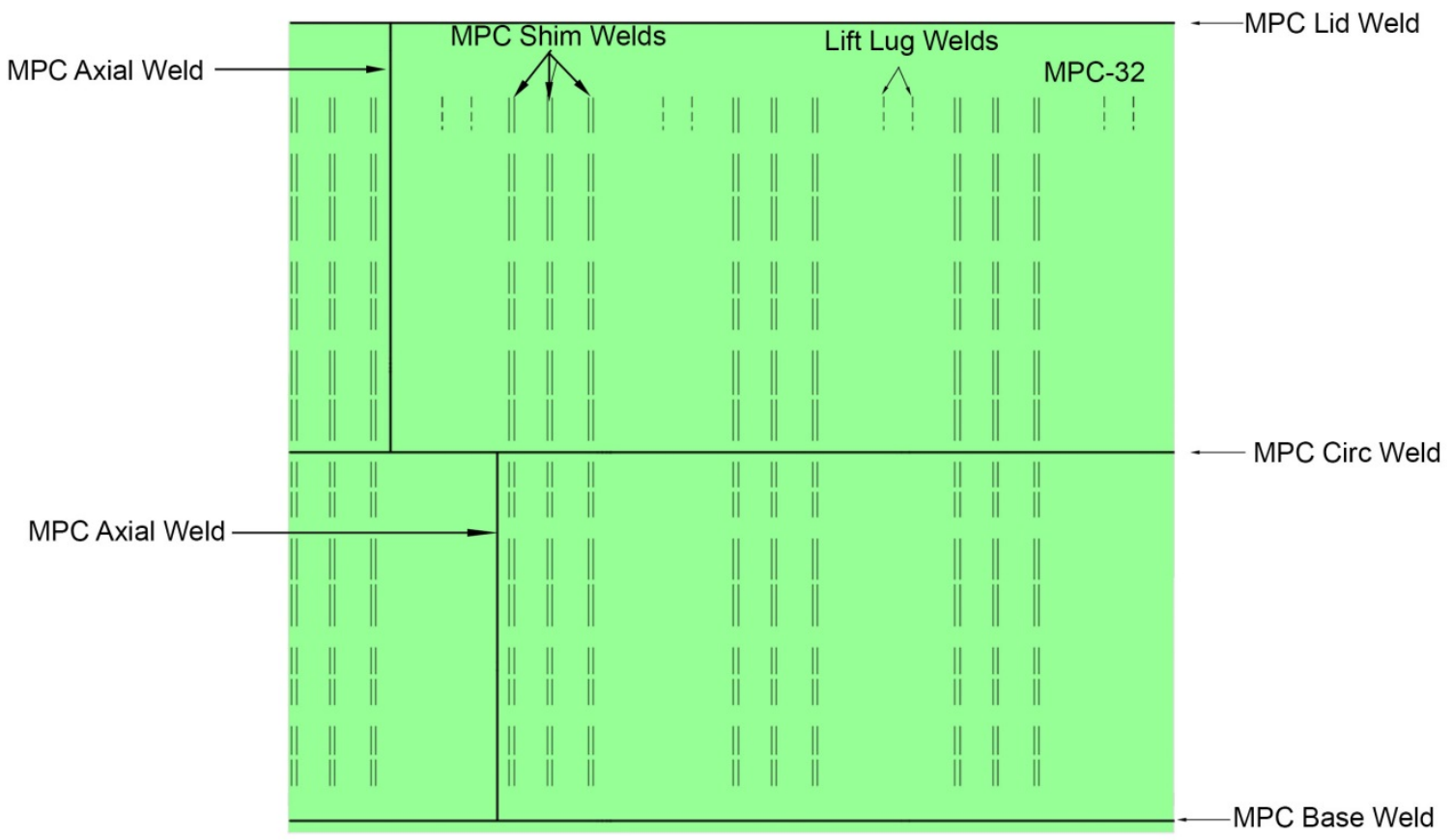

Figure 4.7. Drawing of the MPC-32 Canister Depicting Shell and Lid Welds, Shell-to-Baseplate Welds, and Canister Internal Welds for the Lift Lugs and Fuel Basket Shims 


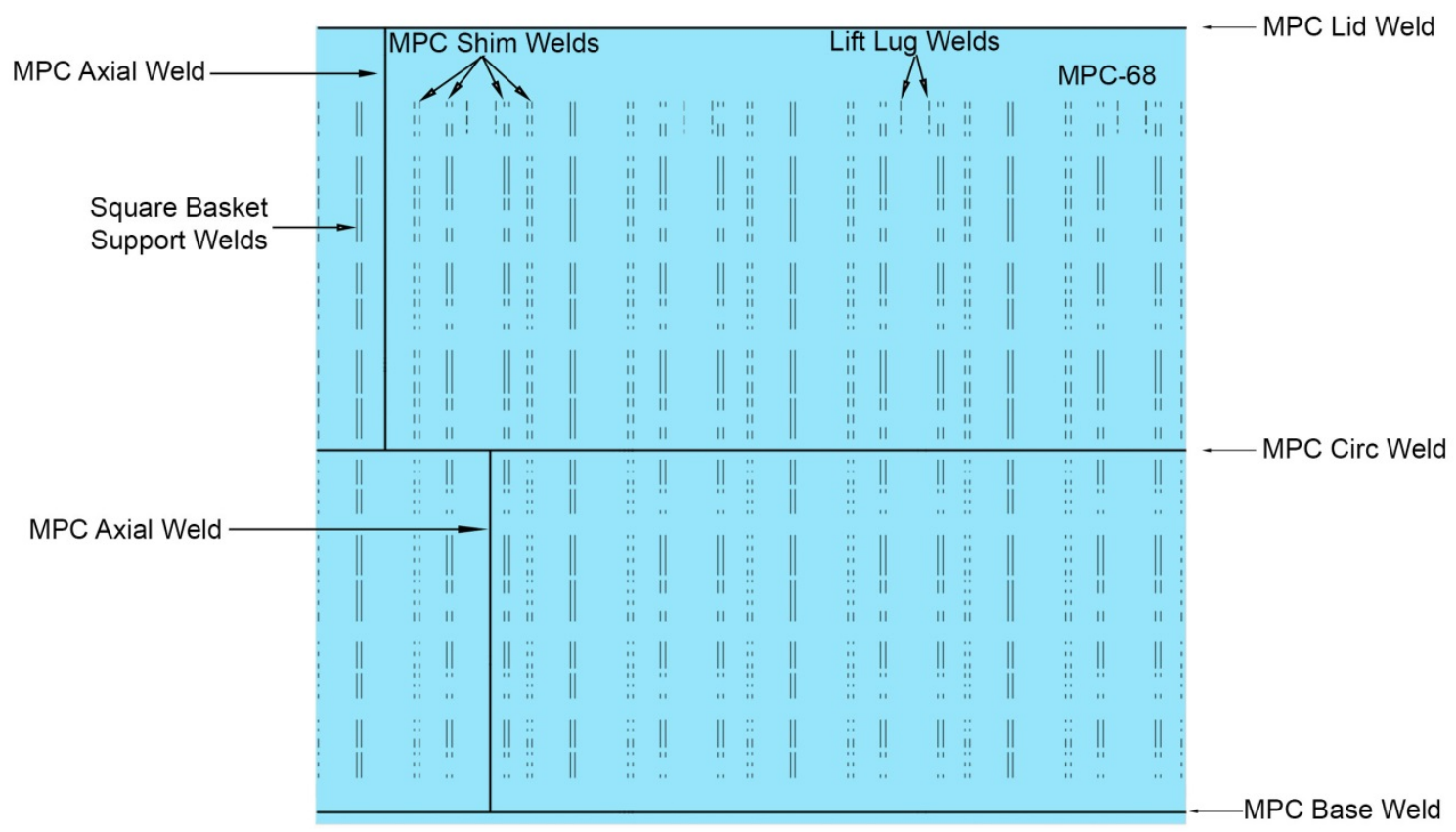

Figure 4.8. Drawing of the MPC-68 Canister Depicting Shell and Lid Welds, Shell-to-Baseplate Welds, and Canister Internal Welds for the Lift Lugs and Fuel Basket Shims

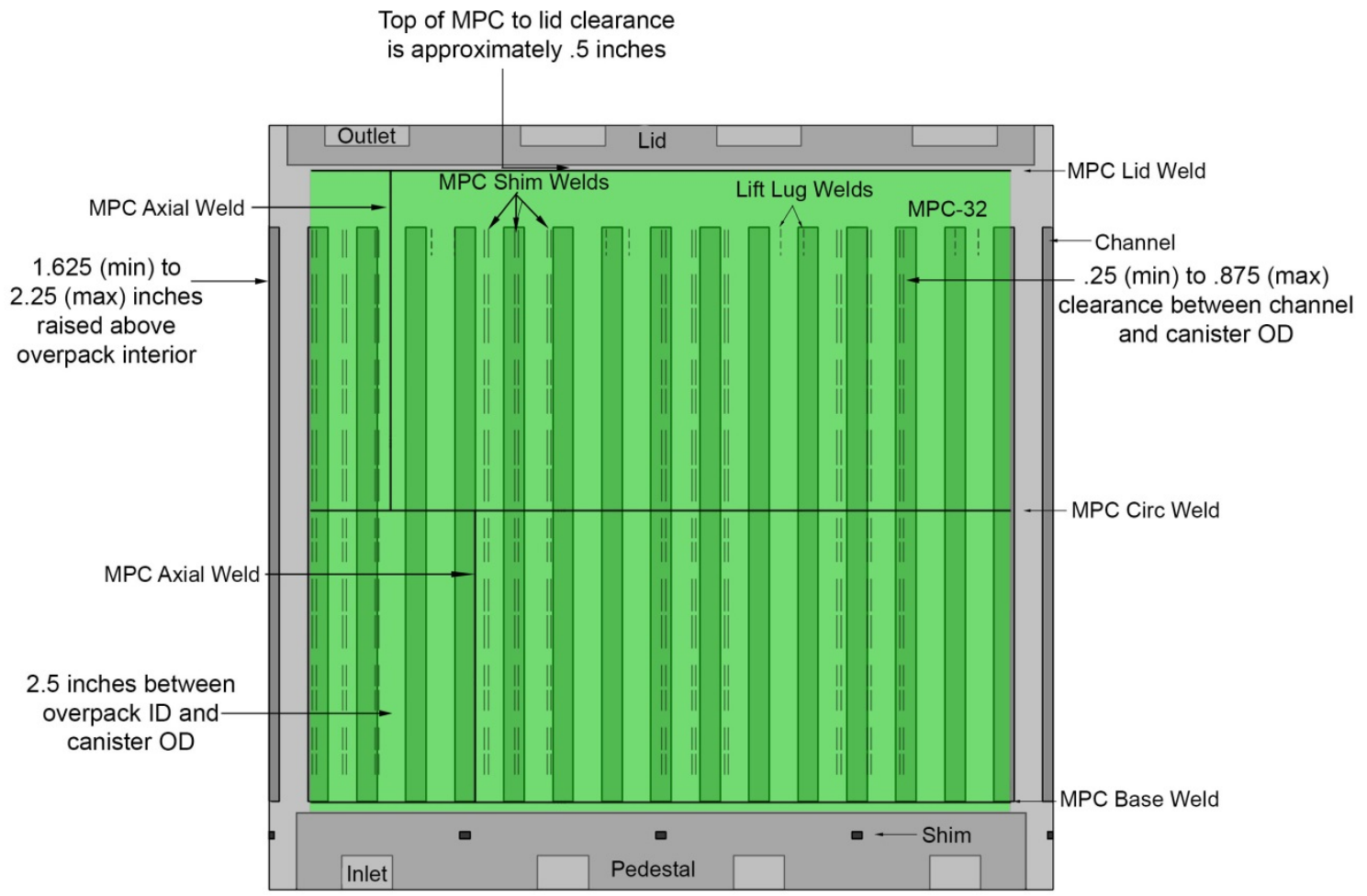

Figure 4.9. Overlay of MPC-32 on the HI-STORM 100 Overpack with Clearance Dimensions Specified Between the Overpack Inner Cavity Wall and the Canister, Between the Channels and the Canister, and Between the Overpack Lid and MPC Lid 


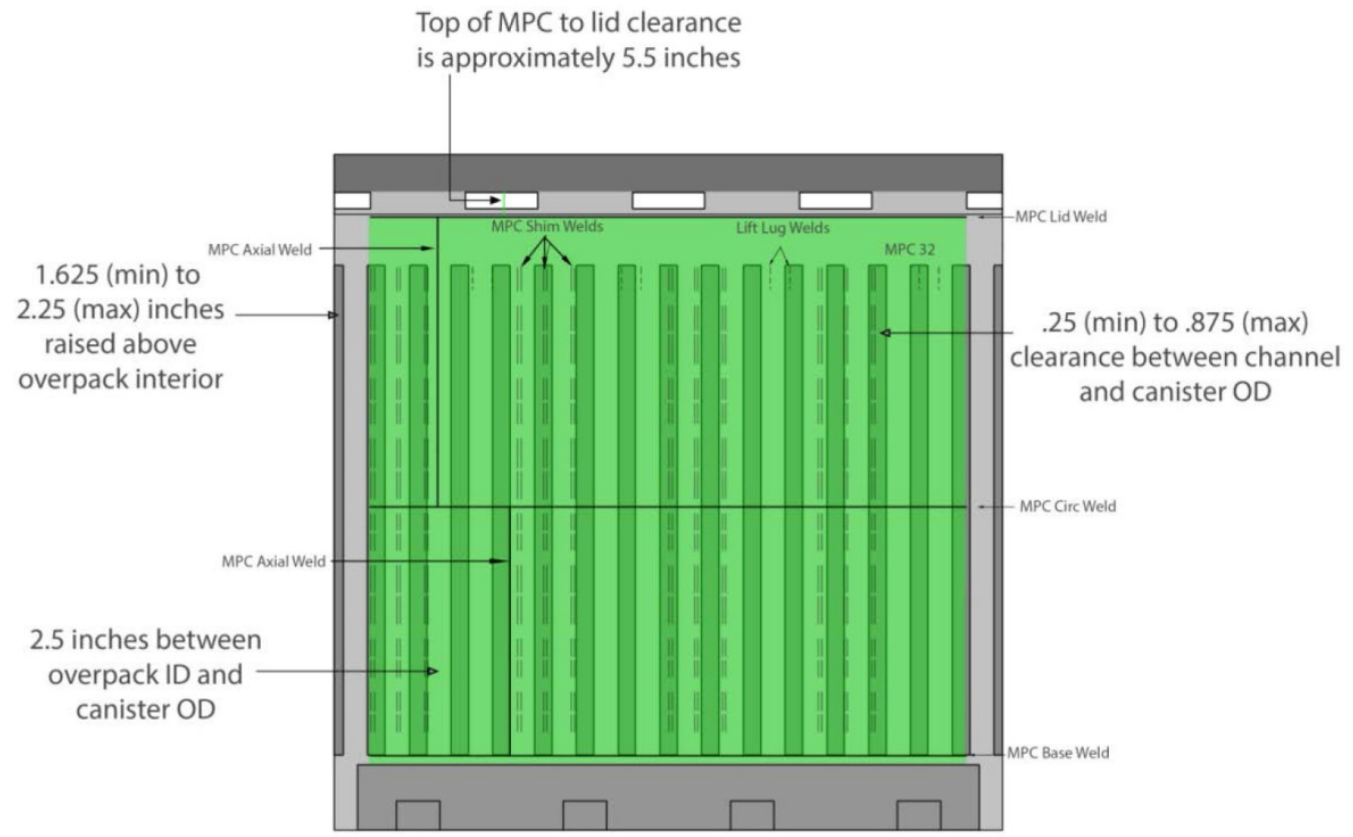

Figure 4.10. Overlay of MPC-32 on the HI-STORM 100S Overpack with Clearance Dimensions Specified Between the Overpack Inner Cavity Wall and the Canister, Between the Channels and the Canister, and Between the Overpack Lid and MPC Lid

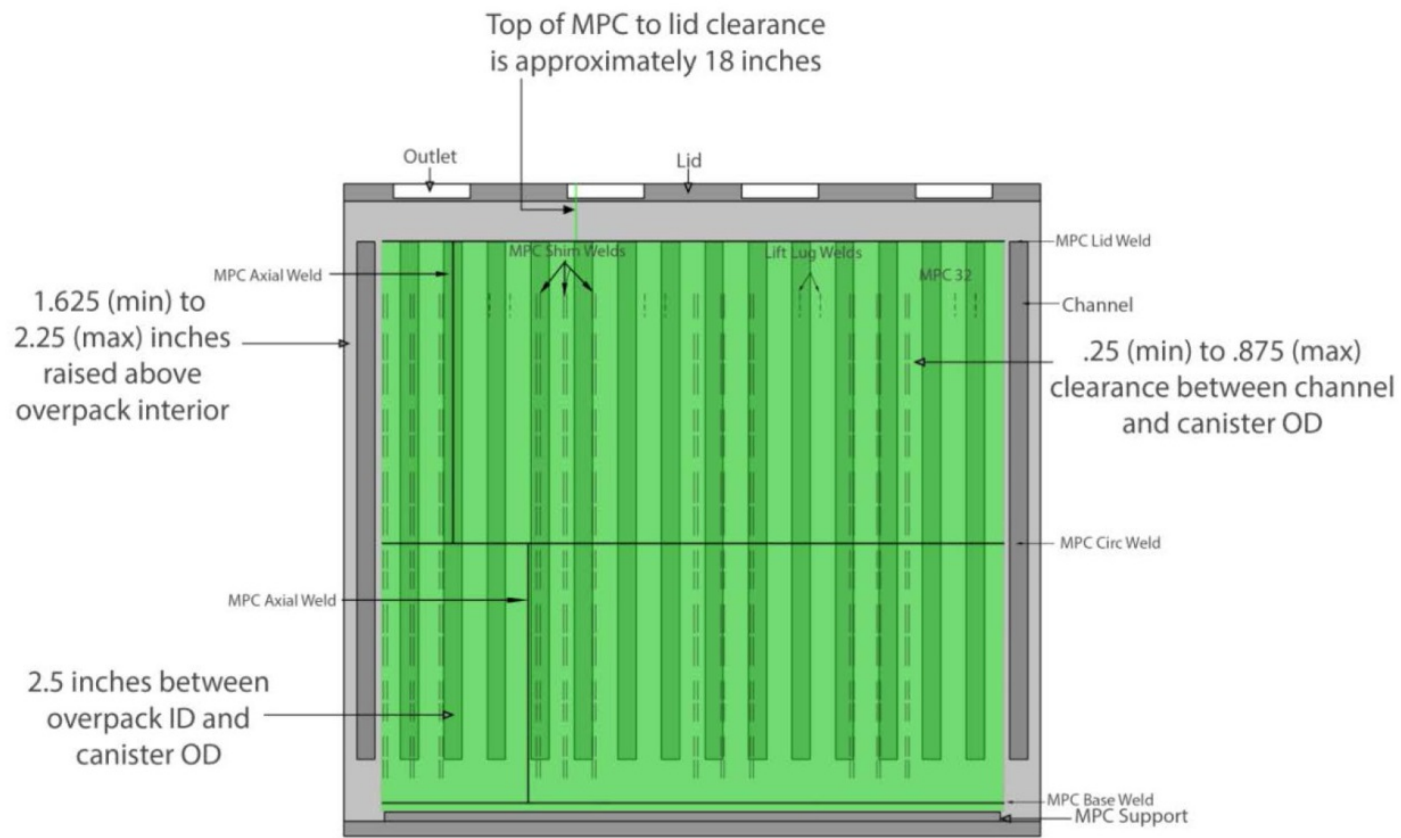

Figure 4.11. Overlay of MPC-32 on the HI-STORM 100S Version B Overpack with Clearance Dimensions Specified Between the Overpack Inner Cavity Wall and the Canister, Between the Channels and the Canister, and Between the Overpack Lid and MPC Lid 


\subsection{Deployment of NDE Sensors in the HI-STORM 100 System}

There is a gap (annulus) around the MPC that provides spacing for inspection vehicles. Within this gap are vertical guide/centering channels that provide equal spacing around the MPC as it is lowered into the overpack. These channels are located uniformly around the inside diameter of the overpack. The channels may obstruct access to the surface of the MPC by inspection instruments, posing an impassable barrier for inspection circumferentially around the MPC. The channels, however, do not go all the way from top to bottom within the overpack; thus there is some room to move inspection devices around within the annulus region.

The first inspection instrument deployment concept (Figure 4.12) is very basic in nature. The concept utilizes ideas that have been developed for inspection of tanks at the Hanford tank farm. As shown in Figure 4.12, a long piece of spring steel material is passed through the outlet vent such that it provides a constant pressure on a probe (either UT or ECT) with the capability of translating the probe from the top to the bottom of the MPC. As the figure indicates, the overpack lid provides a counteracting force to compel the spring steel wand in the downward direction. The figure displays insertion of the spring steel wand through an outlet vent, but insertion through an inlet vent is also conceivable.

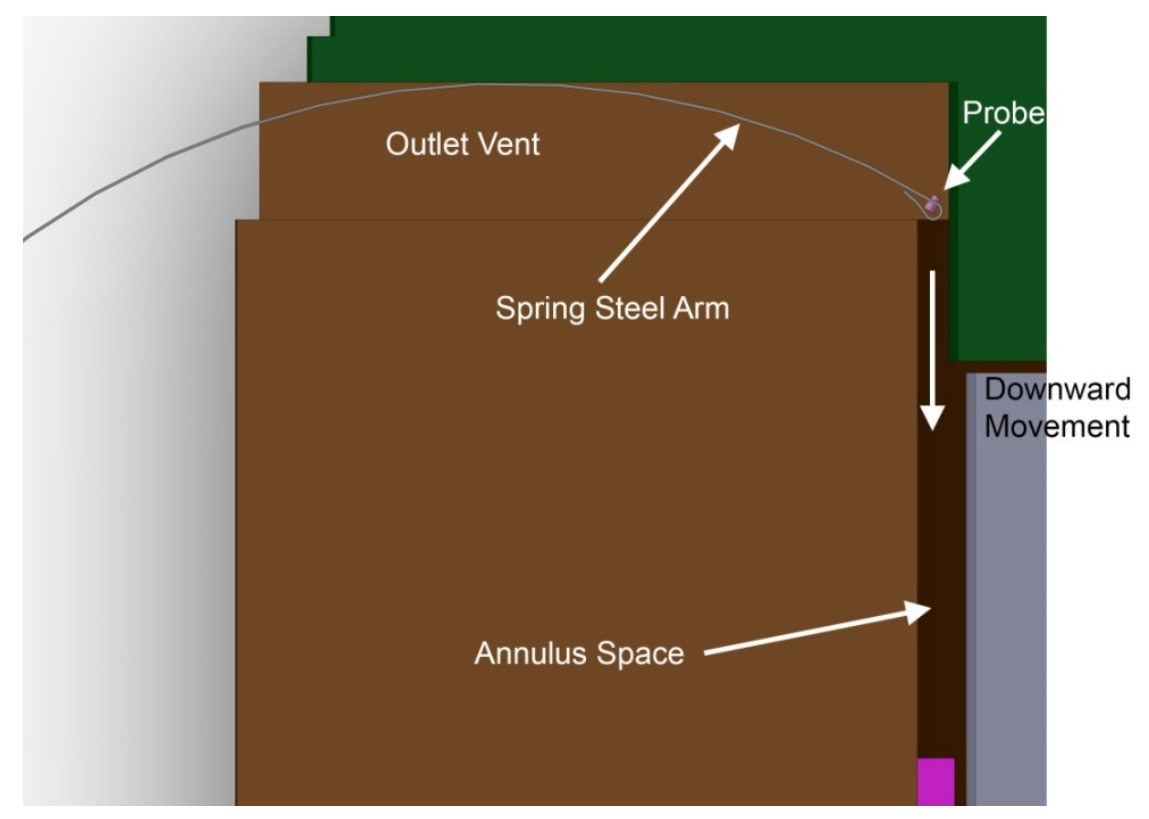

Figure 4.12. NDE Sensor Deployment Concept Utilizing a Long Spring Steel Handle to Maintain the Integrity of Sensor Contact with the Canister

Concept two (Figure 4.13) is more complex in nature than the first, and essentially places a wheeled buggy (albeit not controllable) on the MPC for stability and ease of translation as it is moved from the bottom to the top of the MPC. The buggy is spring-loaded and compresses when it enters the annulus between the MPC and the overpack, providing a more stable and maneuverable platform for the NDE sensors. Again, this figure displays insertion of the spring steel wand through an outlet vent, but insertion through an inlet vent is also conceivable. 


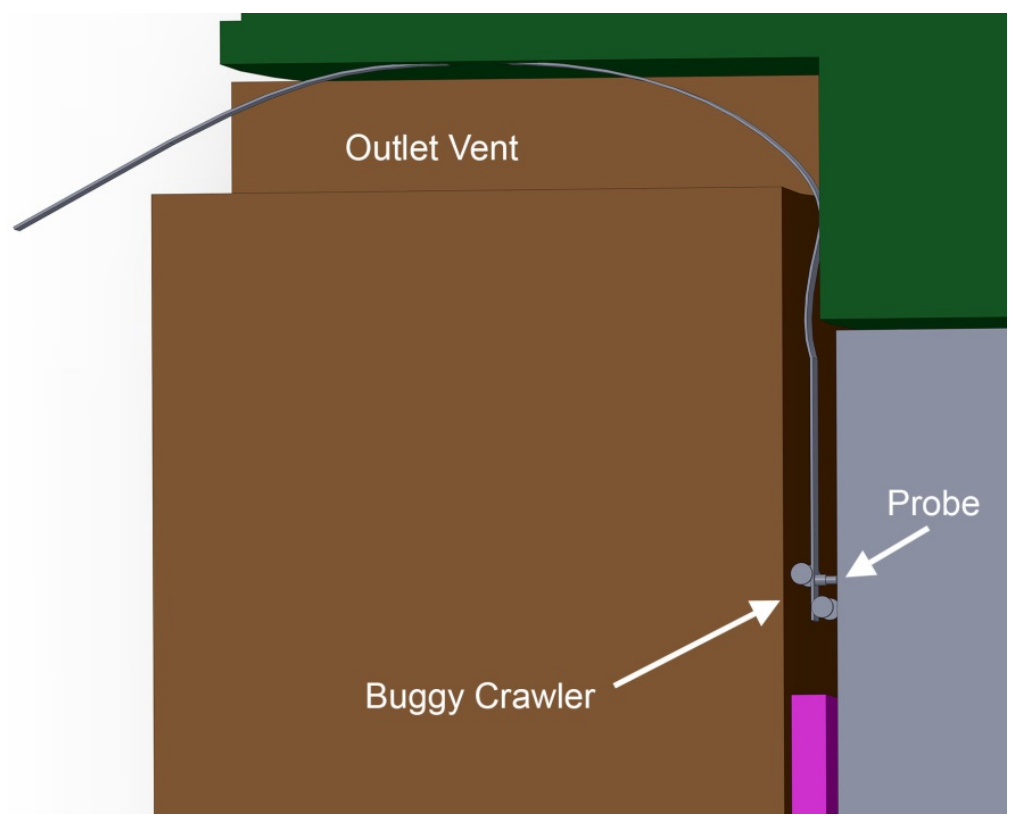

Figure 4.13. NDE Sensor Deployment Concept Utilizing a Spring-Loaded Wheeled Buggy

Concept three (Figure 4.14) is the most complex in nature, but uses a design feature inherent in the overpack. The inside diameter of the overpack is fabricated from carbon steel. This would allow a magnetic wheel crawler to drive around within the annulus region and deploy inspection devices on the MPC. The constraint of the vertical centering channel is still there, but since the centering channel does not go from top to bottom, there is an area where the crawler could be driven around to other areas between the channels for performing inspections. 


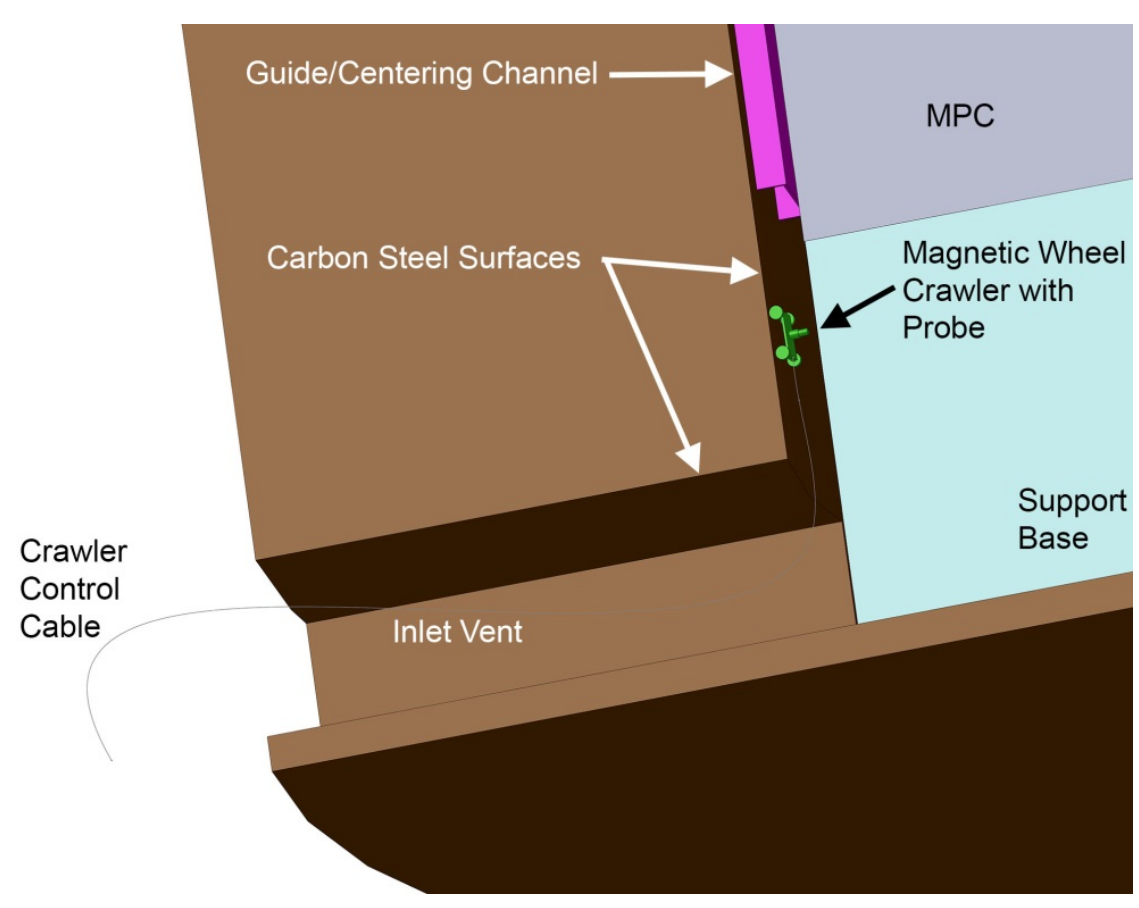

Figure 4.14. NDE Sensor Deployment Concept Utilizing a Magnetic Crawler System

\subsection{NUHOMS System Accessibility and Deployment}

Figure 4.15 provides a cross-sectional view of the NUHOMS HSM employed at Calvert Cliffs, with dimensional information provided for potential access paths to the DSC surface. The DSC may potentially be accessed through the inlet ventilation port located on the bottom front of the module, through the outlet ventilation ports located on the top front and back of the module, and through the main loading port after removal of the shielded door. The ventilation ports provide relatively large channels for access with the smallest dimension near 6". The path for access to the DSC surface through the inlet ventilation port is relatively complex, presenting a challenge for spring steel wand-mounted probes. The back outlet ventilation port provides access to the back end plate of the DSC with a spring steel wandmounted probe but accessing the DSC shell will be difficult, as there are no opposing surfaces to force the probe to glide along the surface of the DSC shell. The shape of the front outlet ventilation port does provide a surface to force spring steel wand-mounted probes to glide along the surface of the DSC, but this provides access to only a strip of the top of the canister (see Figure 4.16). Finally, the shielded door may be removed for DSC access, but clearance between the canister shell and the HSM entry sleeve is restricted to 0.87 " (see Figure 4.17). A spring steel wand-mounted probe may be employed to access the DSC surface by guiding the probe through the gap between the DSC and entry sleeve as shown in Figure 4.18. Figure 4.19 illustrates the deployment of a robotic crawler to perform an inspection on one end of the DSC. Given the above discussion, it appears that the most difficult regions of the DSC to access will be portions of the DSC shell surface located near the rear of the HSM. 


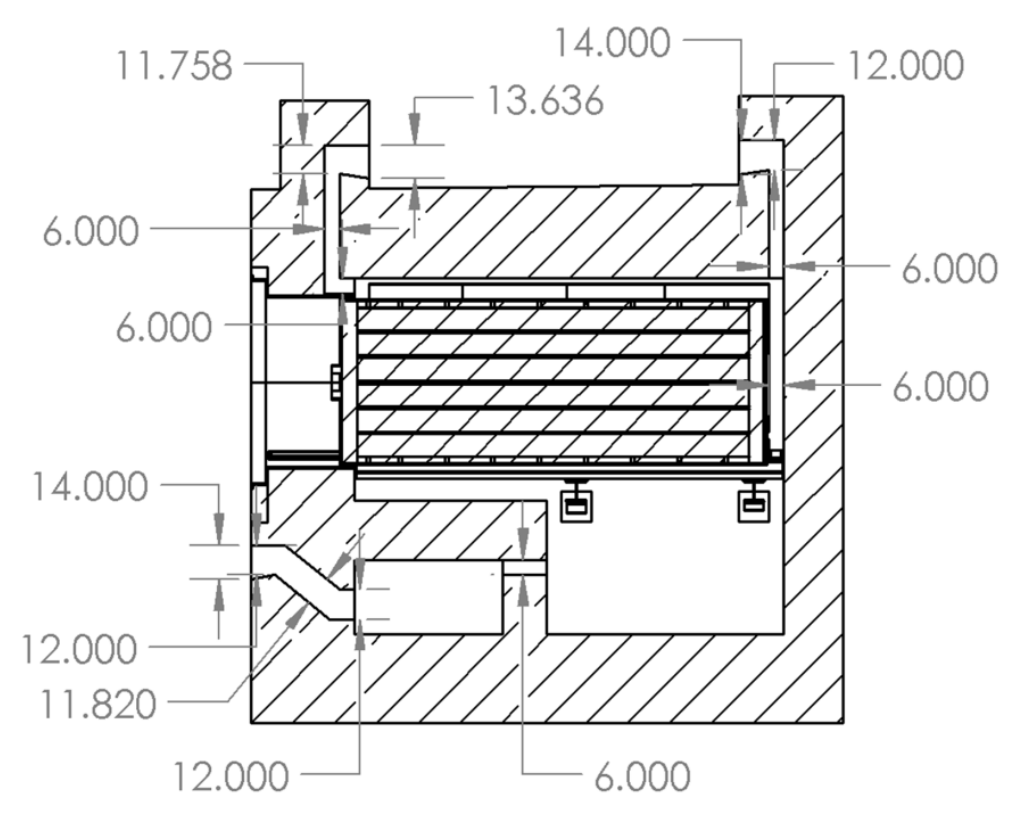

Figure 4.15. Cross-sectional View of the Calvert Cliffs HSM Module with Dimensional Indications for Possible Access Paths for NDE Probes (dimensions are in inches)

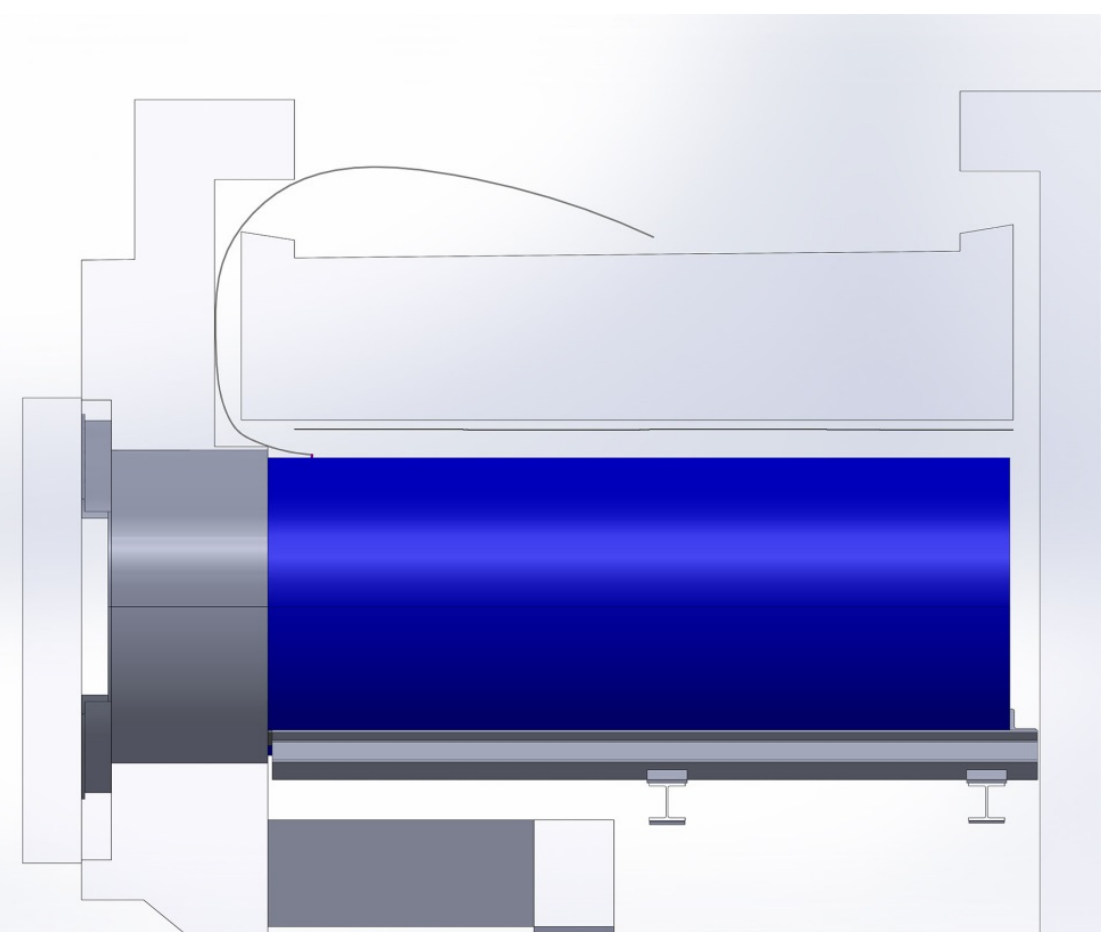

Figure 4.16. Illustration of Insertion of NDE Probe Mounted to Spring Steel Probe through HSM Outlet Vent 


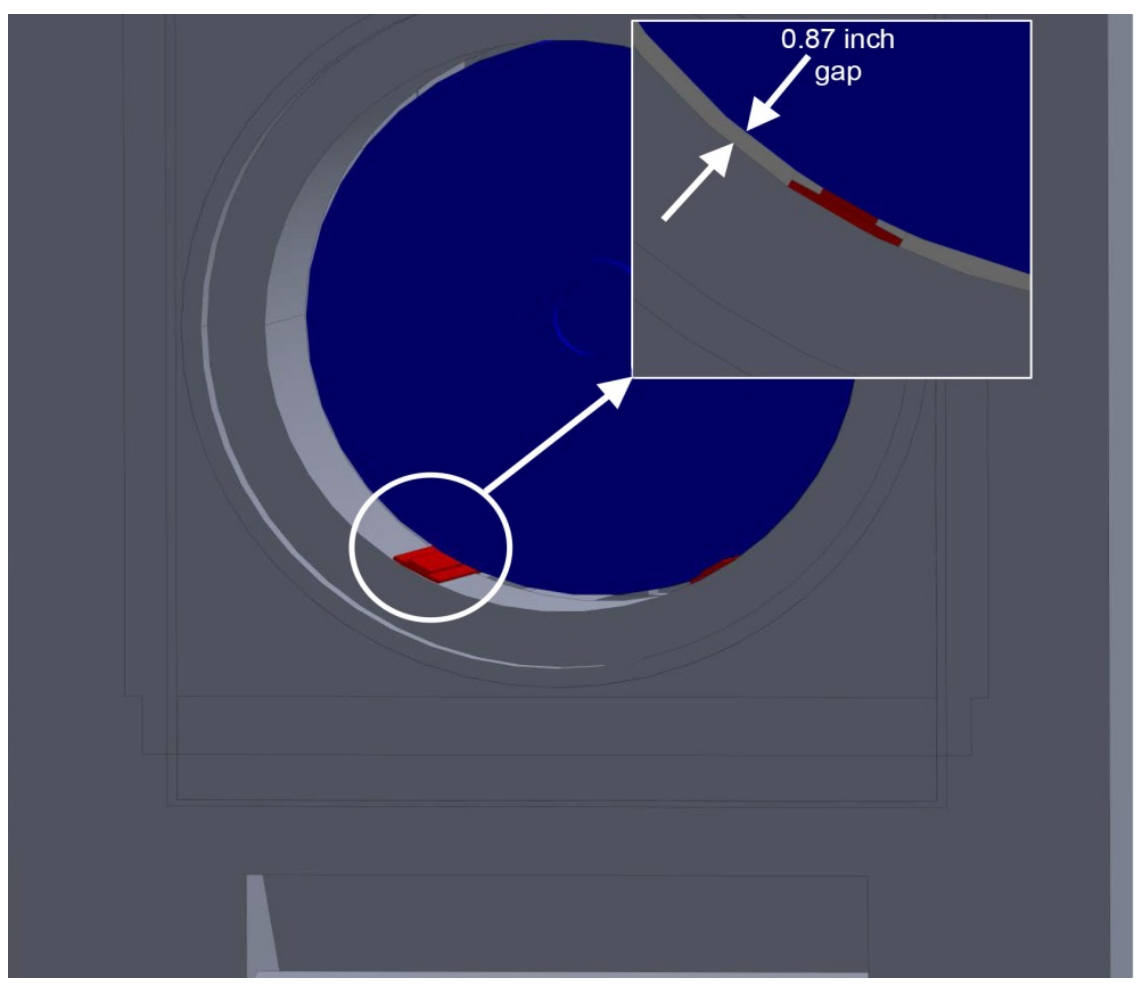

Figure 4.17. Illustration of Front View of HSM Module and Depiction of Clearance between HSM Entry Sleeve and Canister

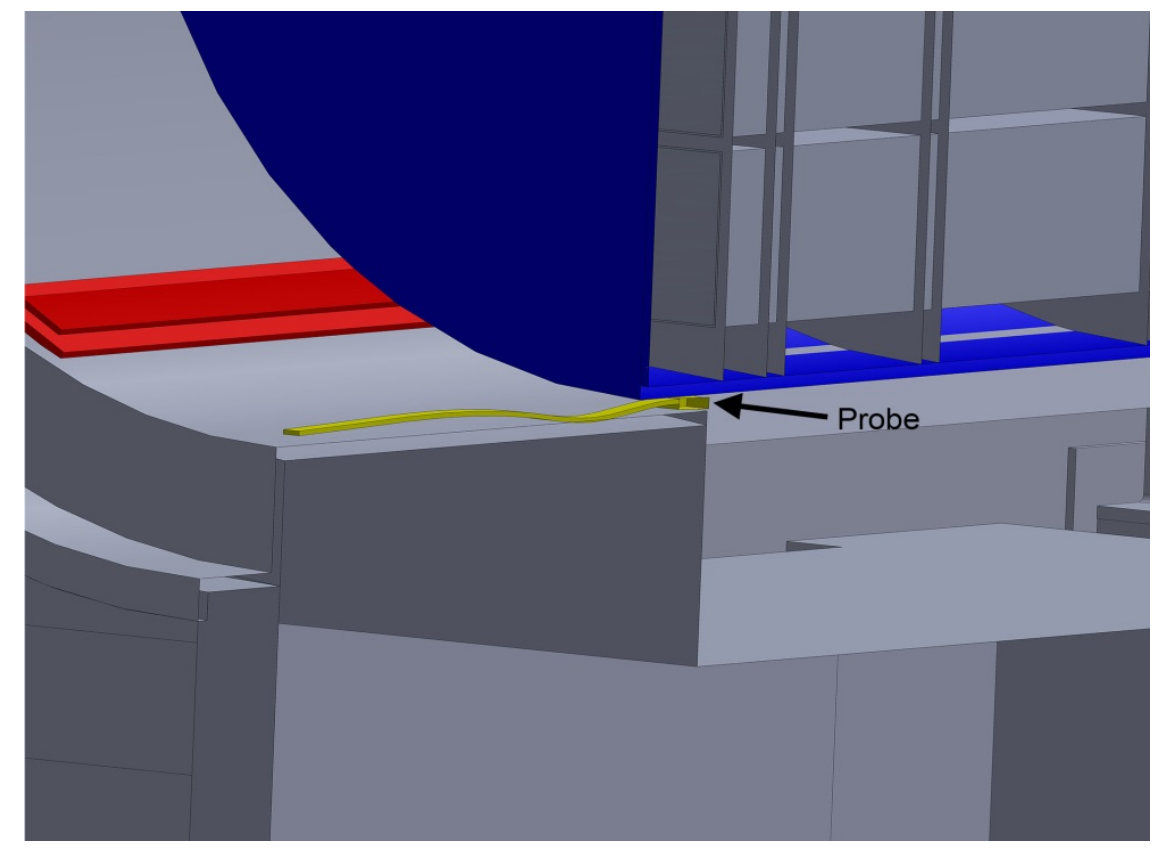

Figure 4.18. Illustration of NDE Probe Mounted to Spring Steel Wand for Examination of the DSC Surface 


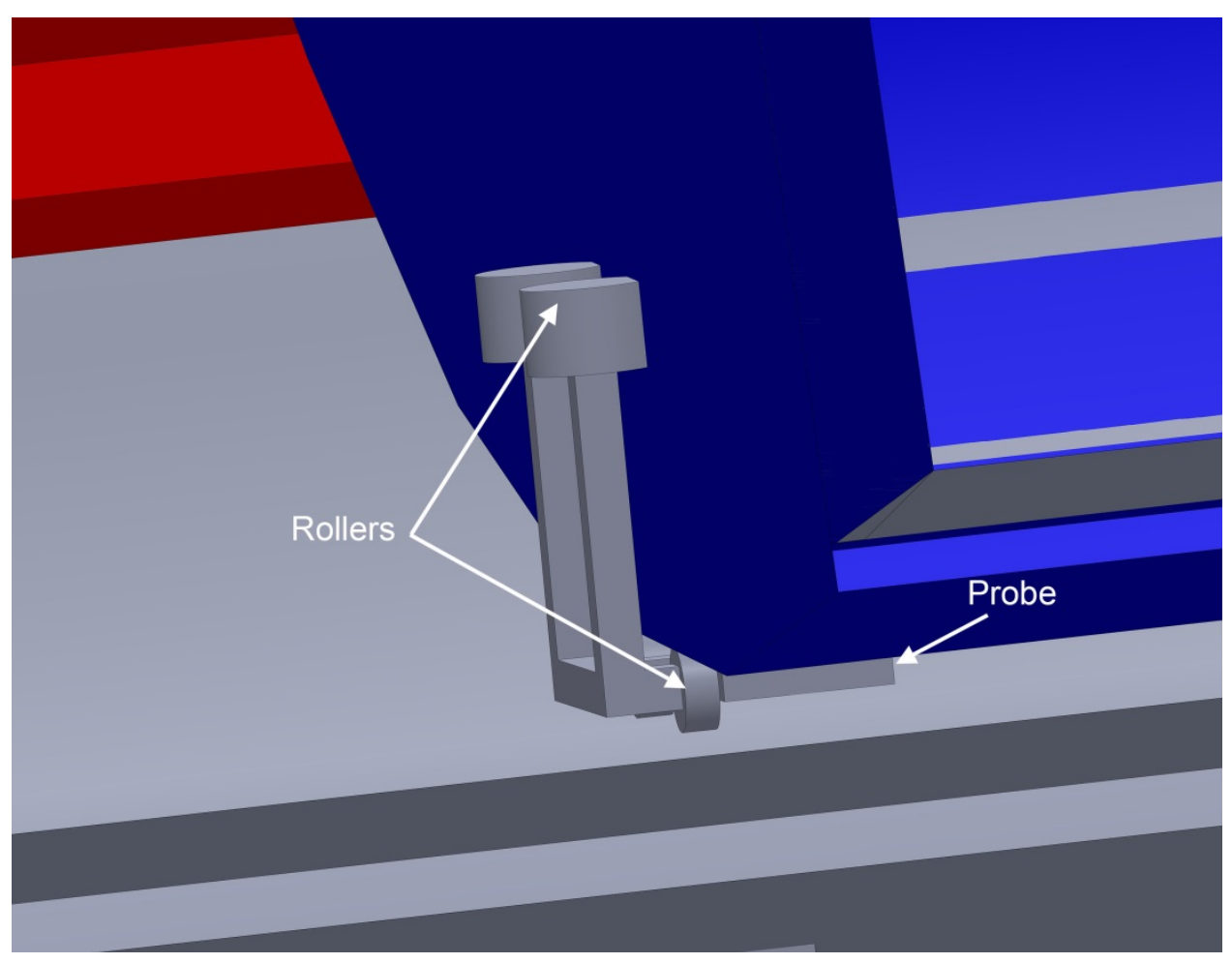

Figure 4.19. Illustration of NDE Probed Deployed on Robotic Crawler for Examination of End Plate to Shell Weld for DSC 



\subsection{Environmental Compatibility}

Environmental conditions near and at the outer DCSS canister surface will determine environmental compatibility requirements for sensors used to perform NDE of the canisters. This requires a comparison of the temperature and radiation dose that sensors placed in the annulus can expect to receive as well as an understanding of temperature and radiation dose tolerances of the sensors. In some instances, these environmental specifications are easily accessible for commercial sensors such as video cameras. In other cases, it is more difficult to access such information for total sensor packages and the approach is to evaluate environmental tolerance based on the tolerance of components or materials that make up the sensor package.

\subsection{Temperature at the Canister Surface}

The temperature at the canister surface and in the annular space between the canister surface and inner cavity wall of the overpack will be determined by the decay heat load in the canister when fuel is initially loaded, ambient conditions, time in storage, and specifics of the DCSS design (ventilation path, canister thickness, etc.). Temperature profiles have been calculated for limiting heat loads using thermal analysis codes. Horizontal storage module temperatures are computed from a Star-CD model of the NUHOMS HSM-H that includes a detailed representation of the 32PTH1 dry storage canister. The model assumed that the canister contained WE $14 \times 14$ fuel at $62 \mathrm{MWd} / \mathrm{MTU}$, with a non-uniform basketloading configuration to allow $40.8 \mathrm{~kW}$ for the initial total decay heat load. Vertical storage module temperatures are computed from a COBRA-SFS model of the HI-STORM 100 system with an MPC-32 canister and assuming that the canister contained WE $17 \times 17 \mathrm{OFA}^{(\mathrm{a})}$ at $62 \mathrm{MWd} / \mathrm{MTU}$, with a uniform loading configuration, allowing $30.4 \mathrm{~kW}$ initial total decay heat load. The ambient conditions were treated as constant in time for the entire 300 -year period, at $38^{\circ} \mathrm{C}\left(100^{\circ} \mathrm{F}\right)$ for the horizontal storage module and $27^{\circ} \mathrm{C}\left(80^{\circ} \mathrm{F}\right)$ for the vertical storage module.

The temperature profiles at the canister surface for NUHOMS DSCs under the conditions specified above are shown in Figure 5.1 and Figure 5.2, respectively. These figures illustrate the significant temperature variation over the canister surface. Figure 5.1 shows the axial temperature profile obtained at the peak temperature location which would be the top side of the horizontally oriented canister. The maximum temperature upon loading is approximately $225^{\circ} \mathrm{C}$. Figure 5.2 illustrates an example temperature variation of the full surface of the canister (calculated in support of Calvert Cliffs inspections). These figures illustrate that both ends of the canister tend to be cooler than the mid-section of the canister and that the top of the canister is warmer than the sides and bottom of the canister in the horizontal orientation. Thus, the bottom of the DSC near both ends can be expected to cross the temperature threshold for deliquescence of chloride deposits first. These profiles are computed assuming thermal loading of $41 \mathrm{~kW}$, which is a limiting condition and therefore may not be totally representative of typical canister temperatures. Canister temperature decay curves have been computed at $12 \mathrm{~kW}, 22 \mathrm{~kW}$ and $41 \mathrm{~kW}$, as shown in Figure 5.3. The curves at $12 \mathrm{~kW}$ and $22 \mathrm{~kW}$ may provide more realistic estimates of peak temperatures to be encountered in typical systems. Thermal modeling has also been performed to support recent inspection efforts of HSM-1 and HSM-15 modules at Calvert Cliffs (Suffield et al. 2012). The thermal model was benchmarked with temperature measurements performed near the DSC grappling ring for the two modules. Temperatures at the grappling ring were reported be $44^{\circ} \mathrm{C}$ and

(a) This is the limiting fuel configuration for the MPC-32. 
$51^{\circ} \mathrm{C}$ for the HSM-1 and HSM-15, respectively, and modeling results indicate that peak temperatures for the HSM-1 and HSM-15 DSCs were at $98^{\circ} \mathrm{C}$ and $143^{\circ} \mathrm{C}$, respectively.

The axial temperature profile for the vertical HI-STORM 100 system is provided in Figure 5.4. The temperature at the top of the canister is essentially double the temperature at the bottom of the canister upon loading and the maximum temperature upon loading is roughly $205^{\circ} \mathrm{C}$. With respect to a temperature threshold for deliquescence of chloride deposits, this implies that the MPC bottom plate-toshell weld would initially be most vulnerable to atmospheric SCC and approximately the bottom $25 \%$ of the canister will cross the deliquescence threshold first, followed by the MPC lid assembly. An additional data point is described by a study that included actual measurements of the axial temperature profiles for canisters in two different types of concrete storage modules (Takeda et al. 2008). In this case, decay heat from nuclear fuel is simulated using electrical heaters. Thermal loading is simulated at $22.6 \mathrm{~kW}, 16 \mathrm{~kW}$, and $10 \mathrm{~kW}$. Temperature profiles for one of the canisters in this study are provided in Figure 5.5.

Figure 5.6 includes the results of estimations of the top and bottom canister temperatures under different ambient conditions, assuming the canister is loaded with 24 assemblies, each at $1 \mathrm{~kW}$ (Gordon et al.

2006). This figure indicates that the effect of ambient temperature is significant and also highlights the temperature differential between the top and bottom of the canister, with the bottom of the canister at a significantly cooler temperature.

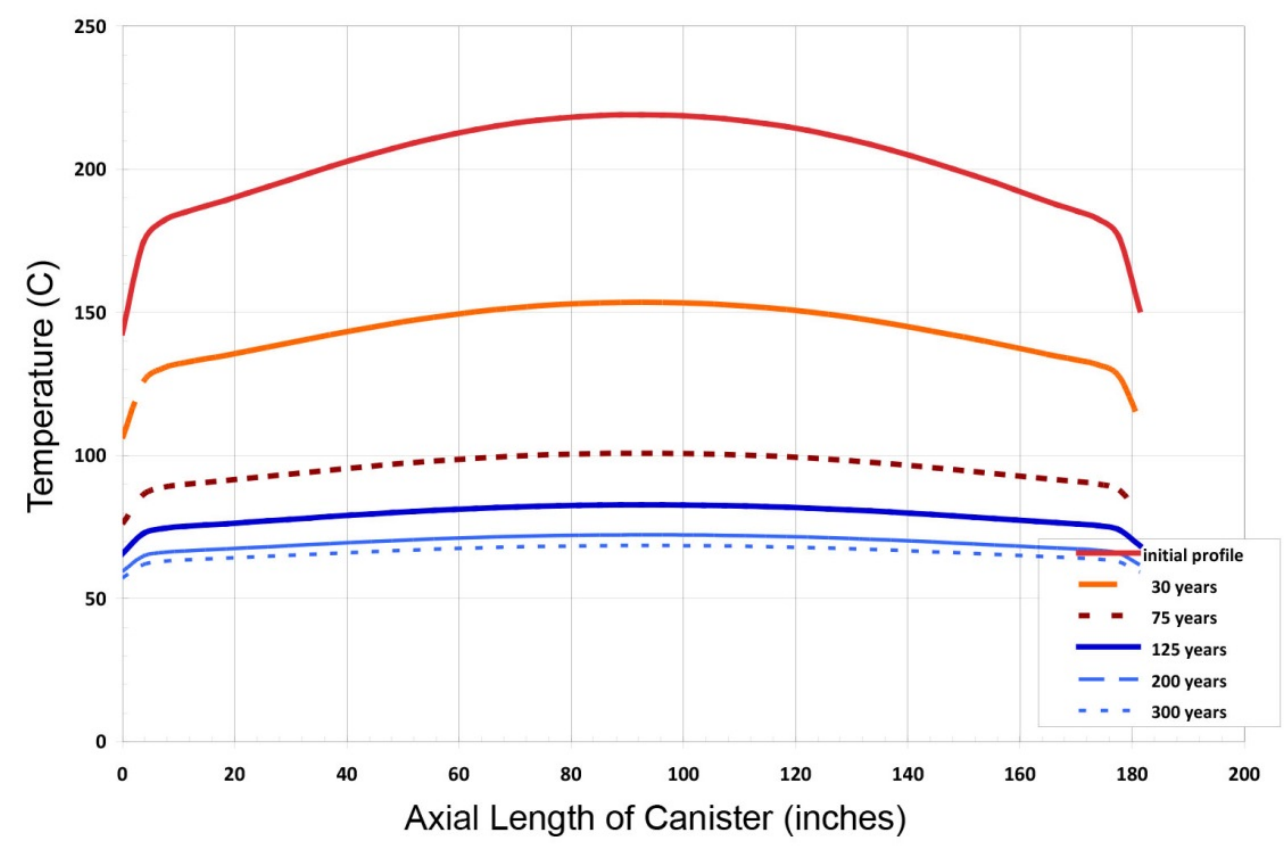

Figure 5.1. Axial Temperature Distribution at the Canister Shell Surface at the Peak Temperature Location for Projected Decay Heat Decrease over Time in Horizontal Storage 


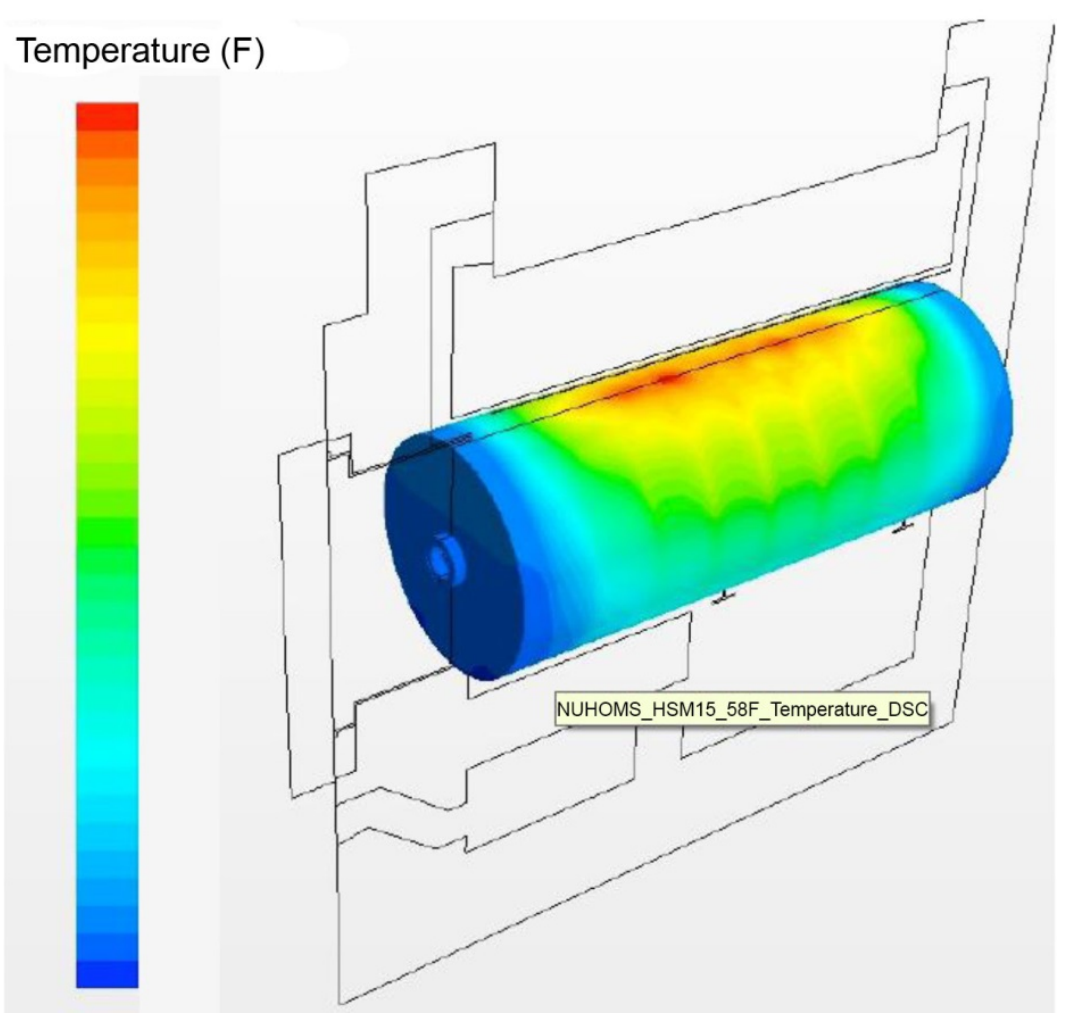

Figure 5.2. S Simulated DSC Shell Surface Temperatures for Calvert Cliffs HSM-15 (Suffield et al. 2012)

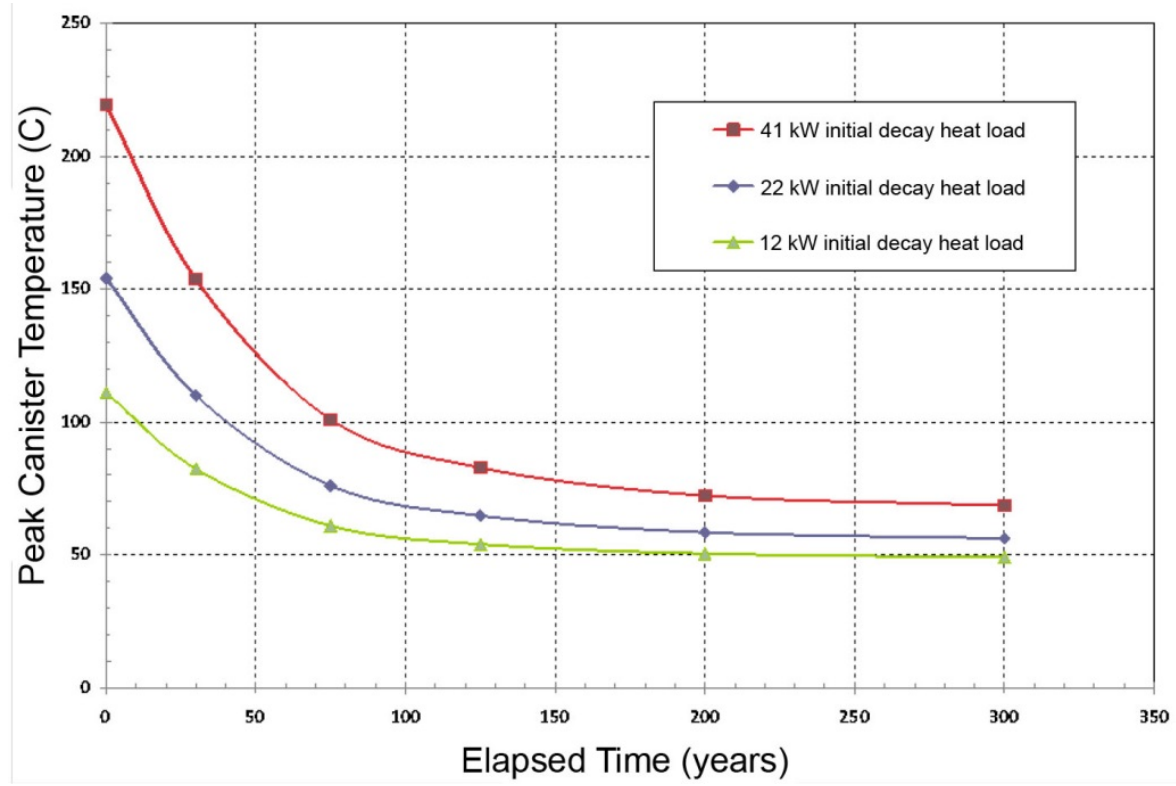

Figure 5.3. Peak Canister Shell Temperature Predictions for Projected Decay Heat Decrease Over Time in Horizontal Storage 


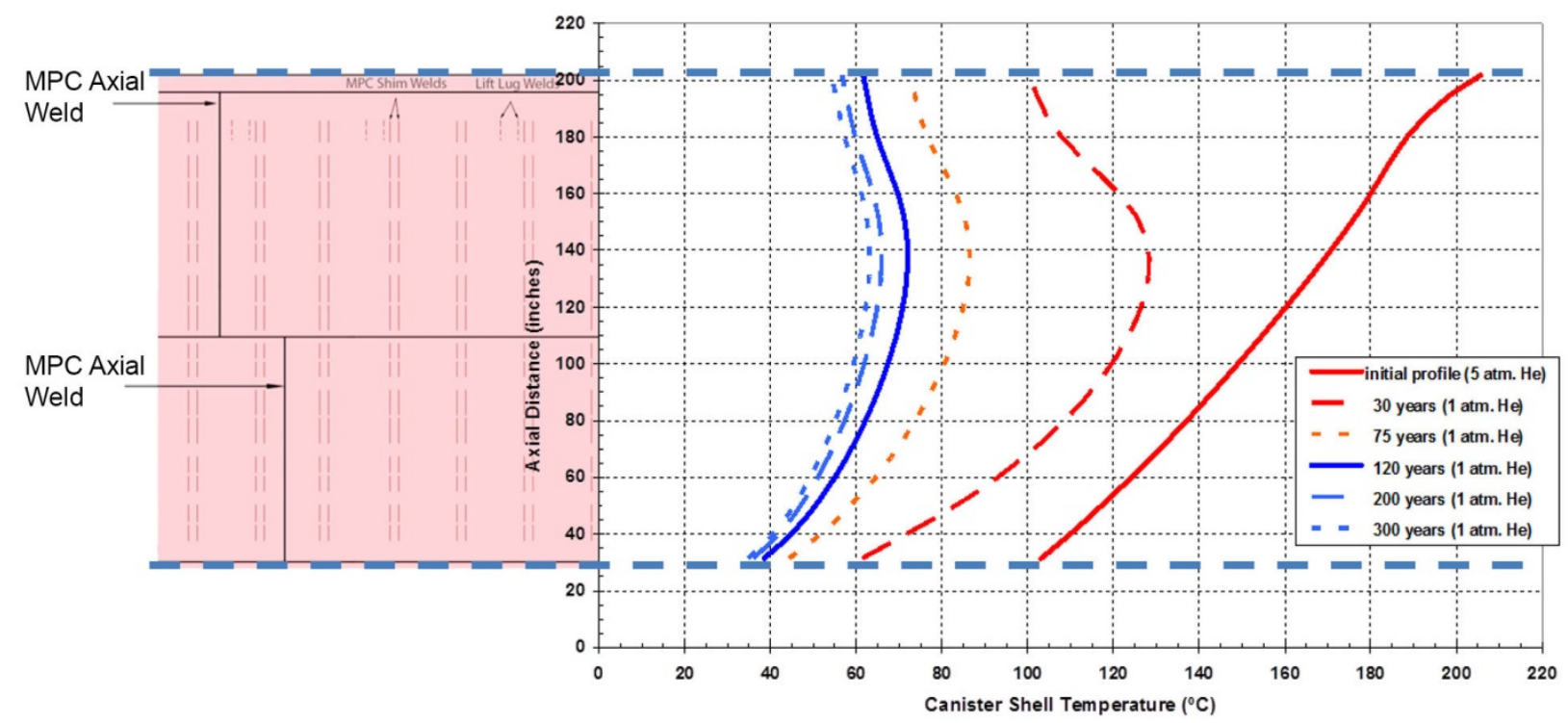

Figure 5.4. Axial Temperature Distribution at the Canister Shell Surface for Projected Decay Heat Decrease Over Time in Vertical Storage

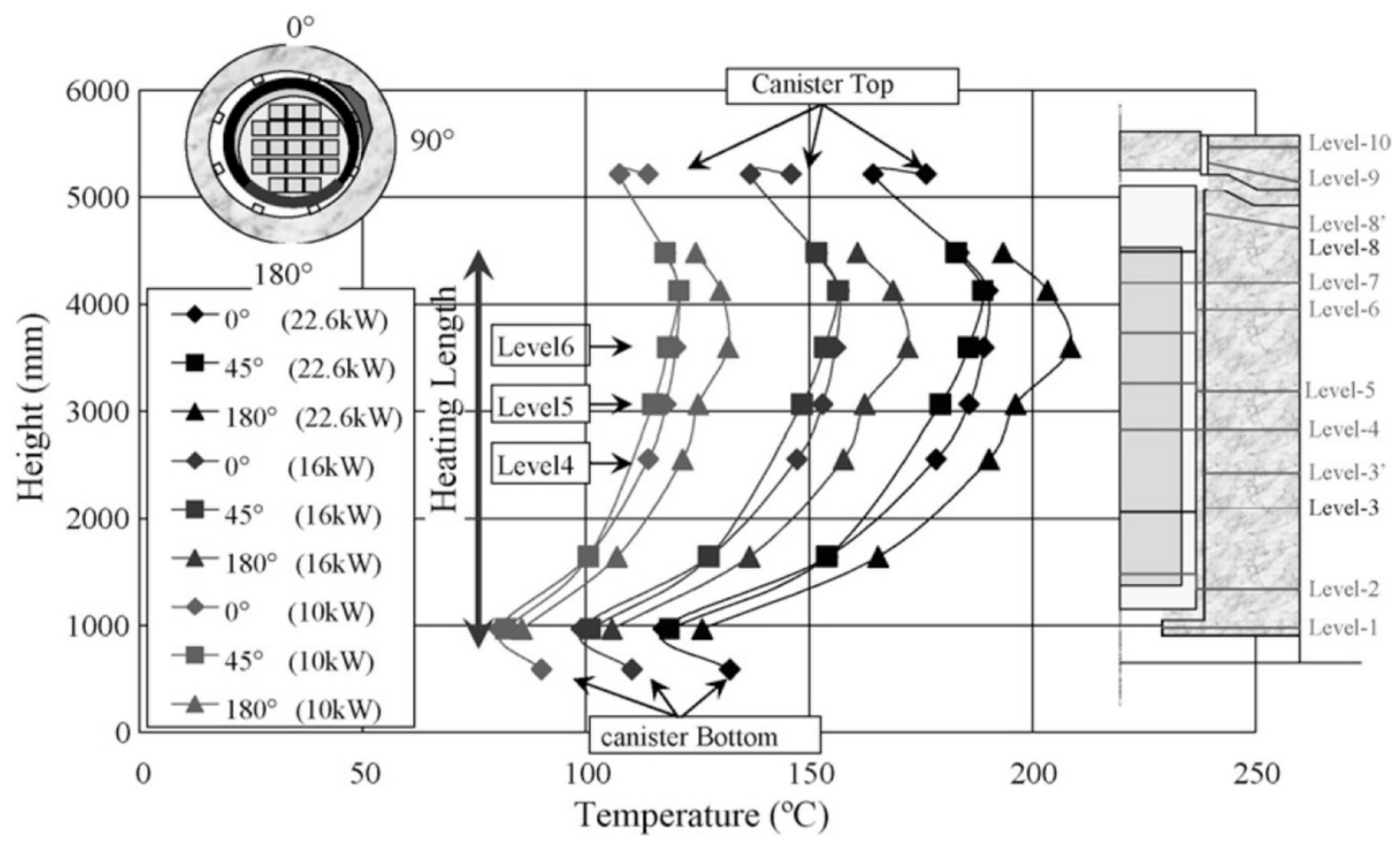

Figure 5.5. Axial Temperature Profile Measurements for Canisters in Vertical Concrete Storage Module (Takeda et al. 2008). Copyright 2008, with permission from Elsevier. 


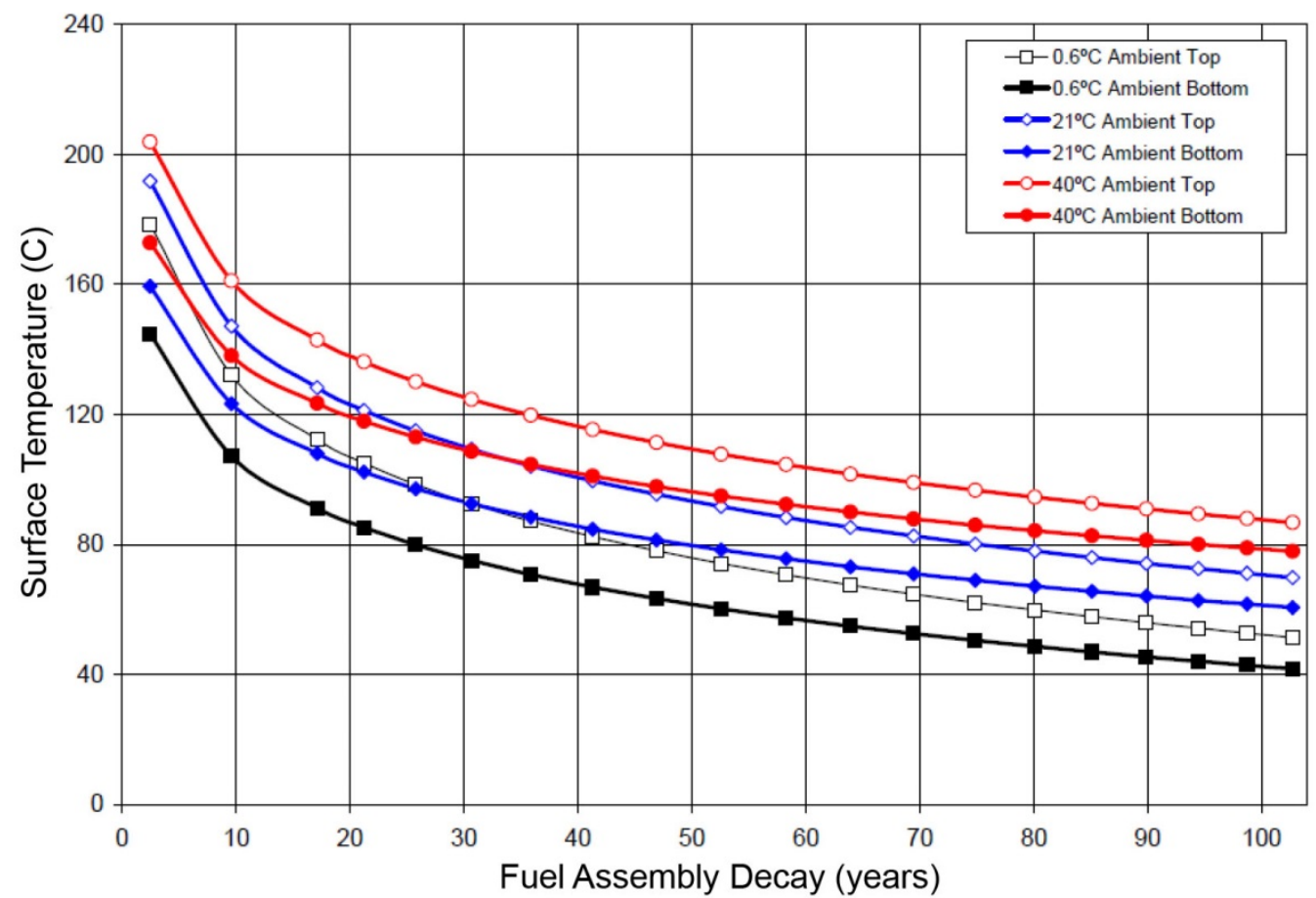

Figure 5.6. Calculated Temperature Estimations for Canisters with an Initial Heat Loading of $24 \mathrm{~kW}$ Under Different Ambient Conditions (Gordon et al. 2006). Copyright 2006, Electric Power Research Institute; used with permission.

\subsection{Gamma Radiation Dose at the Canister Surface}

The FSARS for the HI-STORM 100 and NUHOMS storage modules include details of shielding analysis performed to estimate radiation dose at various locations, including the outer surface of the concrete storage modules, vent locations, and ISFSI site boundaries. Analysis of radiation dose levels at the surface of the canister shell is not included. A simplified model of a vertical storage system has been created in MCNP with source terms calculated with ORIGIN-ARP software to calculate dose rate levels at the canister surface due to gamma radiation. Fuel is modeled as a homogenously smeared source inside of the canister. Dose rate levels at the canister surface are calculated assuming the same type of fuel as used in the thermal analysis that was performed for the vertical system, as discussed in Section 5.1 (i.e., $32 \mathrm{WE} 17 \times 17$ fuel assemblies with $62 \mathrm{GWd}$ /MTU burnup). Dose rate calculations were performed for 5 years, 15 years, and 90 years of cooling. The decay heat after 15 years of cooling is approximately equal to the allowable thermal capacity of the HI-STORM module with MPC-32 canister. Thus, the 5-year cooling scenario would not be expected in the field, and may represent a conservative upper bound to anticipated gamma radiation dose rate levels. At 90 years, the entire vertical canister surface is expected to dip below the deliquescence threshold temperature (defined here as $85^{\circ} \mathrm{C}$ ) (see Figure 5.4). A summary of the results of these calculations is included in Table 5.1. 
Table 5.1. Summary of Results of Peak Dose Rate Calculations

\begin{tabular}{lccc}
\hline & 5 Years Cooling & 15 Years Cooling & 90 Years Cooling \\
\hline Peak Dose Rate (rad/hr) & $2.71 \times 10^{4}$ & $1.19 \times 10^{4}$ & $1.86 \times 10^{3}$ \\
\hline
\end{tabular}

In addition to the data provided above, dose rate calculations have been performed for waste packages intended for the Yucca Mountain repository (Office of Civilian Radioactive Waste Management 2001; Bechtel SAIC Company 2006). These calculations indicated that the dose rates at the surface of waste packages could be range from approximately $10^{3}$ to $10^{5} \mathrm{Rad} / \mathrm{hr}$.

\subsection{Environmental Tolerance of NDE Sensors}

The environmental compatibility of various NDE sensors is evaluated in the following sections based on information obtained from vendors of NDE sensor technologies and information collected regarding materials that make up the components of NDE sensors. Values for limiting tolerances of classes of materials/components to gamma radiation are documented in the NASA Radiation effects Design Handbook (Hanks and Hamman 1971) and are provided in Table 5.2. This table also includes temperature specifications that are provided by manufacturers for some products that fall within the various material or component classes. This information is supplemented with rating specifications for commercial sensors and information from other sources in the following subsections to assess the compatibility of cables, eddy current probes, ultrasonic/acoustic transducers, video cameras, and fiber optic cables.

\subsubsection{Environmental Tolerance of Cables}

An illustration of a typical coaxial cable is provided in Figure 5.7. The illustration depicts a multiconductor cable and shows various components including the conductors, insulation, electromagnetic shield, and jacket materials. A paper filler material may also be included to fill in gaps between conductors. The insulation and jacket are most significant for an environmental assessment of cables because they perform critical cable function and are composed of materials that are the most vulnerable to damage by radiation or thermal stresses. Insulation and jacket components are typically composed of polymeric materials. According to Hanks and Hamman (1971), many polymeric materials can tolerate gamma radiation exposures of up to $10^{7}$ to $10^{9} \mathrm{Rad}$. Table 5.2 indicates that a sample of two polymeric products (i.e., Torlon and Celozole) is typically rated for maximum temperatures up to $260^{\circ} \mathrm{C}$. Teflon is also commonly used as a cable insulation and jacket material but is less resistant to gamma radiation (up to $\left.10^{5} \mathrm{Rad}\right)$. 
Table 5.2. Summary of Temperature and Gamma Radiation Tolerance of Several Types of Materials and Components

\begin{tabular}{|c|c|c|c|c|}
\hline $\begin{array}{c}\text { Material/Component } \\
\text { Category }\end{array}$ & Typical Use & Products & $\begin{array}{l}\text { Rated } \\
\text { Temp. }\end{array}$ & $\begin{array}{c}\text { Gamma Exposure } \\
\text { (Rads) }^{(a)}\end{array}$ \\
\hline Polymers & $\begin{array}{l}\text { Ultrasonic/acoustic } \\
\text { Eddy current }\end{array}$ & $\begin{array}{c}\text { Torlon, Celazole }{ }^{(\mathrm{b})} \\
\text { Teflon }^{(\mathrm{c})}\end{array}$ & $\begin{array}{l}<260^{\circ} \mathrm{C} \\
<200^{\circ} \mathrm{C}\end{array}$ & $\begin{array}{c}10^{7} \text { to } 10^{9} \\
\text { Teflon to } 10^{5}\end{array}$ \\
\hline Adhesives & Ultrasonic/acoustic & Epoxy $^{(\mathrm{d})}$ & $<260^{\circ} \mathrm{C}$ & $10^{8}$ \\
\hline Cabling & $\begin{array}{c}\text { Ultrasonic/acoustic } \\
\text { Eddy current } \\
\text { Visual }\end{array}$ & RG-178 ${ }^{(\mathrm{c})}$ & $<200^{\circ} \mathrm{C}$ & $10^{5}$ \\
\hline Lubricants & Ultrasonic/acoustic & $\begin{array}{c}\text { Krytox }^{(\mathrm{e})} \\
\text { Ultratherm couplant }^{(\mathrm{f})}\end{array}$ & $\begin{array}{l}<400^{\circ} \mathrm{C} \\
<520^{\circ} \mathrm{C}\end{array}$ & $10^{6}$ to $10^{9}$ \\
\hline $\begin{array}{c}\text { Seals/ } \\
\text { elastomers }\end{array}$ & $\begin{array}{c}\text { Ultrasonic/acoustic } \\
\text { Visual }\end{array}$ & Endura ${ }^{(\mathrm{g})}$ & $<250^{\circ} \mathrm{C}$ & $10^{7}$ \\
\hline Glass & Visual & $\begin{array}{c}\text { Vycor }^{(\mathrm{h})} \\
\text { Fiberscope }^{(\mathrm{i})}\end{array}$ & $\begin{array}{l}<900^{\circ} \mathrm{C} \\
<240^{\circ} \mathrm{C}\end{array}$ & $10^{5}$ to $10^{10}$ \\
\hline Ceramics & Ultrasonic/acoustic & $\begin{array}{l}\text { Lead zirconate titanate } \\
\text { Bismuth titanate }\end{array}$ & $\begin{array}{l}<250^{\circ} \mathrm{C} \\
<550^{\circ} \mathrm{C}\end{array}$ & $10^{12}$ \\
\hline Metals (stainless steel) & $\begin{array}{c}\text { Ultrasonic/acoustic } \\
\text { Eddy current } \\
\text { Visual }\end{array}$ & N/A & $>500^{\circ} \mathrm{C}$ & $10^{18}$ \\
\hline
\end{tabular}

(a) Hanks and Hamman (1971)

(b) PBI Performance Products, Inc., http://www.pbiproducts.com/polymers/products/celazole-u-series/

(c) Belden Specifications, RG178, http://www.belden.com/techdatas/metric/83265.pdf

(d) Masterbond White Paper, http://www.masterbond.com/whitepaper/high-temperature-resistant-adhesivesbeat-heat

(e) DuPont Specifications, http://www2.dupont.com/Lubricants/en_US/index.html?src=gg_krytox_us_krytox

(f) Olympus Specifications, http://www.olympus-ims.com/en/ultrasonic-transducers/couplant/

(g) Precision Polymer Engineering, http://www.prepol.com/product-range/ppe-material-brands/endura-

(h) Corning Specifications, http://www.corning.com/docs/specialtymaterials/pisheets/Vycor\%207930.pdf

(i) Fujikura, http://www.aflglobal.com/productlist/Product-Lines/Fiber-Optic-Imaging,-Energy--Sensing/Fiber-scopes/doc/FJKBROFiberscopes.aspx

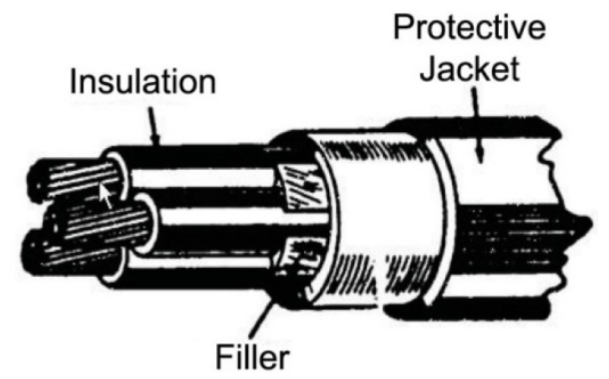

Figure 5.7. Illustration of a Typical Coaxial Cable Structure 


\subsubsection{Environmental Tolerance of Eddy Current Probes}

Fundamentally, an eddy current probe consists of a coil of wire that generates a magnetic field to induce eddy currents in an adjacent test piece (see Figure 5.8). There are many variations on eddy current probe design and many ways to manufacture the coil winding. Rather than attempt an exhaustive assessment of all possible probe designs, this section will focus on the most basic concept of a tightly wound coil of insulated wire.

Figure 5.9 is a photograph of a surface eddy current probe that is typically used for detection of surface breaking cracks. A view of the coil is also provided showing encasement of the coil within a thermosetting polymer. Based on Table 5.2, it may be anticipated that standard commercial eddy current probes can withstand exposure to gamma radiation levels $10^{7}$ to $10^{9}$ Rads and temperatures up to $260^{\circ} \mathrm{C}$.

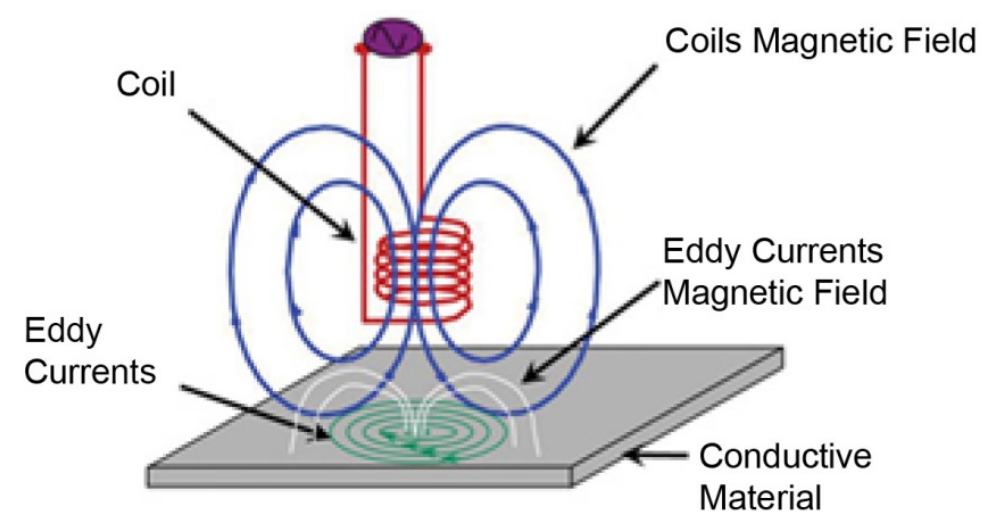

Figure 5.8. Schematic of Eddy Current Probe

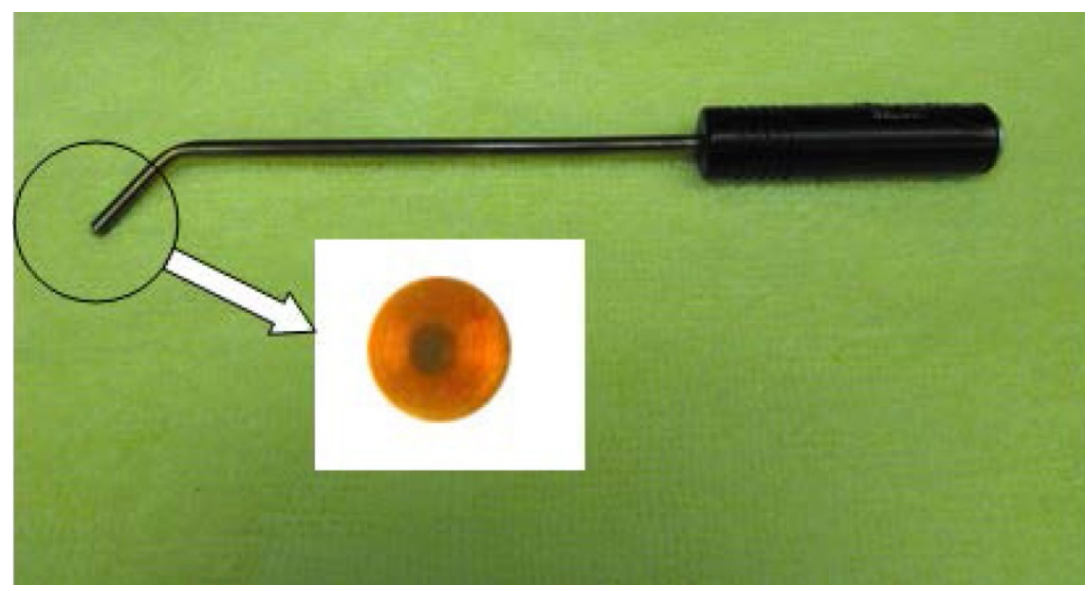

Figure 5.9. Photograph of an Eddy Current Surface Probe and View Showing the Coil Winding 


\subsubsection{Environmental Tolerance of Piezoelectric Transducers}

A diagram of a standard piezoelectric transducer in Figure 5.10 depicts the typical components. The case and front face are metallic, while the sleeve is an electrical insulator such as plastic or ceramic. The backing or damping material may be a metal foam or metal sponge. An adhesive is used to bond the piezoelectric element to the transducer front face and provide good coupling.

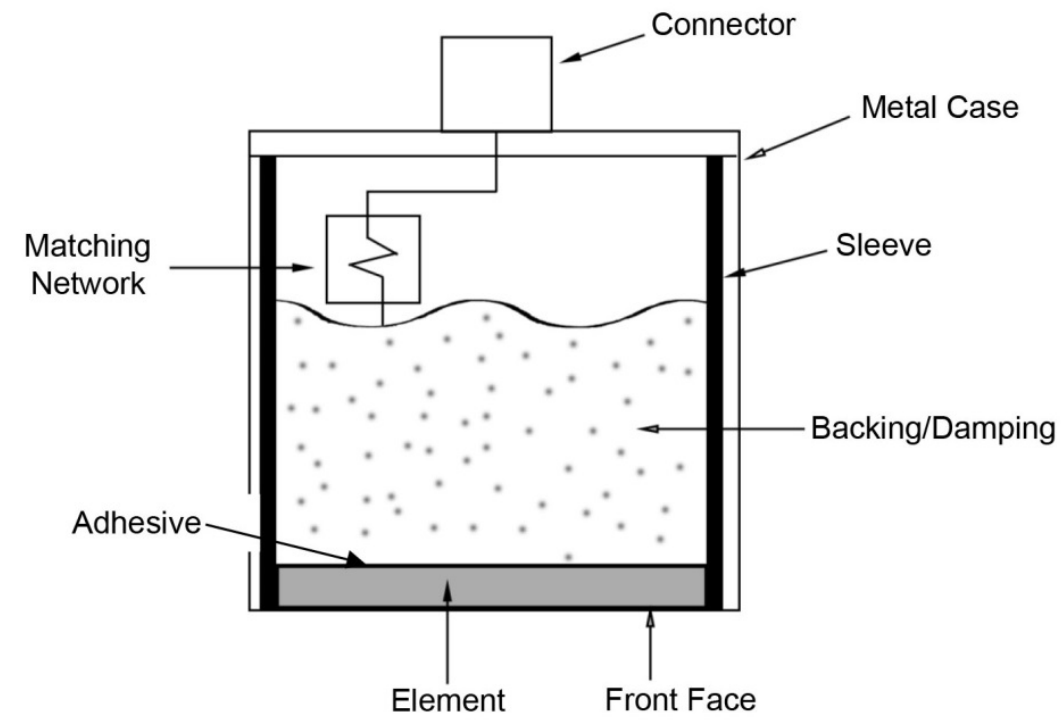

Figure 5.10. Illustration of the Typical Components of a Standard Piezoelectric Transducer

A review of the environmental limitations of piezoelectric materials has been performed to support development of advanced instrumentation for in-pile applications in material test reactors (Rempe et al. 2011). The results of numerous irradiation studies are summarized and discussed for eleven different piezoelectric materials. This information is tabulated along with other properties of the piezoelectric materials such as Curie temperature, $\mathrm{T}_{\mathrm{c}}$, electromechanical coupling coefficient, $\mathrm{k}_{\mathrm{t}}$, and mechanical quality, $\mathrm{Q}_{\mathrm{m}}$. As a rule of thumb, it is noted that the practical limit to operating temperature for piezoelectric materials is half of $T_{c}$. Temperature and gamma dose tolerances for a few of the piezoelectric materials considered are summarized in Table 5.3.

Table 5.3. Summary of Curie Temperatures and Radiation Dosage Exposures for Selected Piezoelectric Materials (Rempe et al. 2011)

\begin{tabular}{cccc}
\hline Piezoelectric Material & $\begin{array}{c}\text { Curie Temperature } \\
\left({ }^{\circ} \mathbf{C}\right)\end{array}$ & $\begin{array}{c}\text { Gamma Dose } \\
\text { Rate }(\text { Rad/hr) }\end{array}$ & $\begin{array}{c}\text { Gamma Total Dose } \\
\text { (Rad) }\end{array}$ \\
\hline Lead Zirconate Titanate (PZT) & $320-610$ & $100-2 \times 10^{6}$ & $1.5 \times 10^{8}$ \\
Bismuth Titanate & $600-920$ & & $2.26 \times 10^{9}$ \\
Lithium Niobate & $1200-1210$ & & $2.26 \times 10^{9}$ \\
Lead Metaniobate & $540-570$ & $1.38 \times 10^{5}$ & Up to $0.83 \times 10^{8}$ \\
\hline
\end{tabular}


Ultrasonic transducers have been researched for application to under-sodium viewing in fast neutron flux reactors. In liquid sodium reactors, sodium temperatures are maintained in the $200-250^{\circ} \mathrm{C}$ range during outages to prevent sodium freezing; significant gamma radiation fluxes may be present as well. Transducers for under-sodium viewing were originally developed at the Hanford Engineering Development Laboratory (HEDL) for use at the Fast Flux Test Facility (FFTF) and Clinch River Breeder Reactor. The original HEDL transducer design incorporated a PZT-5A element coated with copper electrodes. The element was then silver soldered to the back of the transducer faceplate and electrical contact with the element was maintained with a spring loaded mechanism. Efforts are ongoing to improve upon the HEDL design by replacing the PZT-5A element with either bismuth titanate or lead metaniobate and replacing the silver solder bond with a high temperature epoxy or alternative low melting temperature solder. Several metal loaded "high-temperature" epoxies have been tested but all failed adhesively at $260^{\circ} \mathrm{C}$ (Griffin et al. 2012).

Commercially available piezo-electric transducers are available from several vendors. Most of the transducers employ PZT elements although vendors may offer high temperature versions of sensors that are manufactured using one of the alternative materials listed in Table 5.3. A typical rating for acoustic emission sensors from one vendor is a maximum temperature of $177^{\circ} \mathrm{C}$ (PAC 2005). Higher temperature versions are available that tolerate temperatures over $500^{\circ} \mathrm{C}$. A vendor of guided ultrasonic wave ring transducer claims a rating of up to $180^{\circ} \mathrm{C}$ for standard inflatable ring transducers and up to $200^{\circ} \mathrm{C}$ to $300^{\circ} \mathrm{C}$ for high temperature versions (GUL 2012). Finally, a survey of products from a major supplier of conventional ultrasonic sensors for nondestructive testing indicates a range of product ratings from $50^{\circ} \mathrm{C}$ to $400^{\circ} \mathrm{C}$ (Olympus NDT 2013).

\subsubsection{Environmental Tolerance of Video Cameras}

Radiation hardened cameras are commercially available from several manufacturers. The most common application is the inspection and monitoring of nuclear power facilities including underwater operation to monitor fuel storage. The cameras come in a variety of technologies including charge coupled device (CCD), complementary metal-oxide-semiconductor (CMOS), Chalnicon, and charge injection device (CID). A summary of environmental specifications for cameras from several commercial vendors of radiation hardened cameras is provided in Table 5.4 (Meyer et al. 2013). Temperature ratings for cameras are fairly modest with the highest temperature rating at $70^{\circ} \mathrm{C}$ in water and $40^{\circ} \mathrm{C}-50^{\circ} \mathrm{C}$ being more typical for operation in air. Depending on the shielding and the camera type, the total exposure limit for gamma radiation spans from 1 MRad to 200 MRad. 
Table 5.4. Summary of Temperature and Radiation Specifications for Video Cameras from Multiple Vendors (Meyer et al. 2013)

\begin{tabular}{lccc}
\hline \multicolumn{1}{c}{ Vendor } & Max. Temp. $\left({ }^{\circ} \mathbf{C}\right)$ & Total Exposure & Exposure Rate \\
\hline Ahlberg & $50-70$ & $20 \mathrm{kRad}-100 \mathrm{MRad}$ & \\
General Electric & 50 & $22-60 \mathrm{kRad}$ & $1 \mathrm{kRad} / \mathrm{hr}$ \\
Mirion & $40-60$ & $10 \mathrm{kRad}-200 \mathrm{MRad}$ & \\
Diakont & 50 & $100 \mathrm{kRad}-200 \mathrm{MRad}$ & $1 \mathrm{kRad} / \mathrm{hr}-1 \mathrm{MRad} / \mathrm{hr}$ \\
Thermo Scientific & $30-55$ & $1-3 \mathrm{MRad}$ & $100-700 \mathrm{kRad} / \mathrm{hr}$ \\
Symphotic & 30 & $100 \mathrm{MRad}$ & $7 \mathrm{MRad} / \mathrm{hr}$ \\
LightsCamAction & $45-50$ & $70-200 \mathrm{MRad}$ & $100 \mathrm{kRad} / \mathrm{hr}-1 \mathrm{MRad} / \mathrm{hr}$ \\
Centronic & $45-60$ & $100-300 \mathrm{MRad}$ & $5 \mathrm{kRad} / \mathrm{hr}-1 \mathrm{MRad} / \mathrm{hr}$ \\
\hline
\end{tabular}

\subsubsection{Environmental Tolerance of Fiber Optic Cables}

Optical fiber can be produced from any material that has an appropriate refractive index and low optical absorption. Figure 5.11 illustrates the structure of a typical optical fiber. Fused silica and silicabased formulations make up the majority of commercially available fiber products. Very pure silica can provide near infrared losses of less than $1 \mathrm{~dB} / \mathrm{km}$. Pure fused silica melts at around $1600^{\circ} \mathrm{C}$, but will be limited in practical application by the coatings and jackets used to reinforce it. Polyimides, for instance, are quite common and melt around $300^{\circ} \mathrm{C}$. Radiation-induced attenuation in silica glasses, and particularly those doped with germanium, is most strongly observed in the ultraviolet (UV) and visible range. Radiation induced attenuation usually recovers with time, and can be accelerated by annealing at elevated temperatures (Griscom 1991) or photo-bleaching by a UV source (Javed Akhtar et al. 2007). For the purposes of radiation-hardening, doping silica with fluorine seems to make the fibers much more resistant (Aikawa et al. 2008). A hydrogen-loading technique also demonstrated to harden silica fibers in the visible spectrum by reducing radiation-defect precursors (Brichard et al. 2003). Doping silicate glasses with cerium is another common approach to improve radiation tolerance. Cerium ions absorb heavily in the UV and therefore tend to push the UV cutoff to higher wavelengths, however they greatly inhibit hole formation that leads to increased absorption in the rest of the visible range, particularly from gamma rays (Stroud 1965). Some of these glasses show no measurable absorption increase from gamma radiation doses up to $1 \times 10^{8}$ Rad (McGrath et al. 1976).

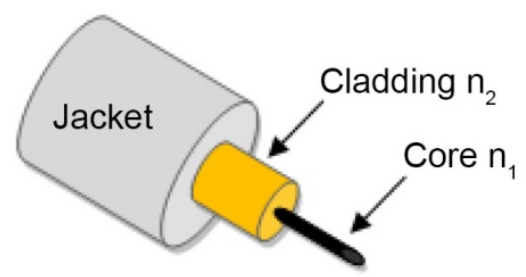

Figure 5.11. Illustration Depicting Typical Fiber Optic Cable Structure 


\subsection{Assessment of Environmental Compatibility}

Standard ultrasonic/acoustic and eddy current sensors and associated electrical cables should be compatible with the environment near most canisters for the duration of a typical inspection (less than a few hours). Piezoelectric transducers incorporating PZT sensors may begin to experience degraded performance above temperatures of approximately $180^{\circ} \mathrm{C}$, however, even in this case, thermal degradation would be expected to accumulate over many hours of exposure. Another concern with piezoelectric sensors may be associated with coupling the transducer to the canister. High temperature coupling materials exist but they are more viscous than water and care must be taken to ensure they do not contain chlorides or other materials that may result in corrosion of the canister surface. This could impact the practicality of scanning a piezoelectric transducer over the surface of a canister for crack detection at temperatures above $100^{\circ} \mathrm{C}$. Polymeric components are also a potential concern with respect to thermal degradation. Some of the polymeric components include electrical cable insulation and jacket materials and jacket materials for fiber optic cables, insulation for eddy current probes, and adhesives used in piezoelectric transducers. The literature indicates that these materials may operate at temperatures up to $260^{\circ} \mathrm{C}$ which is in excess of temperatures predicted even under conditions of canister loading at limiting thermal capacities. Video cameras are found to be rated for temperatures that are too low to survive in many canister surface environments. A comparison between canister temperature values for several conditions and temperature ratings for several NDE sensor related components and materials is provided in Figure 5.12.

The information compiled in this report for radiation tolerance of many types of materials suggests that some polymeric materials may experience degradation if continuously exposed to radiation near canister surfaces over a period of several years (see Figure 5.13). However, Figure 5.13 also shows that most polymeric materials should withstand the exposure to gamma radiation for inspections that last for a few hours. A caveat is that the dose rate tolerance is not reported for polymeric materials. Teflon is also an exception in that it appears to be most vulnerable to gamma radiation damage and may not even be a suitable for inspections that last a few hours. 


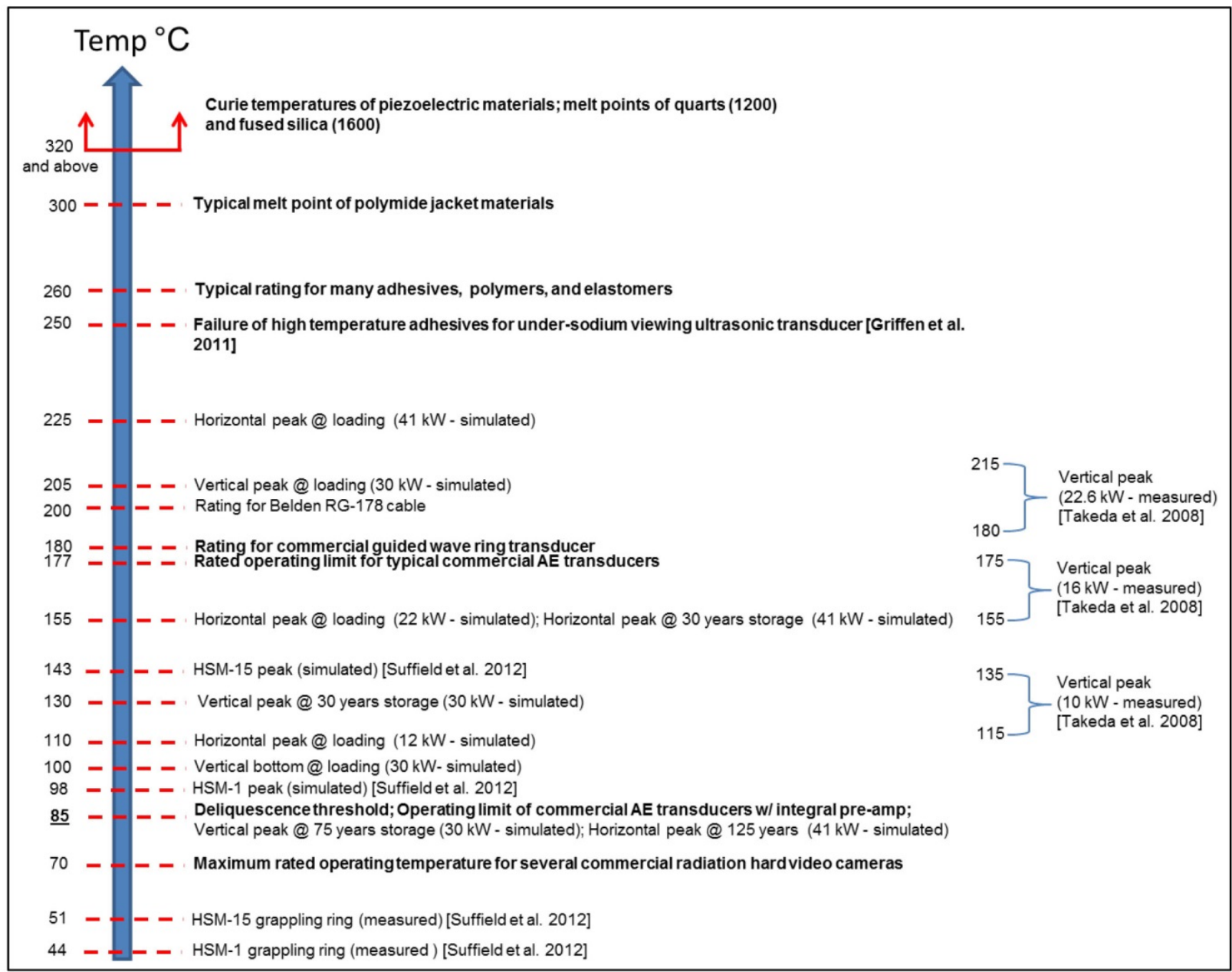

Figure 5.12. Illustration of the Relative Thermal Tolerance of Various NDE Sensor Component Materials to Anticipated Canister Temperature Values 


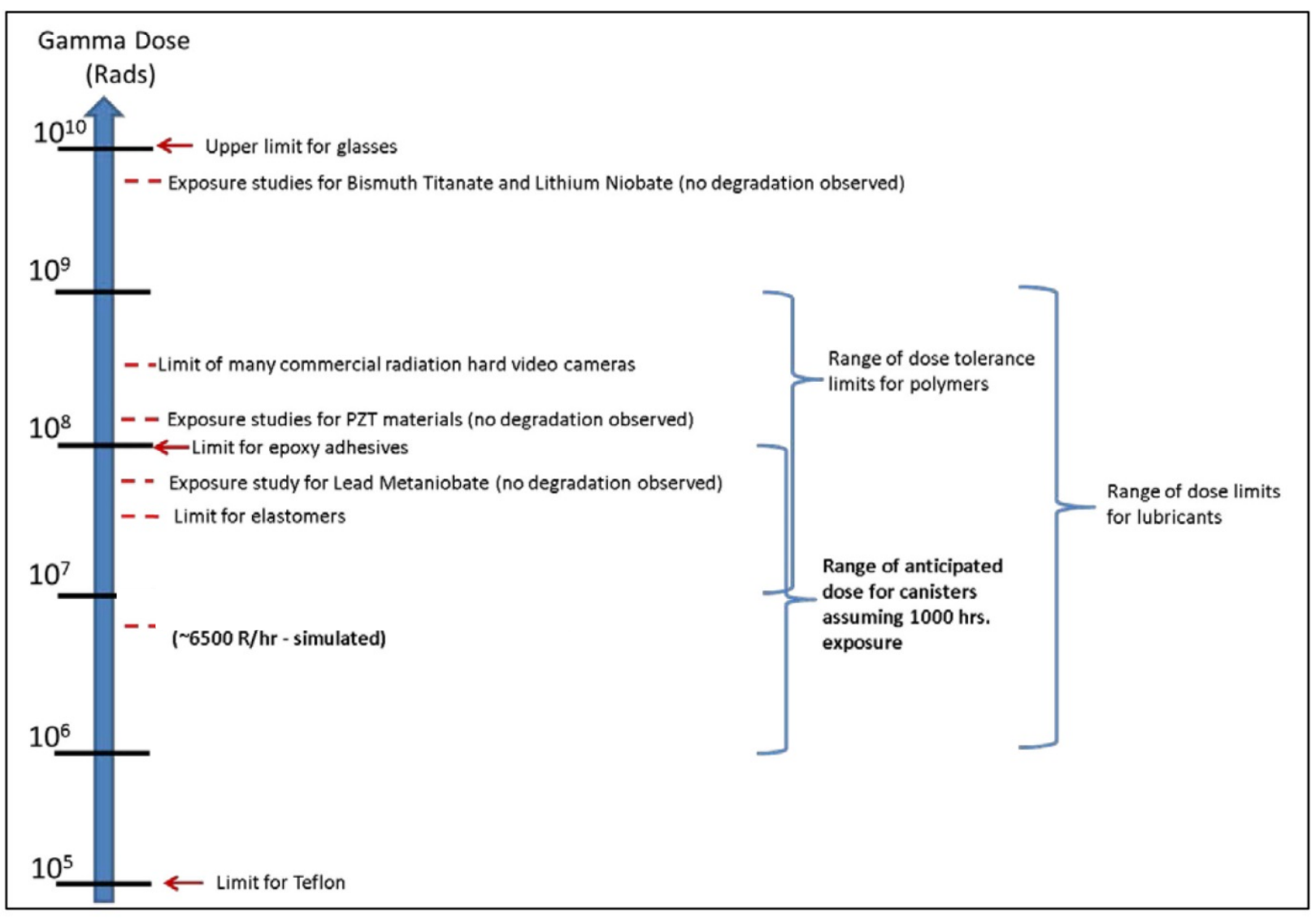

Figure 5.13. Illustration of the Relative Tolerance of Many NDE Sensor Component Materials to Gamma Radiation Compared to Anticipated Gamma Radiation Dose Values Near the Canister Surface 


\subsection{Ultrasonic Testing Performance}

Ultrasonic testing often refers to the variety of bulk ultrasonic techniques that are deployed in nuclear power plants for performing in-service inspections (ISIs) on components that require a volumetric examination. Major reliability studies of UT of wrought stainless steel components are documented in several NUREGs. Studies include the Piping Inspection Round Robin (PIRR) (Heasler and Doctor 1996b), the Mini Round Robin (MRR) (Heasler et al. 1990) and the Programme for Inspection of Steel Components III Austenitic Stainless Steel Testing Study (PISC III AST). A comparison of the results for all three studies is included in NUREG/CR-6795 (Heasler and Doctor 2003).

\subsection{Probability of Detection (POD) Performance}

In PIRR, inspection teams from six commercial ISI vendors participated in a round robin study that included 10-in. diameter Schedule $80(1.51 \mathrm{~cm})$ wall thickness and Schedule $80 \mathrm{~s}(1.27 \mathrm{~cm})$ wall thickness samples of rolled and welded 304 stainless steel pipe. The study included both IGSCC and thermal fatigue cracks and studies were performed to assess UT performance for detection of flaws located on both the near side of a weldment and the far side of the weldment. In the latter case, the UT sound field was required to travel through the weldment and exhibited significantly poorer performance than UT performed on near side flaws. All of the flaws considered were initiated on the inside diameter of the pipes and UT was performed from the outside diameter. Thus, flaws were initiated on the far surface in relation to placement of the UT probe. A depiction of far surface UT probe placement for a near-side weld examination is included in Figure 6.1.

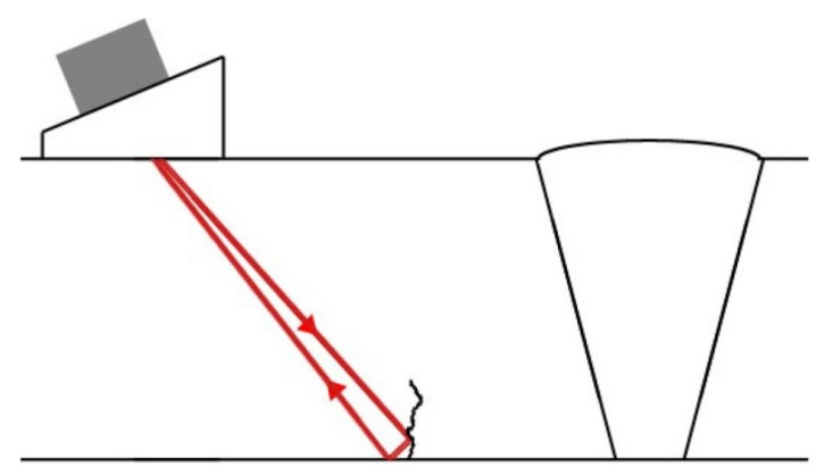

Figure 6.1. Depiction of Far Surface UT Probe Placement for a Near-Side Weldment Examination

The results of far-side weld examinations indicated inadequate UT performance, so only the results of near-side weldment examinations are discussed here. In the PIRR study, UT performance was quantified using probability of detection (POD) curves. POD curves were developed to assign a probability for detecting a flaw of certain size. In PIRR, the POD curves were assumed to have the shape of a logistic function and a regression fit was performed to determine the parameters of the function. POD curves obtained for both IGSCC and thermal fatigue cracks are reported in NUREG/CR-5068 (Heasler and Doctor 1996b) and are provided in Figure 6.2 and Figure 6.3 for convenience. The relative performance of UT for detecting IGSCC vs. thermal fatigue cracks is expressed from the following text from page 10.1 of NUREG/CR-5068: 
"There was an important difference in the POD performance on thermal fatigue cracks versus IGSC cracks in wrought stainless steel, as illustrated in Figures 5.20 and 5.30. POD for the thermal fatigue cracks was much lower than for the IGSCC. For example, the largest thermal fatigue cracks [0.27 in. $(6.9 \mathrm{~mm})$ through-wall and $2.25 \mathrm{in} .(5.7 \mathrm{~cm})$ long] yielded a $70 \%$ POD, while the largest IGSC cracks [0.15 in. (3.8 $\mathrm{mm})$ through-wall and 2 in. $(5.1 \mathrm{~cm})$ long] yielded a 90\% POD. This supports the position that thermal fatigue cracks can indeed be used as conservative surrogates for IGSCC in round-robin and qualification testing."

A comprehensive analysis and comparison of results from the PIRR, MRR, and PISC III AST studies is provided in Heasler and Doctor (2003). In this report, the results from all three studies are combined to predict a POD of $90 \%$ for flaws that are $10-\mathrm{mm}$ deep and a $70 \%$ POD for flaws that are 5-mm deep. This combined analysis included IGSCC, thermal fatigue, mechanical fatigue, and EDM notch defects.
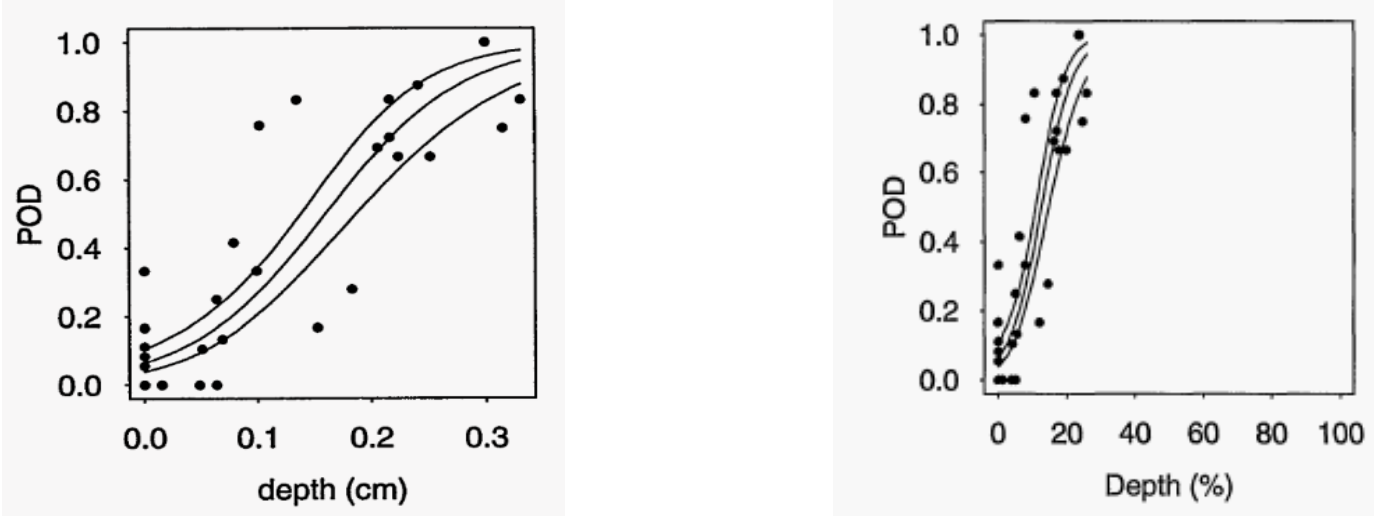

Figure 6.2. POD Results for IGSCC in 304 Stainless Steel Piping with 1.51-cm and 1.27-cm Wall Thickness (Heasler and Doctor 1996a)
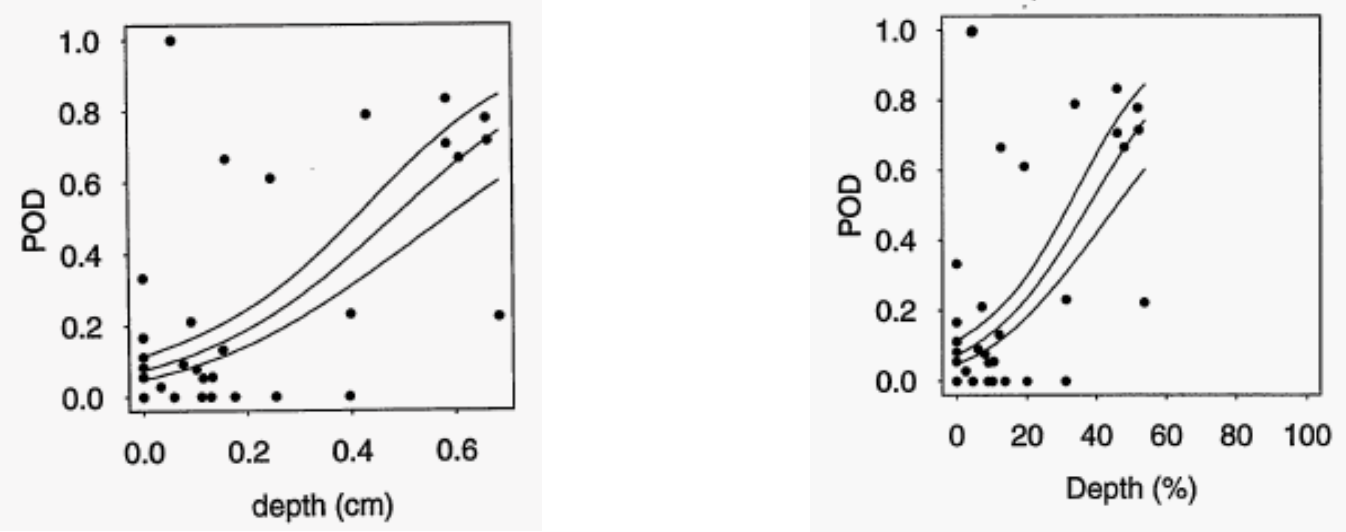

Figure 6.3. POD Results for Thermal Fatigue Cracks in 304 Stainless Steel Piping with 1.51-cm and 1.27 cm Wall Thickness (Heasler and Doctor 1996a) 
Detection performances for more advanced techniques including phased-array UT and low frequency synthetic aperture focusing technique (SAFT) were documented for a study evaluating the performances of these techniques for performing far-side inspections of welds (Anderson et al. 2011). The samples included specimens from 610-mm (24-in.) diameter wrought 304 stainless steel piping with 36-mm (1.4-in.) wall thickness and 711-mm (28-in.) diameter wrought 304 stainless steel piping with thickness ranging from 20-41 mm (0.8-1.6 in.). In this report, phased-array UT is described as having the best detection performance, and it is noted that better performance is observed for inspections performed using longitudinal modes versus shear modes.

\subsection{DCSS Canister Inspection versus NPP Component Inspection}

Significant differences exist between the application of UT to DCSS canister inspections and the inspection of nuclear power plant components. These differences include the placement of the UT transducer relative to the surface in which cracks initiate and the methods of deployment. In nuclear power plants, flaws in pipes usually initiate on the inner diameter surfaces of components exposed to the high temperature coolant and UT examinations performed during ISI are performed by placing transducers on the outer diameter surface. The examinations can be performed utilizing a half V-path sound field as depicted in Figure 6.4. Atmospheric SCC is expected to initiate on the outer surface of the canisters and thus different sound field paths will be best suited for detection. Examples of possible sound paths include the full V-path as depicted in Figure 6.5 and the high angle sound path depicted in Figure 6.6. In addition, surface-wave techniques may be employed for detection of surface-breaking flaws. Relative to half V-paths, it is anticipated that full V-paths will experience greater attenuation caused by the additional surface reflection and longer path that sound travels through the material.

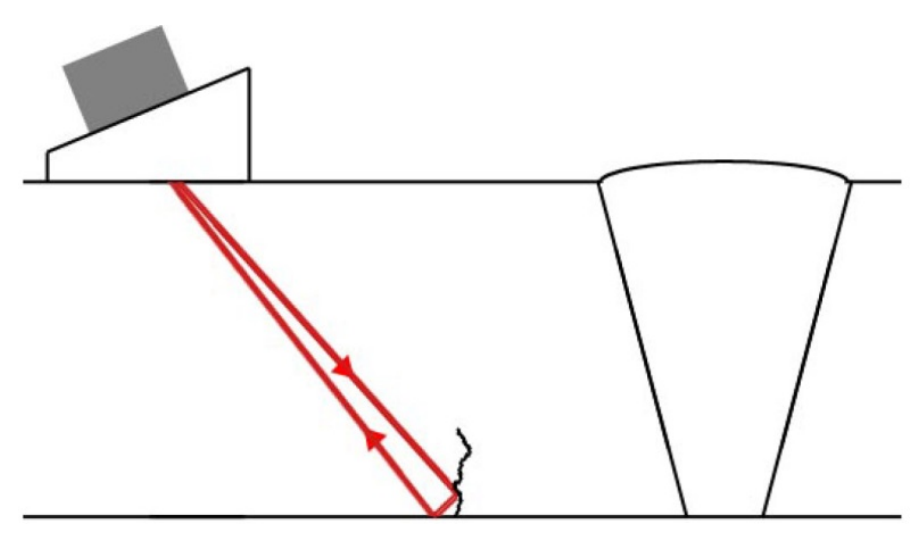

Figure 6.4. Depiction of a Half V-path Inspection for Far-Surface Flaw Detection 


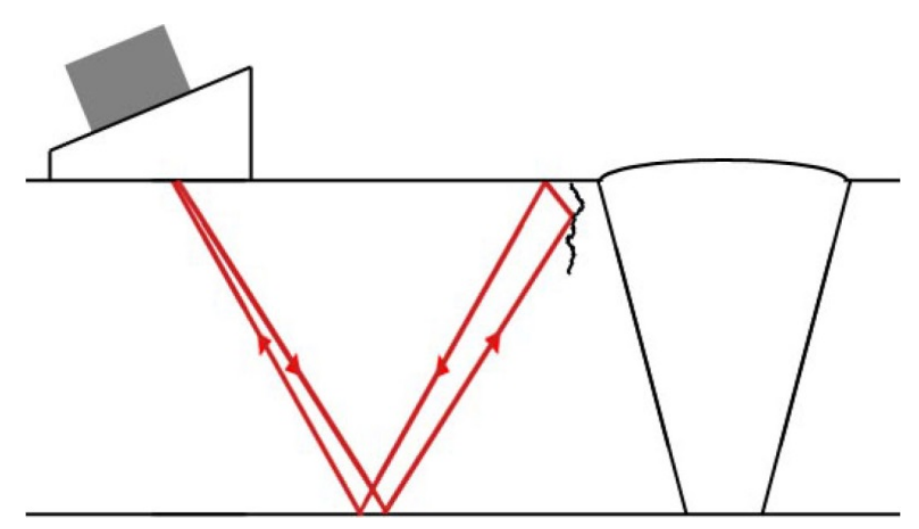

Figure 6.5. Depiction of a Full V-path Inspection for Near-Surface Flaw Detection

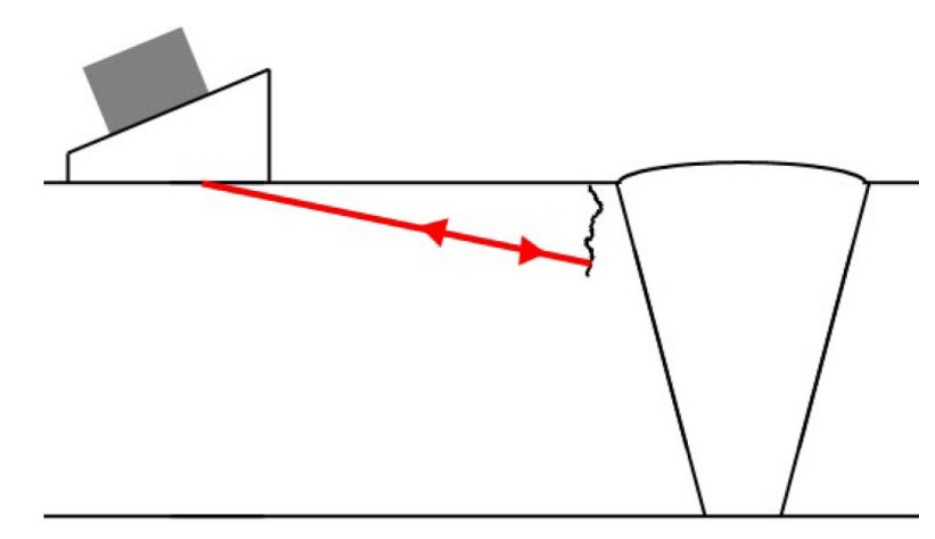

Figure 6.6. Depiction of a High Angle Path Inspection for Near-Surface Flaw Detection

The deployment of UT transducers is a significant challenge for DCSS canisters. In nuclear power plants, UT inspections are conducted during outages with an NDE technician manually scanning the UT transducer over the inspection area in close proximity to the component under test. Accessibility and environmental factors will prohibit this type of inspection scenario for DCSS canisters. UT deployment scenarios are discussed in Section 4.0 and may include the use of a spring steel wand with the UT transducer mounted on one end of it or the use of a robotic crawler.

\subsection{Depth-sizing Performance}

In addition to crack detection, UT has been used for crack sizing to provide information for structural integrity assessment of components in nuclear power plants. For DCSS canisters, measurements of crack depth will be useful for assessing whether a detected crack has penetrated the canister or is only partially through the canister wall. Accurate measurements of crack size are also desirable from the standpoint of understanding how long a cracked canister can remain in-service before mitigating actions are required. Depth-sizing of flaws using ultrasonic techniques can be performed on the basis of amplitude measurements or measuring the time-of-flight difference between the tip-diffracted signals and corner trap signals (Figure 6.7). For SCC-type flaws, multiple branches make depth-sizing more difficult as it becomes more difficult to resolve the signal from the crack tip (Figure 6.8). 

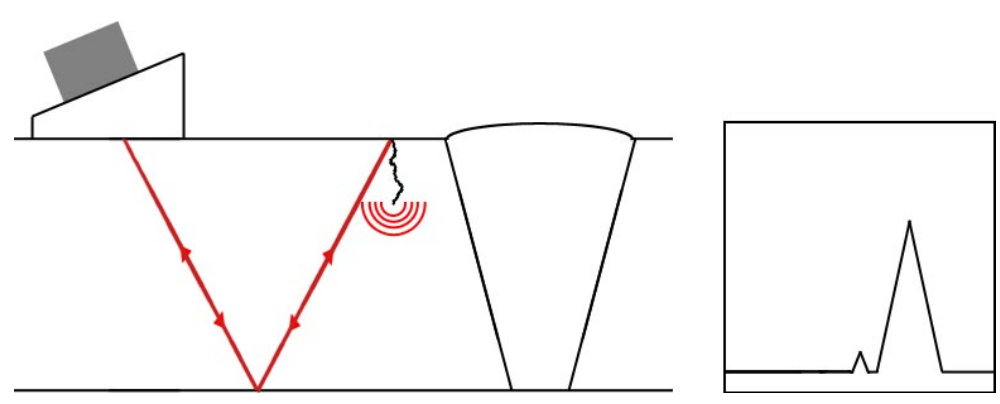

Figure 6.7. Depth-sizing of Flaws Based on Detection of Corner Reflection Signal and Tip-Diffracted Signal
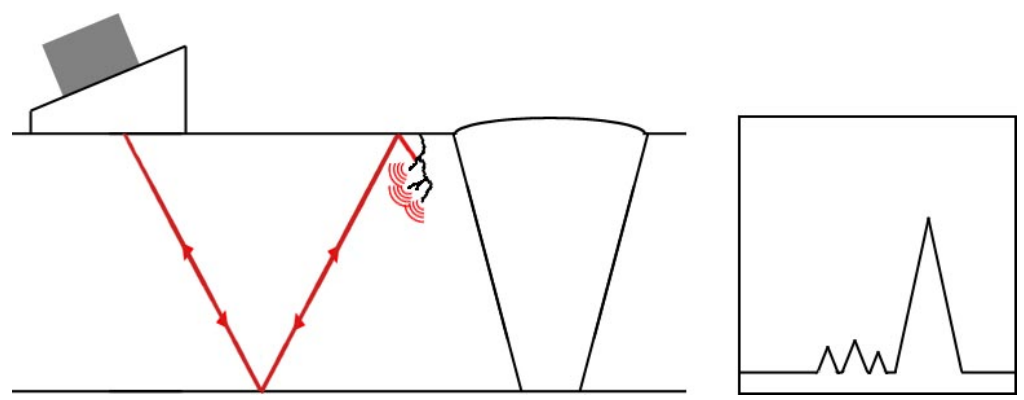

Figure 6.8. Depiction of Multiple Tip-Diffracted Signals from a Multi-Branched Flaw Such as SCC

Depth-sizing accuracy for thermal fatigue and IGSCC cracks in wrought stainless steel specimens in the PIRR study is described as rather poor. Significant improvements in depth-sizing accuracy were observed in the MRR study and the PISC III AST studies; however, the depth-sizing accuracy results were still poorer than the requirements specified in the ASME Code, Section XI, Appendix VIII, which specifies a criterion that the RMSE of the depth measurement is less than $3.2 \mathrm{~mm}$. The sizing accuracy observed in the MRR and PISC III AST studies is described as generally being approximately twice the criteria specified in Section XI, Appendix VIII (Heasler and Doctor 2003). The depth-sizing inaccuracy is attributed to the difficulty in detecting the crack tip.

The PIRR, MRR, and PISC III AST studies did not consider more recent advances in ultrasonic NDE technology such as phased-array UT. However, such techniques are included in the database collected as part of the EPRI's PDI. Data tabulated as part of EPRI's PDI indicates that depth-sizing performance of ultrasonic techniques is adequate to satisfy the ASME Code, Section XI, Appendix VIII criteria of RMSE less than $3.2 \mathrm{~mm}$ (Latiolais 2013).

\subsection{Length-sizing Performance}

Length-sizing performance was also evaluated in the PIRR, MRR, and PISC III AST studies. The best length-sizing results were observed in the PISC III AST studies. In this case, RMSE for flaws of 5-mm, 30-mm, 60-mm, and 100-mm length were $17.74 \mathrm{~mm}, 16.78 \mathrm{~mm}, 20.01 \mathrm{~mm}$, and $28.78 \mathrm{~mm}$, respectively. 
Length-sizing performances for more advanced techniques including phased-array UT and low frequency SAFT were documented for a study evaluating the performances of these techniques for performing far-side inspections of welds (Anderson et al. 2011). The samples included specimens from 610-mm (24-in.) diameter wrought 304 stainless steel piping with 36-mm (1.4-in.) wall thickness and 711-mm (28-in.) diameter wrought 304 stainless steel piping with thickness ranging from $20-41 \mathrm{~mm}$ (0.8-1.6 in.). The results were compared with conventional UT techniques, and all techniques were encoded to record signals with transducer position. For thermal fatigue and saw-cut flaws, conventional UT performed best with RMSE of $2.2 \mathrm{~mm}$ and $4.0 \mathrm{~mm}$, respectively. Phased-array UT performed with an RMSE of $6.3 \mathrm{~mm}$ for both thermal fatigue and saw-cut flaws, while low frequency SAFT techniques exhibited RMSEs of $3.4 \mathrm{~mm}$ and $9.2 \mathrm{~mm}$, for thermal fatigue cracks and saw cuts, respectively.

\subsection{Relationship Between Crack Depth and Crack Surface Profile}

An assessment (Cumblidge et al. 2004) and study (Cumblidge et al. 2007) on visual testing noted that it is generally not feasible to discern crack depth from the surface profile of a crack (e.g., length dimension and COD). In particular, the residual stress distribution is usually unknown and it is usually not feasible to measure it in the field. This inhibits the ability to relate COD and crack length to crack depth.

\subsection{Discussion of Ultrasonic Examination Performance}

Relevant performance reliability data was collected for ultrasonic examinations during the PIRR study for IGSCC flaws in 304 stainless steel pipes with wall thickness of $12.7 \mathrm{~mm}$ and $15 \mathrm{~mm}$. In the PIRR study, the probability of detecting $3.8 \mathrm{~mm}$ deep flaws was $90 \%$ (Heasler and Doctor 1996a). A combined analysis of results from the PIRR, MRR, and PISC III AST studies predicts a POD of $90 \%$ for flaws that are 10-mm deep and a 70\% POD for flaws that are 5-mm deep (Heasler and Doctor 2003). A difference between these studies in the present application is that cracks are anticipated to initiate on the near surface of the component with respect to placement of the ultrasonic transducer. In addition, the pipe components examined in these studies had relatively small diameters compared to the shells of dry storage canisters. Half V-path examinations are usually performed to detect cracks initiating on the far surface of a component with respect to transducer placement; thus, it is not suitable for the present application. More suitable techniques include full V-path, large angle, and surface-wave techniques. Finally, far-side weld examination studies using advanced UT techniques highlight the potential difference in performance between longitudinal and shear wave modes (Anderson et al. 2011).

Much better length-sizing performance is observed in more recent far-side weld examination studies than in the previous PIRR, MRR, and PISC III AST studies, even for conventional UT techniques. It is speculated that most of the improved performance can be attributed to encoding of the data with position

of the transducer and digital storage of the data, which enabled more thorough analysis of the data. In this regard, it is not clear that phased-array UT or low frequency SAFT provide a benefit to conventional UT techniques for length-sizing of flaws.

The depth-sizing accuracy of UT techniques, as determined in the PIRR, MRR, and PISC III AST studies, is described as being approximately twice the criteria specified in the ASME Code, Section XI, Appendix VIII requirements (i.e., RMSE $=3.2 \mathrm{~mm}$ ). This implies that the depth-sizing accuracy is RMSE $\sim 6 \mathrm{~mm}$, making it difficult to categorize flaws into more than one sizing category for canister 
shells that are 12.7-mm thick. However, EPRI PDI data demonstrates that that the ASME Code, Section XI, Appendix VIII requirement of 3.2-mm RMSE can be met. This database includes more advanced techniques, such as phased-array UT, that were not included in the PIRR, MRR, and PISC III AST studies. However, even with this improved performance, it may still only be possible to categorize flaws into 1-2 sizing categories. 



\subsection{Eddy Current Testing Performance}

An ECT inspection is conducted by generating a magnetic field near the surface of the test component to induce eddy currents in the test component material (see Figure 5.8). Changes in the conductivity of the test material as the result of discontinuous degradation result in a change to the measured eddy current coil impedance. The technique is subject to the electromagnetic skin effect which limits the ability of an electromagnetic field to penetrate a conducting body. The depth of penetration is inversely proportional the square root of frequency of the excitation signal and conductivity of the material. Meyer et al. (2013) reported that ECT performance can be impacted by several parameters of the inspection including human factors and factors associated with the test component material and geometry, and the configuration of the inspection. In particular, it is noted that spatial variation in the material properties such as conductivity and permeability can have a negative impact on eddy current performance. Further geometry effects such as un-even surfaces or edge effects can also influence the results of an ECT inspection. In addition, maintaining a consistent probe lift off is important to achieving reliable eddy current results.

\subsection{Probability of Detection Performance}

Singh (2000) summarizes several NDI reliability efforts performed beginning in the 1970s. The studies mostly focus on UT, ET, and liquid penetrant testing. Organizations conducting such studies include the United States Air Force, the Federal Aviation Administration (FAA), and the Nuclear Regulatory Commission. Other institutions performing NDI reliability studies include EPRI and universities. The Air Force's NDI studies focused on the reliability of inspecting aircraft structures and engine components. The FAA sponsored a program to assess the reliability of ECT examinations for detecting flaws near rivets in aircraft skin lap joints.

The Eddy Current Inspection Reliability Experiment (ECIRE) assessed the reliability of highfrequency eddy current to detect flaws near fastener holes in thin aluminum structures for aircraft. The performance was summarized using POD curves with respect to crack length (Spencer and Schurman 1995). The results of this study indicated that cracks of length 0.06 in. to 0.07 in. could be detected in the laboratory at a probability of $90 \%$. In the field, the average crack length that could be detected with a $90 \%$ probability was nominally 0.09 in. The performance was impacted by several factors including surface conditions (painted or bare), crack orientation, and "accessibility.”

A round-robin study was performed to assess the reliability of ECT techniques used in the nuclear power industry to inspect steam generator tubing (Kupperman et al. 2007). The study was performed on a mockup tube bundle containing alloy 600 tubes of diameter $22.2 \mathrm{~mm}$ (7/8 in.) with several types of simulated flaws. The performance of ECT techniques was quantified with POD curves plotted versus flaw depth, length, and another parameter, $m_{p}$, which related the stress intensity of a crack tip to the stress intensity experience in an unflawed tube at the same loading conditions. Bobbin coil (BC) probes and magnetic rotating pancake coil (MRPC) probes were tested for ability to detect longitudinal outer diameter stress corrosion crack (LODSCC) flaws and longitudinal inner diameter stress corrosion crack (LIDSCC) flaws in tube support plate and free span regions. A passage from NUREG/CR-6791 (Kupperman et al. 2007) describing the performance of MRPC probes for detecting flaws is provided below: 
“... For the MRPC in the tube-sheet, the POD for inner-diameter SCC is about 75\% with a one-sided 95\% confidence limit of about 65\%. The highest tube-sheet MRPC POD curve is for LIDSCC, where the POD for $60 \%$ through wall flaws is $85 \%$.

A review was carried out of MRPC results for BC voltages from 2.0 to $5.6 \mathrm{~V}$. Such calls are normally made to confirm or dismiss the BC flaw call. The result for LODSCC $>75 \% \mathrm{TW}$, which are of greatest concern in terms of integrity, is an average correct call of 98\%."

Some general observations of the study include the observation that false call rate was observed to be higher for regions near tube support plates than for free span regions of the tube. Also, it was observed that electo-discharge machined (EDM) notches are not very good surrogates for cracks as they tend to give unrealistically high performance results.

Eddy current techniques have also been considered for the inspection of cast austenitic stainless steel (CASS) components in nuclear power plants (Diaz et al. 2007). CASS material has a very coarse macrostructure with large grains that tend to scatter and redirect the sound field of ultrasonic probes used for inspection. Thus, ECT has been suggested for performing inner diameter surface (same surface as flaw initiation) inspections of CASS components when such access is feasible. Both thermal fatigue cracks and mechanical fatigue cracks were grown into the CASS test specimens. In all, 19 specimens were included in this study and the flaws in each of the specimens were detected with no false calls for the criteria used in this study. Specimen thicknesses generally ranged from 2.5-in. to 3.5-in. thick. The cracks ranged in depth from $11.4 \mathrm{~mm}$ to $26.4 \mathrm{~mm}$. In this study, false call decisions are made based on the signal amplitude and phase information and the associated spatial patterns including length and extent. In general, responses $12.7 \mathrm{~mm}$ in length and smaller were considered non-crack responses. This threshold was set due to the background of anomalous signals, attributed in part to the material heterogeneity. The noise levels observed in isotropic, homogenous, and fine-grained materials such as forged stainless steel and carbon steel were approximately $10 \mathrm{~dB}$ to $15 \mathrm{~dB}$ lower than cast stainless steels. Finally, it is noted that orientation of the flaw relative to the probe has a significant impact on performance and that the techniques employed in this study are not useful for depth-sizing of flaws.

Eddy current techniques were also evaluated as part of the NRC's Program for the Inspection of Nickel Alloy Components (PINC) (Cumblidge et al. 2010). Both dissimilar metal welds (DMWs) and bottom-mounted instrumentation (BMI) components are considered in this study. In this study, ECT techniques were evaluated along with several UT techniques and potential drop techniques. ECT exhibited the best detection performance for both DMW and BMI components.

\subsection{Length-sizing Performance}

The ability of eddy current to accurately length size flaws was also assessed in the study of CASS specimens (Diaz et al. 2007). In this study, the lengths of thermal fatigue and mechanical fatigue cracks ranged from $39.4 \mathrm{~mm}$ to $69.9 \mathrm{~mm}$. Most of the flaws (16 out of 19) were undersized with a RMSE of $7.7 \mathrm{~mm}$. An x-y scanner was employed to automatically scan the eddy current probe over the surface of the specimens and encode data to position of the probe. 


\subsection{Detection and Characterization of Stress Corrosion Cracks (SCC)}

Although eddy current is not generally considered for depth-sizing of flaws, depth-sizing may be possible by employing lower frequencies to achieve greater penetration. An extensive review of the theoretical framework for sizing flaws with eddy current is provided by Auld and Moulder (1999). For the purpose of eddy current flaw characterization, an ideal flaw exhibits 1) infinite impedance (zero conductivity), and 2) a zero thickness. Real cracks deviate from both of these conditions as partial contact between crack faces results in non-zero conductivity and real cracks have a non-zero width (Beissner 1994). Yusa et al. (2006) consider models of real cracks that are defined as rectangular-shaped regions with a uniformly distributed non-zero conductivity and significant width dimension (i.e., a 3-dimensional profile). The model was applied to characterization of fatigue and SCC cracks where it was determined that while fatigue cracks do not deviate significantly from ideal crack assumptions, SCC flaws deviate significantly. Further investigations of this SCC crack model by Yusa and Hashizume (2009) found no observable correlation between the real flaw dimensions (depth, length) and model equivalent conductivity and width. The authors defined a new parameter, the equivalent flaw resistance, defined as the ratio of equivalent width to equivalent conductivity and found that equivalent resistance generally increased as real flaw dimensions increased. The increased number of parameters (depth, equivalent conductivity, and equivalent width) of SCC flaws increases the complexity of characterization and is an ongoing area of research (Huang et al. 2011).

Experimental eddy current measurements on SCC flaws are documented in Yusa et al. (2007). In this work, the investigators describe efforts to determine the response of eddy current to manufactured SCC flaws over a range of frequencies from 10 to $400 \mathrm{kHz}$ using a plus-point probe. The SCC cracks were grown into 316 stainless steel plate with a 15-mm thickness. The lengths of three SCC flaws were 15, 27, and $13 \mathrm{~mm}$, respectively, with corresponding depths of 5.9, 7.4, and $4.3 \mathrm{~mm}$. Eddy current responses at $400 \mathrm{kHz}$ are provided, indicating a clear ability for detection for the three flaws. Photographs of the flaw cross sections indicate that the width of the flaw can vary significantly along its depth and that the crack width immediately sub-surface can be very different than the width at the surface (COD).

\subsection{Relationship Between Crack Depth and Crack Surface Profile}

An assessment (Cumblidge et al. 2004) and study (Cumblidge et al. 2007) on visual testing noted that it is generally not feasible to discern crack depth from the surface profile of a crack (e.g., length dimension and COD). In particular, the residual stress distribution is usually unknown and it is usually not feasible to measure it in the field. This inhibits the ability to relate COD and crack length to crack depth.

\subsection{Discussion of Eddy Current Performance}

Laboratory efforts have demonstrated the capability to detect SCC flaws with depths of 5.9, 7.4, and $4.3 \mathrm{~mm}$ in 15-mm-thick 316 stainless steel plates. These flaw depths correspond to through-wall penetration depths from approximately 30\%-50\% (Yusa et al. 2007).

Reliability studies have been performed to quantify the performance of ECT inspections for detecting cracks in aluminum structures for aircraft and steam generator tubing. The ECIRE studies indicated that ECT could detect fatigue cracks with a nominal 0.09-in. length at a reliability of $90 \%$ under field 
conditions in aluminum skins for aircraft (Spencer and Schurman 1995). It can be inferred from reliability studies performed on steam generator tubing that sub-millimeter deep flaws can be detected with high reliability using ECT (Kupperman et al. 2007). In these applications, the thickness of inspected components (e.g., steam generator walls, air craft skins) is significantly less than the thickness of dry storage canister shells. ECT was capable of detecting all mechanical and thermal fatigue cracks (19 of 19) in CASS specimens ranging from 2.5 in. to $3.5 \mathrm{in}$. in thickness and with crack depths ranging from $11.4 \mathrm{~mm}$ to $26.4 \mathrm{~mm}$ (Diaz et al. 2007). The noise level in the CASS material was $10 \mathrm{~dB}$ to $15 \mathrm{~dB}$ higher than forged stainless steel or carbon steel materials.

The depth of a crack cannot be inferred from the surface length or the COD unless the residual stress distribution is known (Cumblidge et al. 2007). Generally, the stress distribution is unknown and cannot be measured in the field. If the residual stress distribution in dry storage canisters can be determined, then it may be feasible to extract some information regarding crack depth from eddy current measurements of the surface profile (i.e., length).

Characterizing the depth of SCC flaws is more difficult compared to characterizing the depth of EDM notches and fatigue cracks. The complexity arises due to the deviation of SCC flaws from ideal crack assumptions and requires determination of more parameters (i.e., equivalent conductivity and equivalent width) in addition to crack depth. Knowledge of the effective conductivities or equivalent widths of atmospheric SCC flaws in dry storage canisters would facilitate development of effective depth-sizing techniques. The development of techniques to characterize deep SCC flaws in thick components is currently an area of research (Huang et al. 2011). 


\subsection{Discussions}

This section includes a brief analysis of the assessments performed in previous sections of this report including the atmospheric SCC assessment, environmental assessment, accessibility and deployment assessment, and UT and ECT performance assessments.

\subsection{Environmental Assessment}

Canister temperature is unlikely to prohibit the use of standard NDE sensor probes and associated cabling, especially if examinations target cooler portions of the canister that will cross the deliquescence temperature threshold first. Continuous exposure to gamma radiation near the canister surface for several years could potentially result in degradation of polymeric materials. Teflon is especially sensitive to gamma radiation and may not even be suitable to use for only a few hours for some canisters.

Thermal profile data for vertical canisters indicates that the bottom plate-to-shell weld will cross the deliquescence threshold first, followed by approximately the bottom $25 \%$ of the longitudinal shell weld, and then followed by welds in the lid assembly. For horizontal systems, thermal profiles indicate that the coolest portions will be at the bottom of both ends of the canister. This information can be used to target examinations.

\subsection{Crevice Conditions}

As discussed in Section 2.0, crevice conditions can be a contributing factor to atmospheric SCC initiation by trapping or collecting chloride deposits on the canister surface. In the vertical and horizontal systems, crevice conditions are created where the canister makes contact with the storage module support structure. In the HI-STORM system, this is occurs where the MPC bottom plate contacts the pedestal. In the NUHOMS system, this occurs where the DSC contacts the support rails. These locations could be considered targets for examination.

\subsection{Access and Deployment Assessment}

The bottom (inlet) and top (outlet) ventilation ports provide potential access to the MPC surface for the HI-STORM systems. Referring to Figures 8.1 to 8.3, it is clear that the HI-STORM 100S and HI-STORM 100S version B systems provide easier access to the top of the MPC lid as the clearance between the MPC lid and the overpack lid is much greater for these systems compared to the HI-STORM 100 system. The short pedestal in the HI-STORM 100S version B system causes the canister to sit lower with respect to the channels on the inner cavity wall of the overpack. As a consequence, significant clearance exists between the bottom plate-to-shell weld and the bottom of the channels. In the HI-STORM 100 and HI-STORM 100S systems, the bottom of the channels extend down to the bottom plate-to-shell weld and may partially restrict access to this weld.

In general, the channels will obstruct portions of the canister surface. Besides the bottom plate-toshell weld, the channels will partially obstruct the circumferential shell weld and could potentially obstruct the longitudinal shell welds, depending on the orientation of the canister inside of the overpack. 
Careful loading of canisters into the overpack to ensure the bottom longitudinal shell weld is not obstructed by channels will enable more effective canister examinations.

It is clear from Figures 8.1 to 8.3 that the misalignment of inlet and outlet ports in the HI-STORM $100 \mathrm{~S}$ and HI-STORM 100S version B systems potentially enables greater access to the MPC surface compared to the HI-STORM 100 system because the accessible regions of the MPC from the inlet and outlet ports do not overlap for the HI-STORM 100S and HI-STORM 100S version B systems.

Deployment options for NDE sensors essentially include probes mounted on flexible wands or robotic crawlers. The inner cavity wall of the HI-STORM systems are lined with carbon steel which is convenient for deployment of magnetic crawlers.

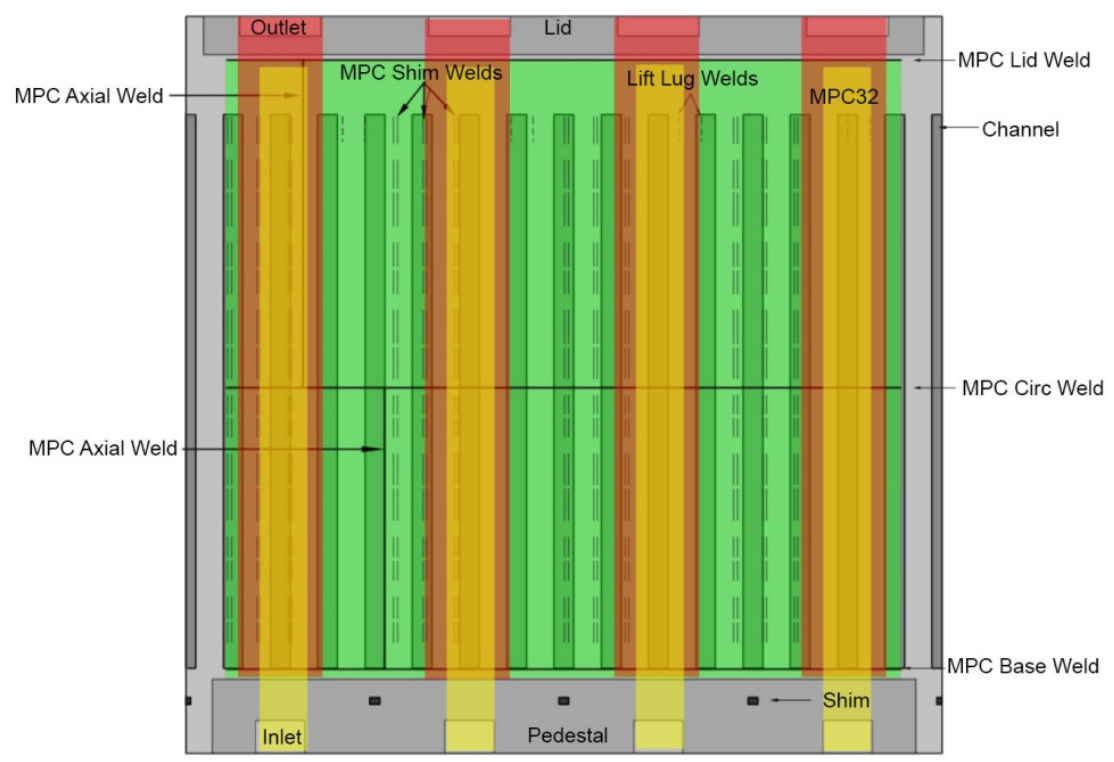

Figure 8.1. Illustration of Accessible Zones of the MPC Surface from Inlet and Outlet Ventilation Ports of the HI-STORM 100 System 


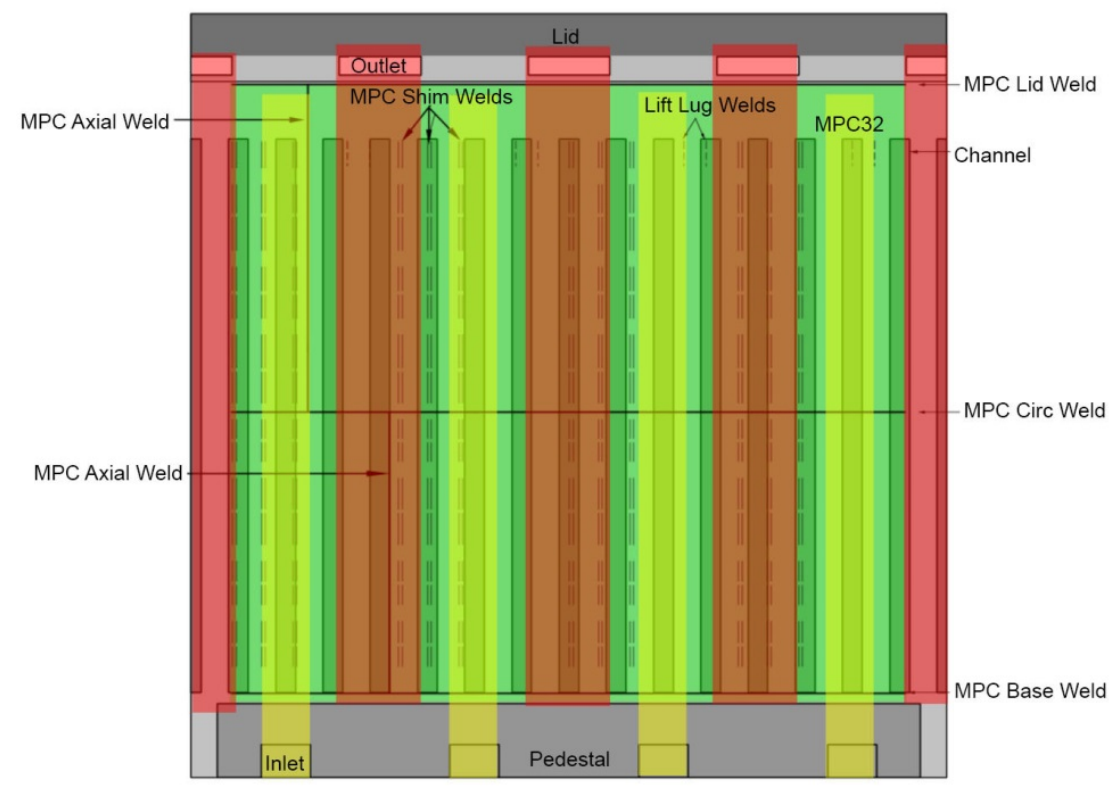

Figure 8.2. Illustration of Accessible Zones of the MPC Surface from Inlet and Outlet Ventilation Ports of the HI-STORM 100S System

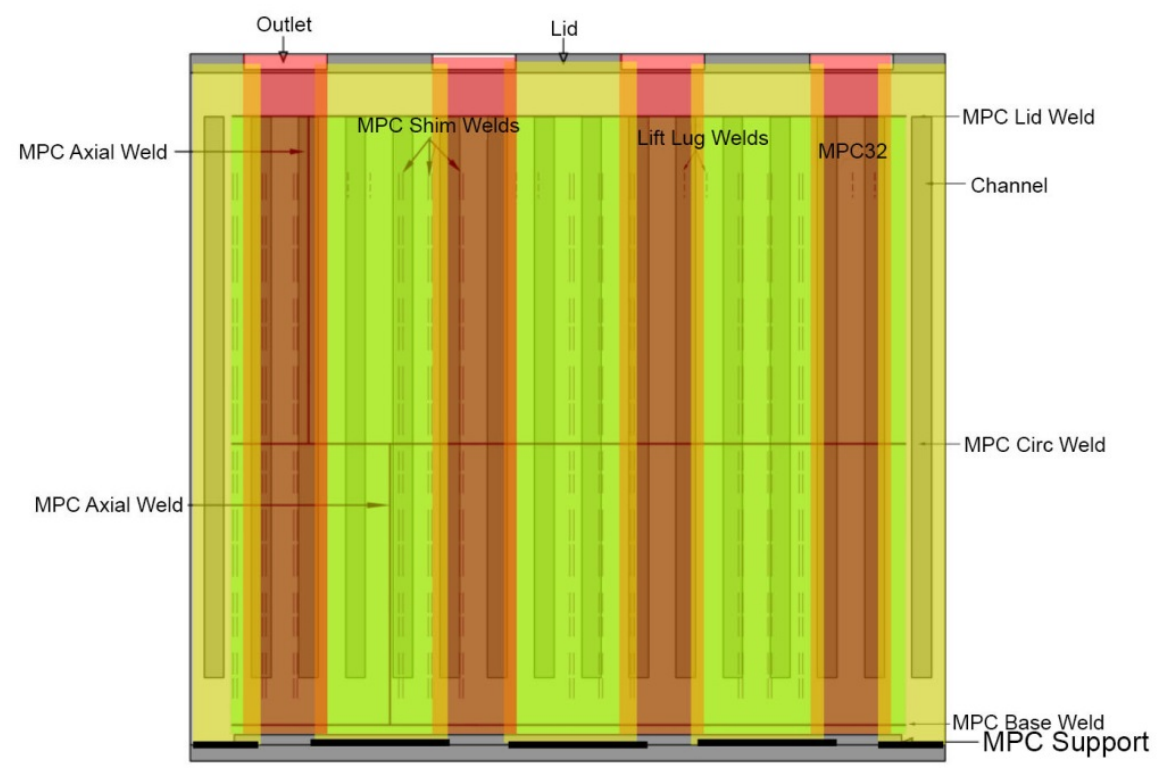

Figure 8.3. Illustration of Accessible Zones of the MPC Surface from Inlet and Outlet Ventilation Ports of the HI-STORM 100S Version B System

The NUHOMS DSC is accessible through the HSM inlet and outlet ports and the entry port for loading canisters in the HSM. The front outlet port for the Calvert Cliffs HSM enables access to a strip along the top surface of the DSC using a flexible wand as depicted in Figure 4.12. The back outlet port can potentially enable access to the DSC endplate surface. The shielded door to the HSM has been removed for inspections at Calvert Cliffs and a similar scenario may be considered for future NDE 
examinations. In this case, relatively direct access to the end of the canister is accessible via flexible wand and crawler methods as illustrated in Figure 4.13 and Figure 4.14. The bottom rear of the DSC is relatively difficult to access and is one of the coolest regions on the canister surface. In this case, it may be desirable and feasible to use the rails to help guide a wand mounted probe to the rear of the DSC. The deployment of crawler mounted sensors will be difficult for the NUHOMS system because the contour of the inner HSM surface does not follow the contour of the DSC surface, in general.

A hybrid deployment method utilizing flexible wands to deploy crawler systems is an alternative to manually controlled wand probes or completely autonomous crawlers. Another alternative consists of retrofitting storage modules with permanently installed scanning hardware.

\subsection{Assessment of UT and ECT}

A summary of performance data from reliability studies for UT and ECT methods and techniques is summarized in Table 8.1. The detection performance for UT methods and techniques is good (90\%) for cracks that are nearly through wall (10-mm deep flaws represent $\sim 80 \%$ through-wall cracks for 0.5 -in. thick canisters). For cracks that are approximately $40 \%$ through-wall (5-mm deep), this performance drops to $70 \%$. The data in Table 8.1 does not provide a direct comparison of UT and ECT because the reliability studies were performed on components with vastly different geometries and fabricated from different materials. However, the data from steam generator tube studies indicates superior capability for ECT at detecting shallow flaws. This is consistent with results of the NRC's PINC program in which ECT exhibited superior performance compared to UT and potential drop techniques when applied to the same flaw set (Cumblidge et al. 2010).

Table 8.1. Summary of Best Documented Performance Data for UT and ECT

\begin{tabular}{lll}
\hline & \multicolumn{1}{c}{ UT } & \multicolumn{1}{c}{ ECT } \\
\hline POD & $\begin{array}{l}\text { 90\% for flaws } 10 \mathrm{~mm} \text { deep and 70\% for flaws } \\
5 \mathrm{~mm} \text { deep (Heasler and Doctor 2003) }\end{array}$ & $\begin{array}{l}\text { Can be inferred that good performance is } \\
\text { observed for detecting sub-millimeter deep } \\
\text { flaws in steam generator tubes (POD > 85\%) } \\
\text { (Kupperman et al. 2007) }\end{array}$ \\
\hline Depth-sizing & $\begin{array}{l}\text { Can meet the ASME Code Section XI, } \\
\text { Appendix VIII criteria for depth-sizing } \\
\text { accuracy, which specifies that the RMSE of } \\
\text { the depth measurement is less than 3.2 mm } \\
\text { (Latiolais 2013) }\end{array}$ & $\begin{array}{l}\text { The development of techniques and theory } \\
\text { for depth-sizing of SCC flaws is a current } \\
\text { area of research (Huang et al. 2011) }\end{array}$ \\
\hline $\begin{array}{l}\text { RMSE from 2.2 mm to 9.2 mm for encoded } \\
\text { techniques (Anderson et al. 2011) }\end{array}$ & $\begin{array}{l}\text { 39.4-mm to 69.9-mm long flaws were } \\
\text { undersized with a RMSE of 7.7 mm in CASS } \\
\text { material (Diaz et al. 2007) }\end{array}$ \\
\hline
\end{tabular}

The studies indicate that length-sizing performance for UT can be significantly improved by encoding the data with the position of the transducer and storing data for later analysis. In this case, the lengthsizing performance for UT applied to far-side weld examination applications is observed to be comparable to the results of ECT applied to the inspection of CASS material. In the case of UT, EPRI PDI data indicates that the ASME Code, Section XI, Appendix VIII criteria for depth-sizing performance 
can be met (RMSE $<3.2 \mathrm{~mm}$ ). With this depth-sizing error, it is difficult to categorize flaws into more than two depth-size categories for 12.7-mm thick canister shells. Depth-sizing performance of ECT cannot be quantified from the performance studies documented in this report. Eddy current does not appear to currently be viable for characterizing the depth of deep SCC flaws in thick components. Theories and techniques for this area are still under development (Huang et al. 2011). An alternative to direct measurements of crack depth would be to infer crack depth from crack surface profile characteristics. However, this assumes that a consistent relationship between crack length and crack depth will exist, and that this relationship can be determined.

Several caveats should be considered with respect extrapolating performance data from previous reliability studies to the inspection of dry storage canisters. First, the previous performance studies targeted flaws that initiated on the far surface of components with respect to transducer placement, in which case the sound field propagates along a half V-path for crack detection. In the application considered here, flaws will initiate on the near surface, requiring the sound field to travel along a full $\mathrm{V}$-path, at a large angle, or on the surface of the canister. The second caveat relates to the component geometry. Reliability studies are often performed on representative samples of piping that have a much smaller diameter than dry storage canister shells. Third, surface conditions of the canisters can have an impact on inspection performance. The build-up of dust or other deposits can adversely impact ECT inspections if a consistent lift-off (distance between probe and test surface) cannot be maintained. In the case of UT inspections, dust or deposits may need to be removed to ensure/enable adequate coupling. Fourth, for both UT and ECT, additional challenges to performance are associated with deployment. The choice of deployment method (e.g., flexible wand or robotic crawler) can significantly influence the effectiveness of an examination. As noted, encoding the data with the position of the transducer can significantly improve performance. Finally, the frequency at which inspections are performed and the growth rate of atmospheric flaws will impact the effectiveness of inspections. For instance, even though UT may exhibit good performance reliability for the detection of 10-mm deep flaws (90\%), such flaws may be unlikely to exist at the time of an inspection if flaw growth is too rapid. On the other hand, if residual stress distributions, or other effects, result in slow crack growth rates when they reach approximately $10 \mathrm{~mm}$ in depth, then it is more likely that flaws will be detected during UT inspections. In light of all of these factors, techniques and deployment methods should be carefully selected to ensure best performance.

\subsection{Pitting Corrosion}

Pitting corrosion is a potential pre-cursor to atmospheric SCC and a significant evaluation was not performed in this report as most of the focus was on crack detection and monitoring. At this point, it is unclear if detectable pitting corrosion will always accompany atmospheric SCC. Several potential NDE methods and techniques could be applied to detecting or monitoring pitting corrosion including electrochemical noise analysis, acoustic emission, visual, eddy current, and ultrasonic. A comprehensive evaluation of each technique to determine capability for detecting and/or quantify pitting corrosion represents a significant effort.

\subsection{Crack Morphology}

Depending on the NDE method or technique, different crack morphology features will be most relevant to the examination performance. 
- As an example, for visual techniques, the COD is the flaw parameter with the greatest influence on detectability over the flaw sizes generally of interest.

- In the case of UT, the crack depth is usually the feature that has the most significant influence on detection probability. In addition, depth-sizing is often performed based on detection of the crack tip signal. For highly branching cracks, other crack branches may interfere and limit the ability to accurately determine the depth of flaws.

- ECT techniques are sensitive to local changes in impedance of a material regardless of the specific morphology. Yusa and Hashizume (2009) has introduced the concept of equivalent resistance to describe the significance of a crack from an eddy current perspective. This indicates that it may be more appropriate to define eddy current performance with respect to equivalent resistance versus flaw dimension (i.e., length, depth, or COD).

- In order to depth size flaws based on their surface profiles, an assumption of aspect ratio (i.e., ratio of length over depth) is required.

Acquiring much of this information may not be possible, or may, at least, take several years. However, the information is provided to highlight the importance that knowledge of several morphological factors can have with respect to facilitating improvements in the NDE of dry storage canisters. 


\subsection{Summary}

In this effort, an assessment of UT and ECT methods and techniques is performed for inspecting the surfaces of dry cask storage systems (DCSSs) canisters. UT and ECT methods and techniques are already used to inspect nuclear power plant components and this experience, along with their relative maturity, makes these methods and techniques likely frontrunners for near-term application to examination of dry storage canister surfaces. In this report, the results of several performance reliability studies for UT and ECT are reviewed. The detection, depth-sizing, and length-sizing results are documented and summarized to quantitatively estimate the adequacy of UT and ECT testing for inspecting dry storage canister surfaces. In addition, this effort focuses on the implementation of NDE methods and techniques in the Holtec HI-STORM 100 system and the Transnuclear NUHOMS horizontal storage modules and considers environmental compatibility, accessibility constraints, and NDE sensor deployment options for these systems.

The environmental assessment indicates regions on the canister surface that are expected to drop below the deliquescence threshold temperature first. For HI-STORM systems, the bottom plate-to-shell weld can be expected to drop below the deliquescence threshold first followed by the lower $25 \%$ of the longitudinal shell weld. For NUHOMS systems, the bottom regions of both ends of the canister are expected to drop below the deliquescence point first. An assessment of NDE sensor environmental compatibility indicates that sensor degradation as a result of exposure to the canister environment should not be a significant concern. Standard technologies should be suitable for most applications. The scenario that seems most likely for sensor degradation would be the degradation of sensors mounted permanently for continuous monitoring over the life time of the canister. In which case, the cumulative radiation dose may have the potential to result in degradation of certain sensor components.

The accessibility assessment may be performed to identify regions that are easiest and most difficult to access with NDE sensors. Generally, portions of the canister directly in-line with port openings in the concrete shield modules should be the easiest to access. Finally, in addition to weld regions, other regions of the canister that may be susceptible to degradation are those regions that are subject to crevice conditions. In the HI-STORM systems, a crevice condition may occur at the interface between the overpack pedestal and the MPC bottom plate. In the NUHOMS system, crevice conditions may exist at the contact point between the DSC and the support rails. A variety of options are available for the deployment of NDE sensors for canister examination. This report does not exhaustively consider all options, but highlights two methods employed for examination of Hanford waste tanks. These options vary in sophistication and include the manual examinations using NDE sensors mounted to the end of a flexible wand and the use of autonomous robotic crawlers. Hybrids of these two concepts may also be conceived. The impact of the chosen deployment method on NDE reliability will be an important consideration.

Several reliability studies for UT and ECT testing have been reviewed. The best performance data documented in this report for UT and ECT are summarized in Table 8.1. The performance data indicates that both UT and ECT should be capable of detecting flaws that do not fully penetrate DCSS canisters with good reliability. ECT is likely to exhibit better detection performance than UT for shallow flaws and good detection performance has been exhibited for sub-millimeter deep flaws ( $>85 \%$ ) in steam generator tubing. In the case of flaw length-sizing, improved performance is gained by encoding the signals with transducer position. In this case, length-sizing accuracy for both methods is similar and is approximately 
6-mm RMSE. It may be possible to determine flaw depth based on measurements of flaw length, but only if a relationship between flaw depth and flaw length can be determined. Depth-sizing performance of eddy current cannot be quantified from the performance studies documented in this report. In fact, many studies highlight the difficulties of depth-sizing stress corrosion cracks in thick components (Yusa and Hashizume 2009; Huang et al. 2011). For UT techniques, data from the Electric Power Research Institute’s Performance Demonstration Initiative indicates that the ASME Code, Section XI, Appendix VIII criteria for depth-sizing performance can be met (RMSE <= $3.2 \mathrm{~mm}$ ) (Latiolais 2013). 


\subsection{References}

Aikawa K, K Izoe, N Shamoto, M Kudoh and T Tsumanuma. 2008. "Radiation-Resistant Single-Mode Optical Fibers." Fujikura Technical Review 113, 10-14.

Anderson MT, AA Diaz, AD Cinson, SL Crawford, SE Cumblidge, SR Doctor, KM Denslow and S Ahmed. 2011. An Assessment of Ultrasonic Techniques for Far-Side Examinations of Austenitic Stainless Steel Piping Welds. NUREG/CR-7113, PNNL-19353, U.S. Nuclear Regulatory Commission, Washington, D.C.

Andresen PL. 2010. "Stress Corrosion Cracking (SCC) of Austenitic Stainless Steels in High Temperature Light Water Reactor (LWR) Environments." In Understanding and Mitigating Ageing in Nuclear Power Plants: Materials and Operational Aspects of Plant Life Management (PLiM), Woodhead Publishing Series in Energy: Number 4, pp. 236-307 ed: PG Tipping. Ch. 9. Woodhead Publishing Limited, Cambridge, United Kingdom.

Auld BA and JC Moulder. 1999. "Review of Advances in Quantitative Eddy Current Nondestructive Evaluation." Journal of Nondestructive Evaluation 18(1):3-36.

Bechtel SAIC Company L. 2006. TAD Source Term and Dose Rate Evaluation. 000-30R-GGDE00100-000-00A, Bechtel SAIC Company, LLC, Las Vegas, Nevada.

Beissner RE. 1994. "Slots vs. Cracks in Eddy Current NDE." Journal of Nondestructive Evaluation 13(4):175-183.

Brichard B, AF Fernandez, H Ooms, P Borgermans and F Berghmans. 2003. "Dependence of the POR and NBOHC Defects as Function of the Dose in Hydrogen-treated and Untreated KU1 Glass Fibers." IEEE Transactions on Nuclear Science 50(6):2024-2029.

Caseres L and TS Mintz. 2010. Atmospheric Stress Corrosion Cracking Susceptibility of Welded and Unwelded 304, 304L, and 316L Austenitic Stainless Steels Commonly Used for Dry Cask Storage

Containers Exposed to Marine Environments. NUREG/CR-7030, U.S. Nuclear Regulatory Commission, Washington, D.C.

Chopra OK, D Diercks, R Fabian, D Ma, V Shah, S-W Tam and YY Liu. 2012. Managing Aging Effects on Dry Cask Storage Systems for Extended Long-Term Storage and Transportation of Used Fuel Rev. 0. ANL-12/29, Argonne National Laboratory, Argonne, Illinois.

Cumblidge SE, MT Anderson and SR Doctor. 2004. An Assessment of Visual Testing. NUREG/CR6860, U.S. Nuclear Regulatory Commission, Washington, D.C.

Cumblidge SE, MT Anderson, SR Doctor, FA Simonen and AJ Elliot. 2007. A Study of Remote Visual Methods to Detect Cracking in Reactor Components. NUREG/CR-6943, PNNL-16472, U.S. Nuclear Regulatory Commission, Washington, D.C.

Cumblidge SE, SR Doctor, PG Heasler and TT Taylor. 2010. Results of the Program for the Inspection of Nickel Alloy Components. NUREG/CR-7019; PNNL-18713, Rev. 1, U.S. Nuclear Regulatory Commission, Washington, D.C. 
Diaz AA, RA Mathews, J Hixon and SR Doctor. 2007. Assessment of Eddy Current Testing for the Detection of Cracks in Cast Stainless Steel Reactor Piping Components. PNNL-16253, Pacific Northwest National Laboratory, Richland, Washington.

Ekstrom P and J Wåle. 1995. Crack Characterization for In-service Inspection Planning. SKI Report 95:70, Swedish Nuclear Power Inspectorate, Stockholm, Sweden.

Gordon B, M Taylor, R Arthur and A Machiels. 2006. Climatic Corrosion Considerations for Independent Spent Fuel Storage Installations in Marine Environments. 1013524, Electric Power Research Institute, Palo Alto, California.

Griffin JW, GJ Posakony, RV Harris, DL Baldwin, AM Jones and LJ Bond. 2012. "High Temperature Ultrasonic Transducers for In-Service Inspection of Liquid Metal Fast Reactors." In 2011 IEEE International Ultrasonics Symposium, pp. 1924-1927. DOI 10.1109/ultsym.2011.0479.

Griscom DL. 1991. "Optical Properties and Structure of Defects in Silica Glass." Optical Materials Journal of the Ceramic Society of Japan 99(1154):923-942.

GUL. 2012. Capability. Guided Ultrasonics Ltd. (GUL). Brentford, United Kingdom. Accessed March 26, 2013. Available at http://www.guided-ultrasonics.com/public2012/?portfolio=capability.

Hanks CL and DJ Hamman. 1971. "Electrical Insulating Materials and Capacitors." In Radiation Effects Design Handbook. NASA, Washington, D.C.

Heasler PG and SR Doctor. 1996a. Piping Inspection Round Robin. NUREG/CR-5068, PNL-10475, U.S. Nuclear Regulatory Commission, Washington, D.C.

Heasler PG and SR Doctor. 1996b. Piping Inspection Round Robin. PNNL-10475, Pacific Northwest National Laboratory, Richland, Washington.

Heasler PG and SR Doctor. 2003. A Comparison of Three Round Robin Studies on ISI Reliability of Wrought Stainless Steel Piping. NUREG/CR-6795, PNNL-13873, U.S. Nuclear Regulatory Commission, Washington, D.C.

Heasler PG, TT Taylor, JC Spanner, SR Doctor and JD Deffenbaugh. 1990. Ultrasonic Inspection Reliability for Intergranular Stress Corrosion Cracks: A Round Robin Study of the Effects of Personnel, Procedures, Equipment and Crack Characteristics. PNL-6196, Rev. 5, Pacific Northwest National Laboratory, Richland, Washington.

Holtec International. 2010. Final Safety Analysis Report for the HI-STORM 100 Cask System. HI2002444, Rev. 09, Holtec International, Marlton, New Jersey.

Hosler R and J Hall. 2010. Outside Diameter Initiated Stress Corrosion Cracking Revised Final White Paper. PA-MSC-0474 Westinghouse Electric Company, Cranberry Township, Pennsylvania.

Huang H, N Yusa, K Miya, H Hashizume, T Sera and S Hirano. 2011. "Electromagnetic Modeling of Stress Corrosion Cracks in Inconel Welds." E-Journal of Advanced Maintenance 2(2010/2011):168-180.

Javed Akhtar SM, M Ashraf and SH Khan. 2007. "A Study of Neutron and Gamma Radiation Effects on Transmission of Various Types of Glasses, Optical Coatings, Cemented Optics and Fiber." Optical Materials 29(12):1595-1603. 
Kunerth DC, T McJunkin, M McKay and S Bakhtiari. 2012. Inspection of Used Fuel Dry Storage Casks. INL/EXT-12-27119 Idaho National Laboratory, Idaho Falls, Idaho.

Kupperman DS, S Bakhtiari, WJ Shack, JY Park and S Majumdar. 2007. Eddy Current Reliability Results from the Steam Generator Mock-up Analysis Round-Robin. ANL-08/30, Argonne National Laboratory, Argonne, Illinois.

Lambert JD, S Bakhtiari, I Bodnar, C Kot and J Pence. 2012. NRC Job Code V6060: Extended In-Situ and Real Time Monitoring. Task 3: Long-Term Dry Cask Storage of Spent Nuclear Fuel. ANL/NE12/18, Argonne National Laboratory, Argonne, Illinois.

Latiolais C. 2013. "PDI Pass Rates Update." Presented at PDI/NRC Meeting, June 4, 2013.

McGrath B, H Schonbacher and M Van de Voorde. 1976. "Effects of Nuclear Radiation on the Optical Properties of Cerium-Doped Glass." Nuclear Instruments and Methods 135:93-97.

Meyer R, A Pardini, B Hanson and K Sorenson. 2013. Review of NDE Methods for Detection and Monitoring of Atmospheric SCC in Welded Canisters for the Storage of Used Nuclear Fuel. PNNL22158, Pacific Northwest National Laboratory, Richland, Washington.

NRC. 2011. Contaminants and Stagnant Conditions Affecting Stress Corrosion Cracking in Stainless Steel Piping in Pressurized Water Reactors. NRC Information Notice 2011-04, U.S. Nuclear Regulatory Commission (NRC), Washington, D.C. ADAMS Accession No. ML103410363.

NRC. 2012a. Identification and Prioritization of the Technical Information Needs Affecting Potential Regulation of Extended Storage and Transportation of Spent Nuclear Fuel. U.S. Nuclear Regulatory Commission (NRC), Washington, D.C. Draft Report for Comment. ADAMS Accession No. ML120580143.

NRC. 2012b. Potential Chloride-Induced Stress Corrosion Cracking of Austenitic Stainless Steel and Maintenance of Dry Cask Storage System Canisters. NRC Information Notice 2012-20, U.S. Nuclear Regulatory Commission (NRC), Washington, D.C.

Office of Civilian Radioactive Waste Management. 2001. "Dose Rate Calculation for the 21-PWR UCF Waste Package." Office of Civilian Radioactive Waste Management, Washington, D.C.

Olympus NDT. 2013. Ultrasonic Transducers. Olympus NDT Inc. Waltham, Massachusetts. Accessed March 26, 2013. Available at http://www.olympus-ims.com/en/ultrasonic-transducers/.

PAC. 2005. DiSP with AEwin, User's Manual, Rev. 3. PAC Part \#: 6320-1001, Physical Acoustics Corporation (PAC), Princeton Junction, New Jersey.

Rempe J, J Daw, D Knudson, R Schley, L Bond, J Coble, M Good and R Meyer. 2011. In-pile Instrumentation to Support Fuel Cycle Research and Development - FY11 Status Report. FCRD-FUEL2011-000307, Idaho National Laboratory, Idaho Falls, Idaho.

Singh R. 2000. Three Decades of NDI Reliability Assessment. Report No. Karta-3510-99-01, Karta Technology, Inc., San Antonio, Texas. 
Spencer F and D Schurman. 1995. Reliability Assessment at Airline Inspection Facilities, Volume III. Results of an Eddy Current Inspection Reliability Experiment. DOT/FAA/CT-92/12, III, FAA Technical Center, Atlantic City International Airport, New Jersey.

Stroud JS. 1965. "Color-Center Kinetics in Cerium-Containing Glass." Journal of Chemical Physics 43:2442-2450.

Suffield S, J Cuta, J Fort, B Collins, H Adkins and E Siciliano. 2012. Thermal Modeling of NUHOMS HSM-15 and HSM-1 Storage Modules at Calvert Cliffs Nuclear Power Station ISFSI. PNNL-21788, Pacific Northwest National Laboratory, Richland, Washington.

Takeda H, M Wataru, K Shirai and T Saegusa. 2008. "Heat Removal Verification Tests Using Concrete Casks Under Normal Condition." Nuclear Engineering and Design 238(5):1196-1205.

TenCate JA, TJ Ulrich and NR Brown. 2012. Corrosion and Stress Corrosion Cracking:

Recommendations for Mitigation and Advanced Detection LA-UR-12-26380, Los Alamos National Laboratory, Los Alamos, New Mexico.

Transnuclear. 2004a. Final Safety Analysis Report for the Standardized NUHOMS® Horizontal Modular Storage System for Irradiated Nuclear Fuel. NUH-003, Rev. 8, Transnuclear, Inc., Hawthorne, New York.

Transnuclear. 2004b. NUHOMS® HD Horizontal Modular Storage System for Irradiated Nuclear Fuel: Safety Analysis Report. Rev. 0, 4/04, Transnuclear, Hawthorne, New York.

Wåle J. 2006. Crack Characterisation for In-service Inspection Planning - An Update. SKI Report 2006:24, Swedish Nuclear Power Inspectorate, Stockholm, Sweden.

Yusa N and H Hashizume. 2009. "Evaluation of Stress Corrosion Cracking as a Function of Its Resistance to Eddy Currents." Nuclear Engineering and Design 239:2713-2718.

Yusa N, L Janousek, M Rebican, Z Chen, K Miya, N Dohi, N Chigusa and Y Matsumoto. 2006. "Caution when Applying Eddy Current Inversion to Stress Corrosion Cracking." Nuclear Engineering and Design 236:211-221.

Yusa N, S Perrin and K Miya. 2007. "Eddy Current Data for Characterizing Less Volumetric Stress Corrosion Cracking in Nonmagnetic Materials." Materials Letters 61(3):827-829. 



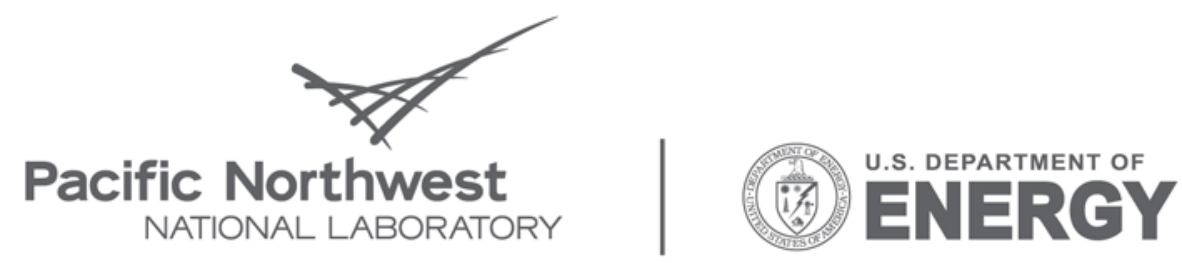

Proudly Operated by Battelle Since 1965

902 Battelle Boulevard

P.O. Box 999

Richland, WA 99352

1-888-375-PNNL (7665)

www.pnl.gov 